\title{
Characteristics of U.S. Energy Production using Nuclear Fission
}

\section{May 2022}

Curtis Smith

Kurt Vedros

S. Andrew Orrell

Jason Christensen

Robert Youngblood

Bruce Hallbert

Idaho National Laboratory

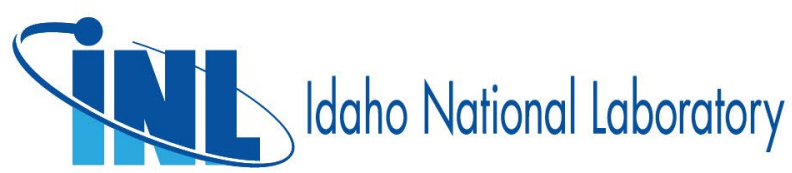




\section{DISCLAIMER}

This information was prepared as an account of work sponsored by an agency of the U.S. Government. Neither the U.S. Government nor any agency thereof, nor any of their employees, makes any warranty, expressed or implied, or assumes any legal liability or responsibility for the accuracy, completeness, or usefulness, of any information, apparatus, product, or process disclosed, or represents that its use would not infringe privately owned rights. References herein to any specific commercial product, process, or service by trade name, trade mark, manufacturer, or otherwise, does not necessarily constitute or imply its endorsement, recommendation, or favoring by the U.S. Government or any agency thereof. The views and opinions of authors expressed herein do not necessarily state or reflect those of the U.S. Government or any agency thereof. 
INL/EXT-21-65272

Revision 1

\title{
Characteristics of U.S. Energy Production using Nuclear Fission
}

\author{
Curtis Smith \\ Kurt Vedros \\ S. Andrew Orrell \\ Jason Christensen \\ Robert Youngblood \\ Bruce Hallbert
}

May 2022

\section{Idaho National Laboratory \\ Idaho Falls, Idaho 83415}

http://www.inl.gov

\author{
Prepared for the \\ U.S. Department of Energy \\ Office of Nuclear Energy \\ Under DOE Idaho Operations Office \\ Contract DE-AC07-05ID14517
}


Page intentionally left blank 


\section{SUMMARY}

When considering potential energy production technologies for the future, a variety of characteristics can be used to evaluate the positive and negative impacts for a specific technology. For this report, we have relied on domain knowledge and reviewed technical, policy, and regulatory documents to determine what types of characteristics could be considered when assessing energy technology impacts. For example, the National Environmental Policy Act provides a focus on environmental aspects that are important to actions such as construction of power production facilities. A second example is the United States goal to reach 100 percent carbon pollution-free electricity by 2035 .

We have categorized our observations into two high-level groups of characteristics: (1) impacts that may be minimized via a "net zero" concept and (2) attributes that provide other considerations typically factored into technology selection processes (e.g., economics). Here, the term "net zero" implies that the technology has a zero or minimal impact on the public and environment while still providing benefits by way of electricity, heat, and other products such as hydrogen and water. And, these potential impacts must be considered over the lifecycle of the technology deployment, from design, construction, operation, and disposition. The first high-level group of characteristics focused on potential net-zero (i.e., having no to almost negligible contribution) elements, of which we grouped into five net-zero pillars:

- Greenhouse gas emissions, including carbon dioxide $\left(\mathrm{CO}_{2}\right)$, methane, nitrous oxide, and fluorinated gases such as ozone-depleting gases

- Water consumption

- Material resource consumption

- Disposition of wastes

- Impacts to the health and safety of the public and the environment.

As the United States replaces fossil fuels in the energy mix, policy mandates the need to consider the possible impacts of adopted technologies. For example, the Executive Order on Catalyzing Clean Energy Industries and Jobs Through Federal Sustainability sets the policy directing the Federal Government to achieve carbon-free electricity generation by 2035 and a net-zero emissions (for greenhouse gas) economy by 2050. This Order also brings in considerations of water use and waste reductions.

In this report, we describe a variety of characteristics related to the five elements above to provide a factual and scientific assessment of nuclear fission as an energy providing technology. By better understanding how nuclear energy via fission power impacts the five elements above, decisionmakers can better assess nuclear energy's role in the overarching goal to provide society with a low-impact energy source.

Using the net-zero pillars and addition technology attributes as guides, we assembled science-based facts for these groups of characteristics demonstrating that nuclear power leads all other energy production technologies by providing the ability to lower greenhouse gas in the atmosphere; provide potable water to communities; minimize the global resources needed to provide cooling, heat, and electricity; dramatically reduce the amount of waste going to landfills; and ensure public and environmental safety is commensurate with the energy provided. 
Page intentionally left blank 


\section{CONTENTS}

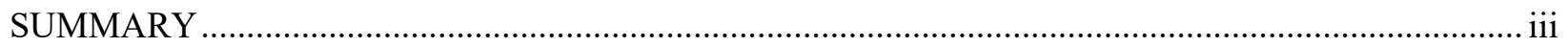

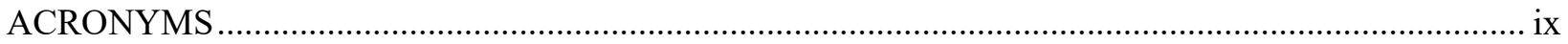

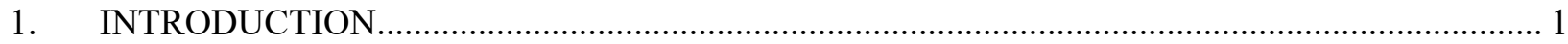

2. CHARACTERISTICS OF NUCLEAR FISSION ENERGY PRODUCTION ............................... 3

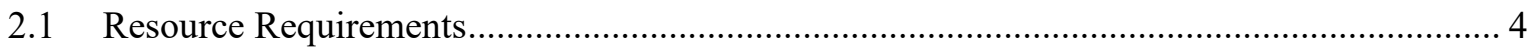

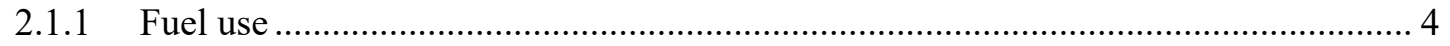

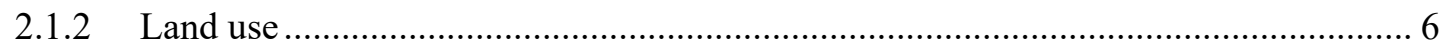

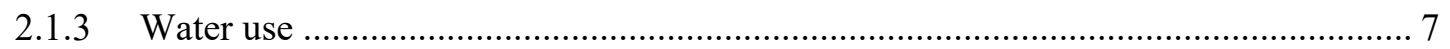

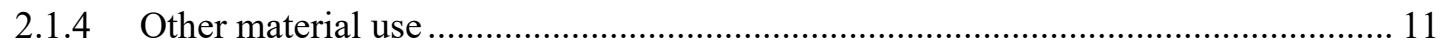

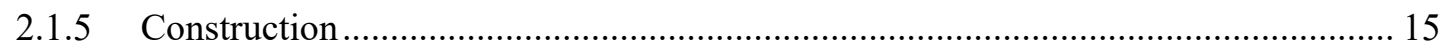

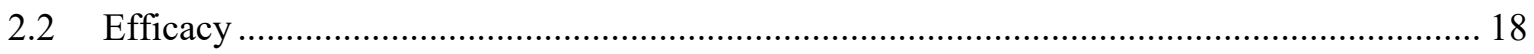

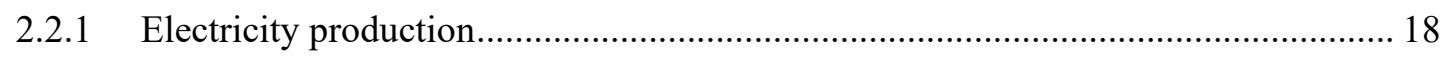

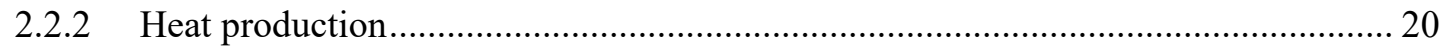

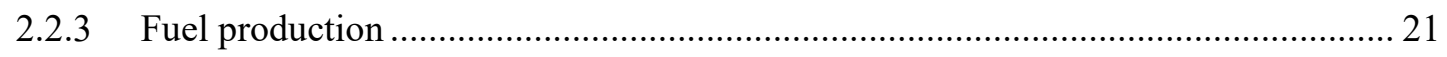

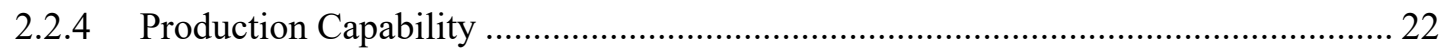

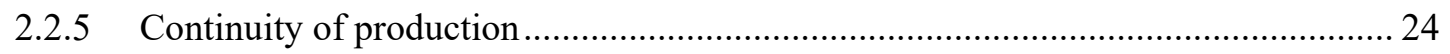

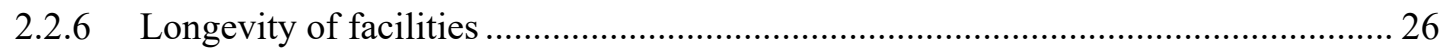

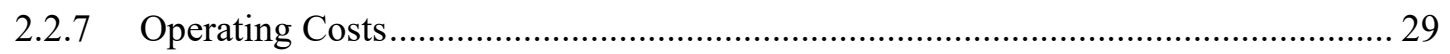

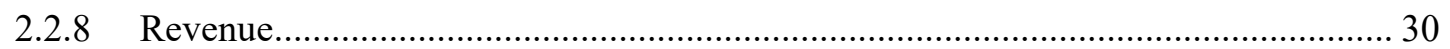

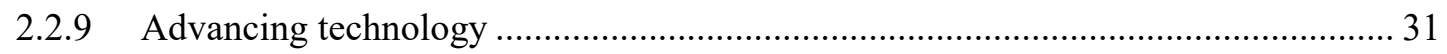

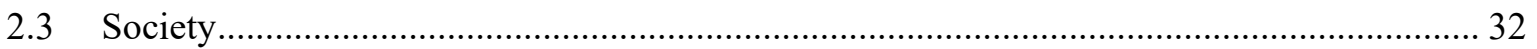

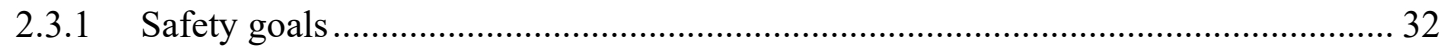

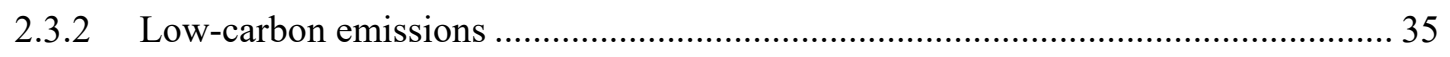

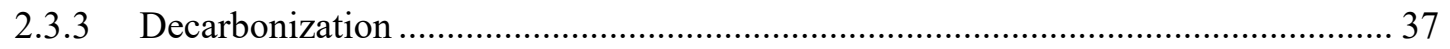

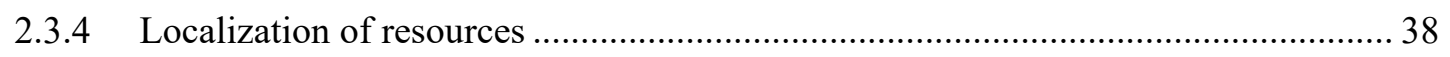

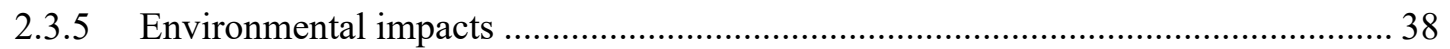

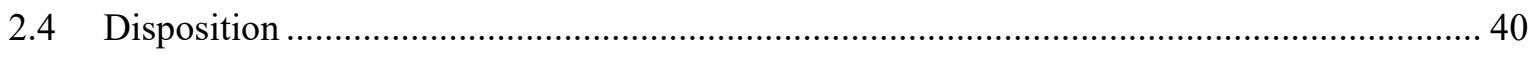

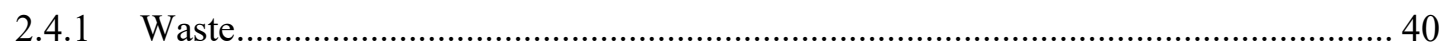

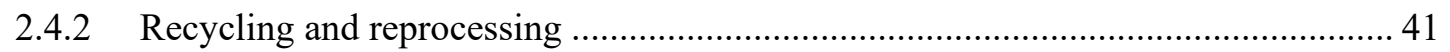

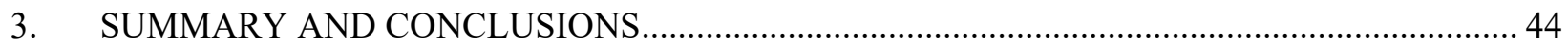

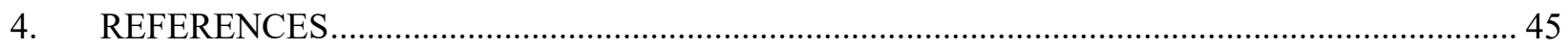




\section{FIGURES}

Figure 1. Locations of U.S. NPPs (EIA 2021b). Note: Indian Point Energy Center north of New York City shut down in 2021. 1

Figure 2. The net-zero pillars used to evaluate potential energy production technologies. 3

Figure 3. Nuclear fuel pellet energy content compared to an equivalent amount of energy from oil and coal. Note: This figure is not to scale since the nuclear cube would become difficult to see.

Figure 4. Comparing the requirements of various energy production technologies needed to power 50,000 U.S. homes for one day.

Figure 5. Land use needed for different power production technologies to produce $1 \mathrm{MW}$ of electricity.

Figure 6. Water consumption in the United States for different types of energy production technologies. Sources: hydroelectric and nuclear/fossil (Torcellini, Long, and Judkoff 2003); PV solar (SEIA); concentrated solar (Frisvold and Marquez 2014).

Figure 7. Trends in water use for thermoelectric power generation in the United States (USGS 2018). 10

Figure 8. Supply risk of renewable sector and other emerging technologies (EC 2020)......................... 11

Figure 9. Worldwide rare earth production in 2020 (USGS 2021) ...................................................... 12

Figure 10. Worldwide rare earth reserves in 2020 (USGS 2021) ….................................................... 12

Figure 11. Projected world uranium production capability versus demand through 2040 (IAEA 2020).

Figure 12. Mineral needs $(\mathrm{kg})$ per MW produced for different energy production technologies (IEA 2021).

Figure 13. Countries that produce key materials needed for different energy production technologies (IEA 2021).....

Figure 14. Countries that process key materials needed for different energy production technologies (IEA 2021). 15

Figure 15. Vogtle Unit 3 construction photo 2019 (Georgia Power Company 2019). . .16

Figure 16. Factory-built SMR modules delivered to site versus on-site construction (Power Tech 2017). 17

Figure 17. Average EROI for different energy technologies (World Nuclear Association 2020b)........... 19

Figure 18. Conceptual framework used to determine EROI (Brockway et al. 2019). 19

Figure 19. Nuclear cogeneration opportunities (Royal Society 2020).

Figure 21. Production, measured in days per year that a specific energy technology is used (or not) to produce electricity, on average, for different technologies in the United States in 2020 .

Figure 22. Trend of the general transient frequency for pressurized-water reactors in the United States (Johnson and Ma 2019)...

Figure 23. NPP initial license date and license extension plans as of September 2018 (NRC 2018). 
Figure 24. Change in energy production from increases or decreases in performance over a typical 30-year period for different energy production technologies.

Figure 25. U.S. NPP generating cost reductions (in 2020 dollars) since 2014 (NEI 2021b). Note: Q1 represents $25 \%$ of the plants with lowest costs, Q2 represents the next 25\%, and Q3 represents the next quartile of plants.

Figure 26. Production costs (including operations, maintenance, and fuel) for different energy technologies (EIA 2021b, Table 8.4).

Figure 27. Human mortality rates (global averages) for different energy producing technologies (Brook et al. 2014). 33

Figure 28. Number of deaths by risk factor in the world for 2017 (Ritchie and Roser 2019).

Figure 29. Volume of all the NPP nuclear high-level waste produced in the United States since the 1950s (NEI 2019).

Figure 30. Specific direct and indirect GHG emissions for different energy production technologies (Pehl et al. 2017)...

Figure 31. Magnified portion of the specific direct and indirect GHG emissions for different energy production technologies (Pehl et al. 2017).

Figure 32. Example of the greenfield remaining after decommissioning a NPP in the United States (Camper 2021).

Figure 33. Wind turbine blades being buried in a landfill in Wyoming (Martin 2020; Rasmussen 2020). 
Page intentionally left blank 


\section{ACRONYMS}

$\begin{array}{ll}\text { ANL } & \text { Argonne National Laboratory } \\ \text { BLS } & \text { Bureau of Labor Statistics } \\ \text { CCS } & \text { Carbon capture and sequestration } \\ \text { DOE } & \text { Department of Energy } \\ \text { EC } & \text { European Commission } \\ \text { EIA } & \text { Energy Information Administration } \\ \text { EROI } & \text { Energy return on investment } \\ \text { FAQS } & \text { Frequently Asked Questions } \\ \text { GAIN } & \text { Gateway for Accelerated Innovation in Nuclear } \\ \text { GHG } & \text { Greenhouse gas } \\ \text { IAEA } & \text { International Atomic Energy Agency } \\ \text { IEA } & \text { International Energy Agency } \\ \text { LEU } & \text { Low Enriched Uranium } \\ \text { LWR } & \text { Light-water reactors } \\ \text { NEA } & \text { Nuclear Energy Agency } \\ \text { NEI } & \text { Nuclear Energy Institute } \\ \text { NPP } & \text { Nuclear power plant } \\ \text { NRC } & \text { Nuclear Regulatory Commission } \\ \text { PV } & \text { Photovoltaic } \\ \text { SMR } & \text { Small modular reactors } \\ \text { USGS } & \text { United States Geological Survey }\end{array}$


Page intentionally left blank 


\section{Characteristics of U.S. Energy Production using Nuclear Fission}

\section{INTRODUCTION}

The purpose of this report is to describe the technical and societal characteristics of nuclear fission energy production. While this report focuses on United States (U.S.) experience, many of the identified insights and observations may also apply to the experiences of other nations worldwide.

Impact assessment of energy production, the generation of electricity and heat, requires a lifecycle approach that recognizes impacts of material acquisition, manufacturing, operation, and disposition. Regardless of the technology used to produce energy, all technologies have risks (i.e., performance shortfalls) that are realized during different phases of the lifecycle. This report adopts an approach recognizing lifecycle impacts and risks involved in nuclear energy production.

Around the world, nuclear power plants (NPPs) provide $26 \%$ of the low-carbon electricity production (Ritchie and Roser 2020). In the United States, nuclear provided 52\% of the country's low-carbon electricity in 2020 (DOE 2021a). Currently, the operating commercial nuclear reactors in the United States consist of light-water reactors (LWRs), of which there are 62 pressurized-water reactors and 31 boiling-water reactors (EIA, 2021b). Figure 1 shows the locations of these facilities in the United States.

There has been renewed interest in building NPPs since 2010 to address the baseload power requirements of an emission-free economy. In 2012, permits were granted to build the first new NPPs since 1986. The Watts Bar Generating Station, Unit 2, was completed from an earlier mothballed state in 2016. The two units under construction at the Vogtle Electric Generating Plants (Units 3 and 4) were started in 2013 and are scheduled for completion in 2022 (Southern Co. 2021).

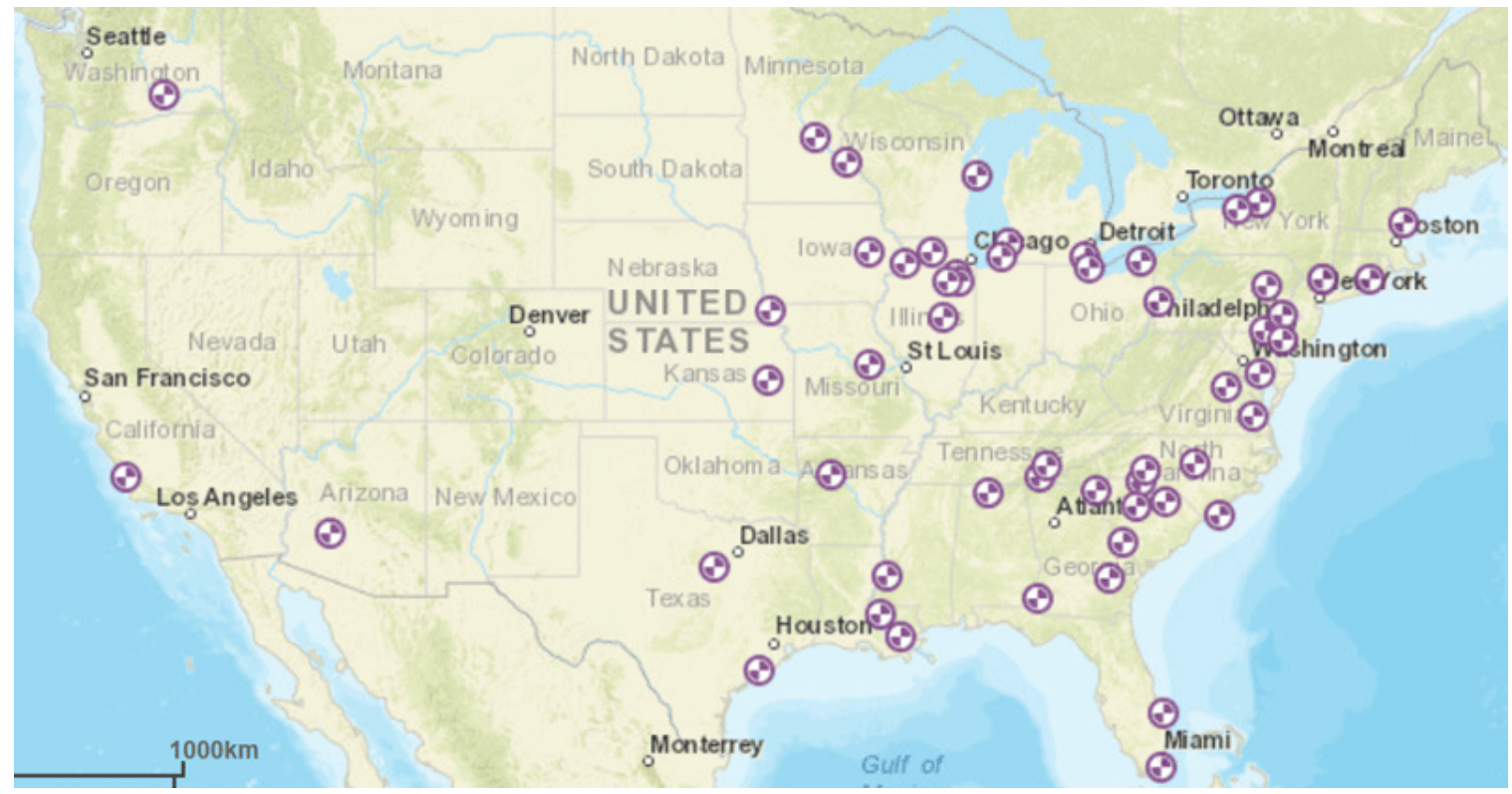

Figure 1. Locations of U.S. NPPs (EIA 2021b). Note: Indian Point Energy Center north of New York City shut down in 2021.

There is also increasing interest in building advanced technology NPPs in the United States. There are multiple advanced NPP developers currently cooperating with the U.S. Department of Energy (DOE) Gateway for Accelerated Innovation in Nuclear (GAIN) program developing a range of reactors. The 
GAIN program produces an advance nuclear technology directory that included 27 reactor developers covering several different fuel and coolant technology types (INL 2021):

- Fast reactors including sodium cooled, lead cooled, gas cooled, and molten salt.

- High temperature reactors including gas and molten salt cooled.

- Uranium and thorium fueled reactors.

These reactor types captured in the GAIN directory span many different power output sizes, ranging from micro-reactors to small modular reactors (SMR) to large reactors (INL 2021).

By 2030, it is expected that three advanced LWRs will be in service on the U.S. electrical grid (one pressurized-water SMR being deployed as part of the Carbon Free Power Project led by the Utah Associated Municipal Power System and the two large-scale pressurized-water reactors at Vogtle). Additionally, it is anticipated that at least two advanced reactors will be providing electricity to the U.S. electrical grid in this decade, for example TerraPower's sodium-cooled fast reactor and X-energy's hightemperature gas reactor designs are both targeting grid connection by 2028 as part of the DOE Advanced Reactor Demonstration Program (ANS 2021). At U.S. national laboratories, multiple designs of microsized high-temperature gas reactors, two high-temperature SMR designs, and two fast neutron reactors will be in demonstration. By 2035, it is expected that these designs will start to replace and add to the currently operating U.S. NPPs.

As current light-water NPPs age, they require additional licensing to continue operation. Due to strong maintenance programs and advances in technology and materials, it is expected that many of these reactors could continue operating for at least 100 years. But it is expected that around 2050 most currently operating U.S. NPPs will be at the end of their operational lifespans. It is anticipated that the newer technology NPPs will be licensed over the next 30 years, steadily replacing the current NPPs to provide a major portion of the emission-free baseload energy needs of the United States. 


\section{CHARACTERISTICS OF NUCLEAR FISSION ENERGY PRODUCTION}

The goal of the data and information in this section is to provide detailed comparisons among different energy production technologies so that informed long-term decisions can be made for technology selection. While the information provided spans the technology lifecycle (from mining, manufacturing, deployment, operation, and disposition), a key focus is also on potential impacts to society. Minimizing these impacts will provide a path to a sustainable energy technology that would be net-zero (i.e., having no or almost negligible contribution thereby reducing harms to societal objectives) on multiple facets, not just on greenhouse gas (GHG) emissions. To maximize an energy production technology's value, it should have low costs while minimizing:

1. GHG emissions, including carbon dioxide $\left(\mathrm{CO}_{2}\right)$, methane, nitrous oxide, and fluorinated gases such as ozone-depleting gases

2. Water consumption

3. Material resource consumption

4. Disposition of wastes

5. Impacts to the health and safety of the public and the environment.

These "net-zero pillars" are illustrated in Figure 2. To create these net-zero pillars, we relied on domain knowledge and reviews of technical, policy, and regulatory documents to determine the types of characteristics that may be considered when assessing energy technology impacts. For example, the National Environmental Policy Act provides a focus on environmental aspects that are important the construction of power production facilities. A second example is the United States Executive Order on Catalyzing Clean Energy Industries and Jobs Through Federal Sustainability that sets the policy directing the Federal Government to achieve carbon-free electricity generation by 2035 and a net-zero emissions (for greenhouse gas) economy by 2050 . This Order also brings in considerations of water use and waste reductions. Together, we have categorized our observations into two high-level groups of characteristics: (1) impacts that may be minimized via a net-zero pillars concept and (2) attributes that provide other considerations typically factored into technology selection processes (e.g., economics).

\section{Net-Zero Pillars for Sustainable Energy Production Technologies}
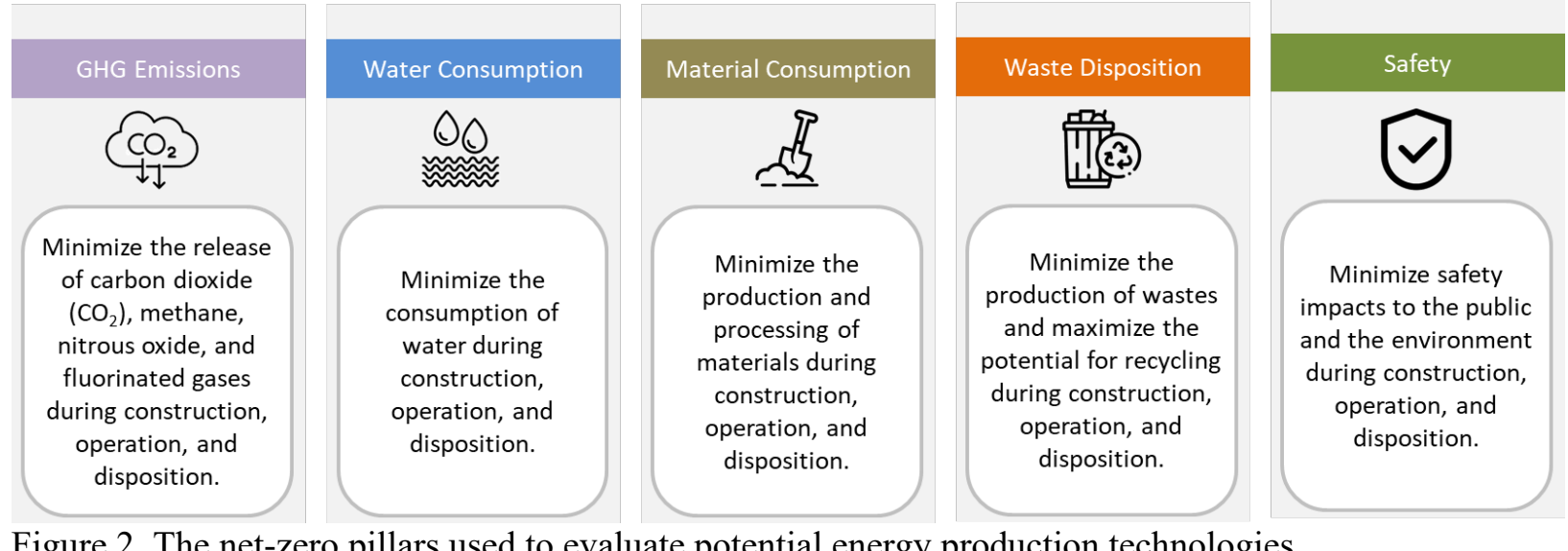

Figure 2. The net-zero pillars used to evaluate potential energy production technologies.

In this report, we evaluate nuclear energy production technologies using a lifecycle focus via the following characteristics: 
- Resource requirements - Attributes that reflect how material resources are used to create, site, support, and power the energy source

- Fuel use

- Land use

- Water use

- Other material use

- Construction

- Efficacy - Attributes that reflect an energy source's technical aspects excluding resource requirements

- Electricity production

- Heat production

- Fuel production

- Production capability

- Continuity of production

- Longevity of facilities

- Operating Costs

- Revenue

- Advancing technology

- Society - Attributes that reflect how an energy source may directly impact society either positively or negatively during energy production

- Safety goals

- Low-carbon emissions

- Decarbonization

- Localization of resources

- Environmental impacts

- Disposition - Attributes that reflect how an energy source will be treated at the end of its useful life

- Waste

- Recycling.

\subsection{Resource Requirements}

Energy production technologies require various amounts of material and labor for construction and operation. These resource needs impose a burden on society; the larger the material resource needs per unit electricity generated, then the less desirable is that energy source due to the increased burden. In this section, we consider the implications for fuel, land, water, and other material use in addition to issues related to construction, long-term operation, and disposition.

\subsubsection{Fuel use}

Nuclear power is the most energy-dense source currently available. High-energy density translates into the ability to provide tailored electricity or heat locally on a small-scale or large quantity of 
electricity and heat on a regional scale. The high-energy density of nuclear also offers the ability to use very little fuel daily unlike other forms of energy production that are reliant on a fuel source. For example, in the United States, NPPs typically shut down to refuel once every 18 to 24 months (EIA 2020).

When compared to fossil fuels for energy production, nuclear provides a very compact source of energy. Using the volume information provided by Nuclear Energy Institute (NEI), Figure 3 illustrates the compact nature of nuclear fuel to oil and coal (NEI 2020b). While this comparison (nuclear to fossil fuels) is informative, the comparison is not complete since:

- A nuclear core contains approximately 15,000,000 (Nuclear Power 2021) to 18,000,000 (ANL 2011) fuel pellets that may stay in a nuclear core for several years.

- For current fission reactors, around 5\% of the possible energy contained in a fuel pin is consumed. When $95 \%$ of the energy content remains, the fuel pellet is removed from a reactor for storage. Thus, this used fuel is potentially a fuel source for future generations (See Section 2.2.3, Fuel Production)

- Fossil fuels are consumed on a constant basis. Thus, fuel needs to continually be supplied for electricity to be provided.
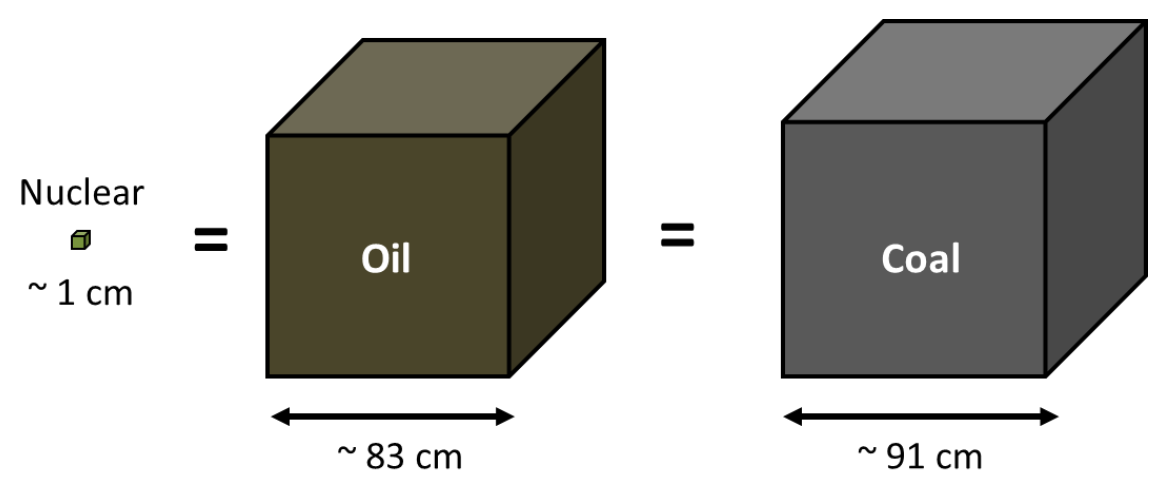

Figure 3. Nuclear fuel pellet energy content compared to an equivalent amount of energy from oil and coal. Note: This figure is not to scale since the nuclear cube would become difficult to see.

Another type of comparison is to look at the requirements from different energy sources to provide a fixed level of electricity. Figure 4 illustrates different types of resource implication for various energy production technologies when supplying electricity to 50,000 U.S. homes for one day. Note that in this figure the resources are shown in different ways such as the daily fuel requirements for coal, gas, and oil and in terms of facility size for nuclear, solar, and wind (since a reactor is not refueled on a daily basis and the majority of the fuel inside a nuclear core is not depleted when it is removed from the reactor; solar uses radiation from the sun when available; and wind turbines rely on wind energy). Other resource requirement such as the required land and water needs are addressed in later sections (Sections 2.1.2 and 2.1.3, respectively). 


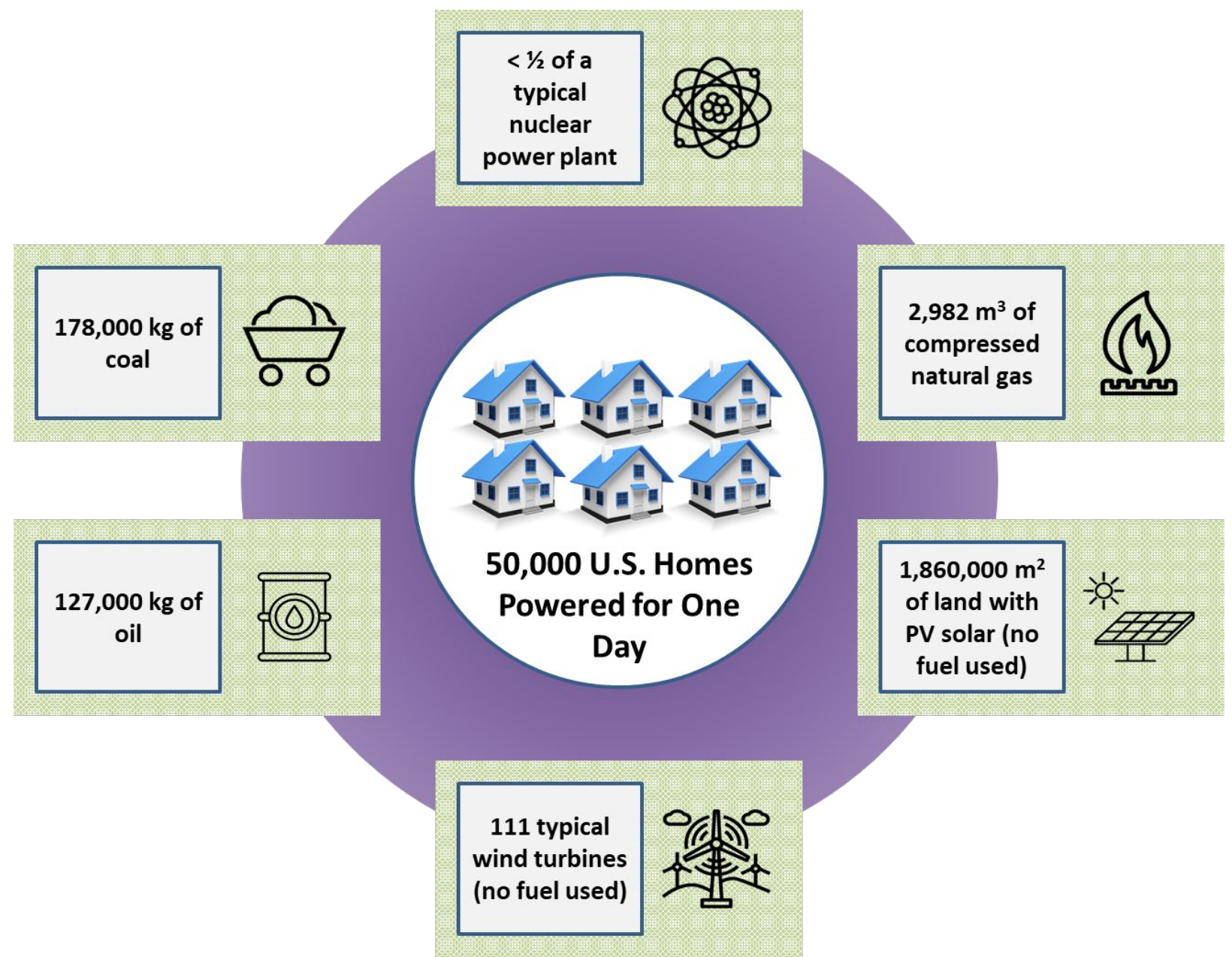

Figure 4. Comparing the requirements of various energy production technologies needed to power 50,000 U.S. homes for one day.

\section{Key Points}

- Nuclear power is the highest density energy source foreseeable for the next several decades.

- High-energy density translates into greatly reduced resource consumption and needs.

- Most NPPs are fueled intermittently, rather than requiring a constant source of fuel, wind, or solar radiation to produce energy.

- Minimization of fuel needs also helps to reduce public, flora, and fauna impacts via reduced mining, transportation, and material needs.

\subsubsection{Land use}

The needed land footprint for nuclear power production is small and inversely correlates to the energy density of nuclear power. Nuclear power produces more electricity on less land than any other low-carbon source (DOE 2021b). From a recent DOE fact sheet:

A typical 1,000-megawatt nuclear facility in the United States needs a little more than 1 square mile $\left(2.6 \mathrm{~km}^{2}\right)$ to operate. NEI says wind farms require 360 times more land area 
to produce the same amount of electricity and solar photovoltaic plants require 75 times more space. To put that in perspective, you would need more than 3 million solar panels to produce the same amount of power as a typical commercial reactor or more than 430 wind turbines (capacity factor not included) (DOE 2021b).

A recent report (Stevens et al. 2017) estimated the land use requirements for different power production technologies (note that some of these estimates differ from the DOE estimates noted above due to uncertainties in the calculation approach). For many technologies, the dominant land use supported the facilities need to move electricity away from the production facility to the end users. We see, though, dense energy sources such as nuclear and fossil fuel use much less land than other sources to produce electricity (see Figure 5).

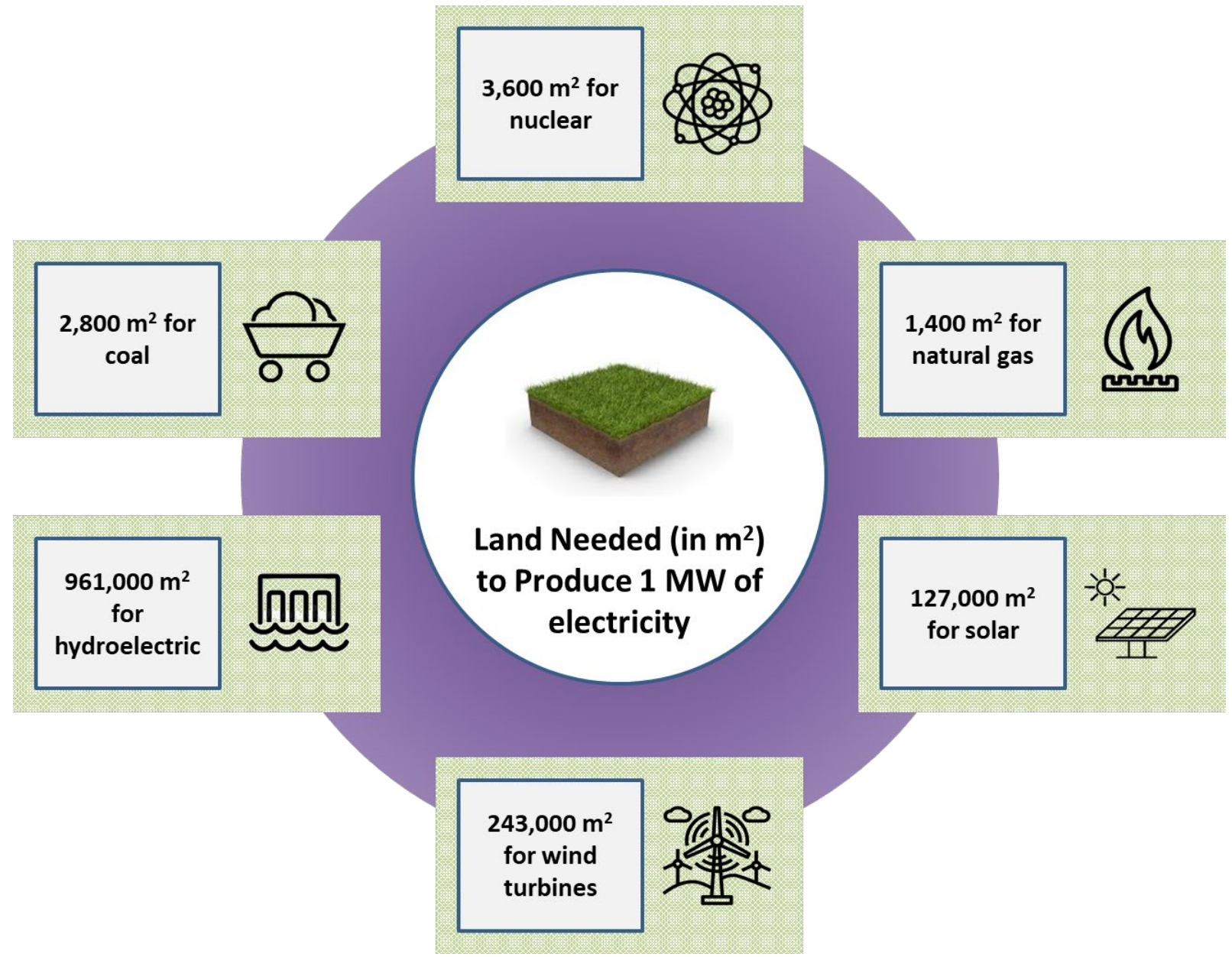

Figure 5. Land use needed for different power production technologies to produce $1 \mathrm{MW}$ of electricity.

\section{Key Points}

- Nuclear power produces more electricity on less land than any other low-carbon source.

- Other low-carbon sources of electricity require 35 to 264 times as much land to produce the same amount of energy.

\subsubsection{Water use}

In the United States in 2015, the largest users of water were agriculture (39\%) and thermoelectric power generation (41\%). Total water use in the United States was estimated to be approximately 1.22 
trillion liters per day (322 billion gallons per day) (Dieter et al. 2018). When water is withdrawn for agriculture, much of it is lost to other purposes; it is consumed for agricultural products. However, when used for electricity generation (cooling or direct use in generation), most of the water withdrawn is returned to the body of water from which it is withdrawn. This water can be reused for other purposes (DOE 2010).

Note that water "use" is not the same as water "consumption." Consumption is the difference between the amount of water withdrawn from the source and the amount returned to the source.

Water is withdrawn and consumed at different rates by different energy production methods. A little more than 3\% of water consumption in the United States is dedicated to the cooling of thermoelectric power plants (i.e., plants that produce electricity by thermal processes, including nuclear plants, coal plants, and natural gas plants, most of which use steam-driven turbines to generate power) (DOE 2010).

Nuclear energy consumes more water than some sources of renewable energy, such as wind and photovoltaic solar, but generally less water than other sources of renewable energy, such as geothermal, hydropower, and concentrating solar (DOE 2010). The differences in water consumption for different energy production types are shown in Figure 6

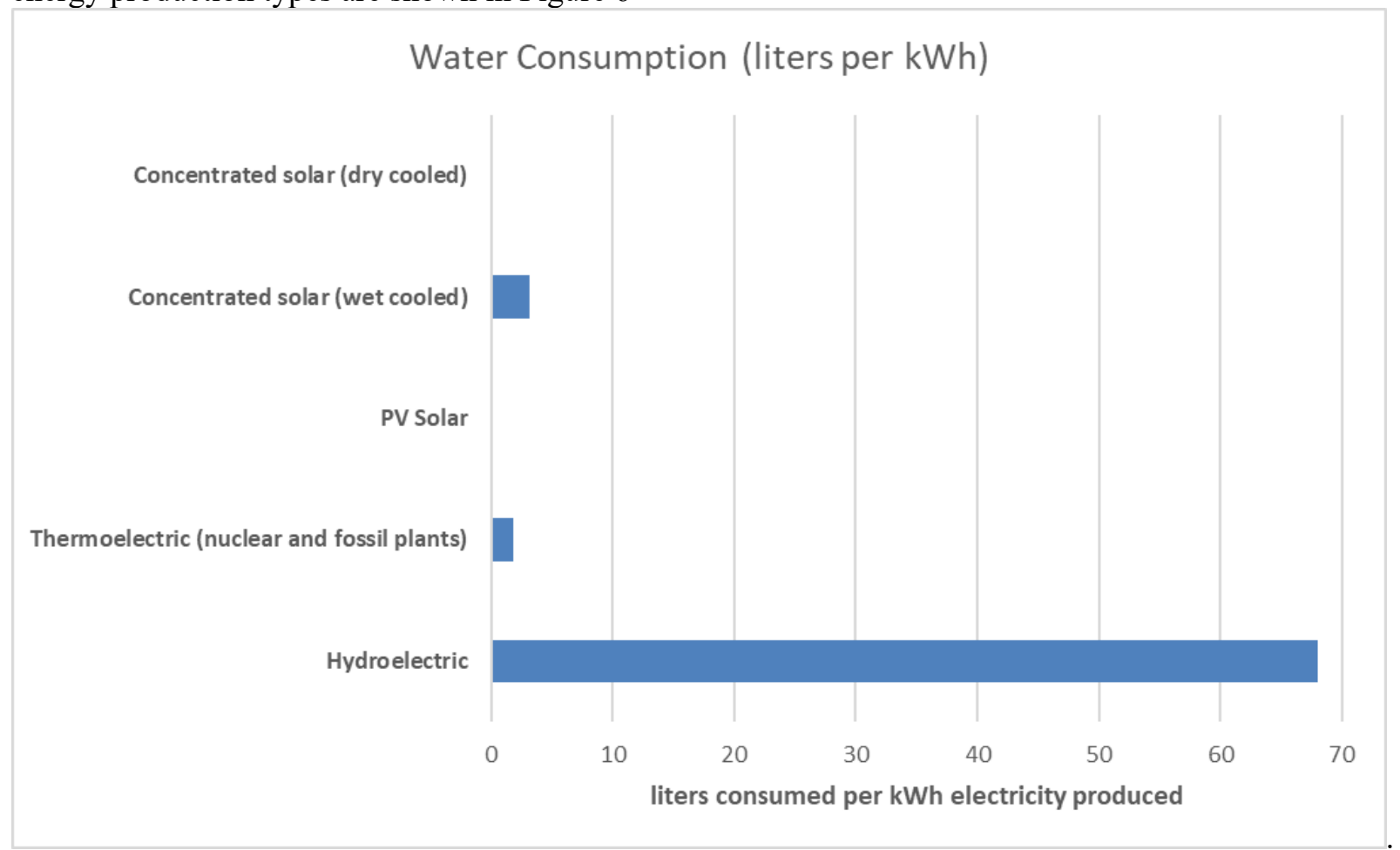

Note that the large consumption of water from hydroelectric power production does not represent the water that flows through the turbine (this water is used, not consumed), instead it represents the water lost through evaporation when stored behind the hydroelectric dam. 


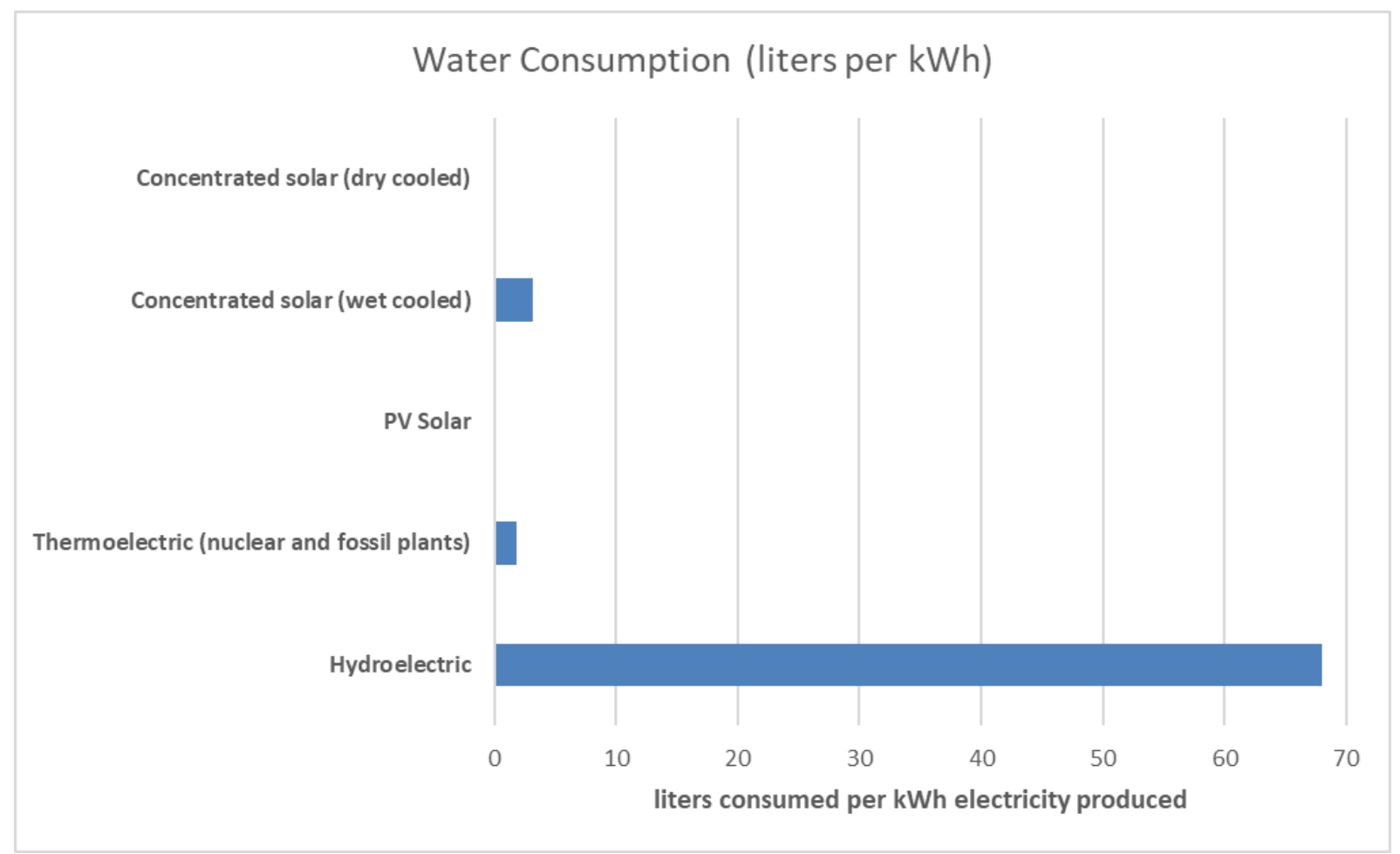

Figure 6. Water consumption in the United States for different types of energy production technologies. Sources: hydroelectric and nuclear/fossil (Torcellini, Long, and Judkoff 2003); PV solar (SEIA); concentrated solar (Frisvold and Marquez 2014).

In the United States, the use of water for thermoelectric power generation has decreased over the last two decades as plants started to use more water-efficient cooling systems and as the use of coal has declined (see Figure 7). Note that the total water consumption value described by (Dieter et al. 2018) does not include any water used during the production of hydroelectric power. It has been estimated, though, that a 1,000 MWe hydroelectric dam would require over $4,000 \mathrm{~km}^{2}$ of land for typical water storage (Herald 2016). 


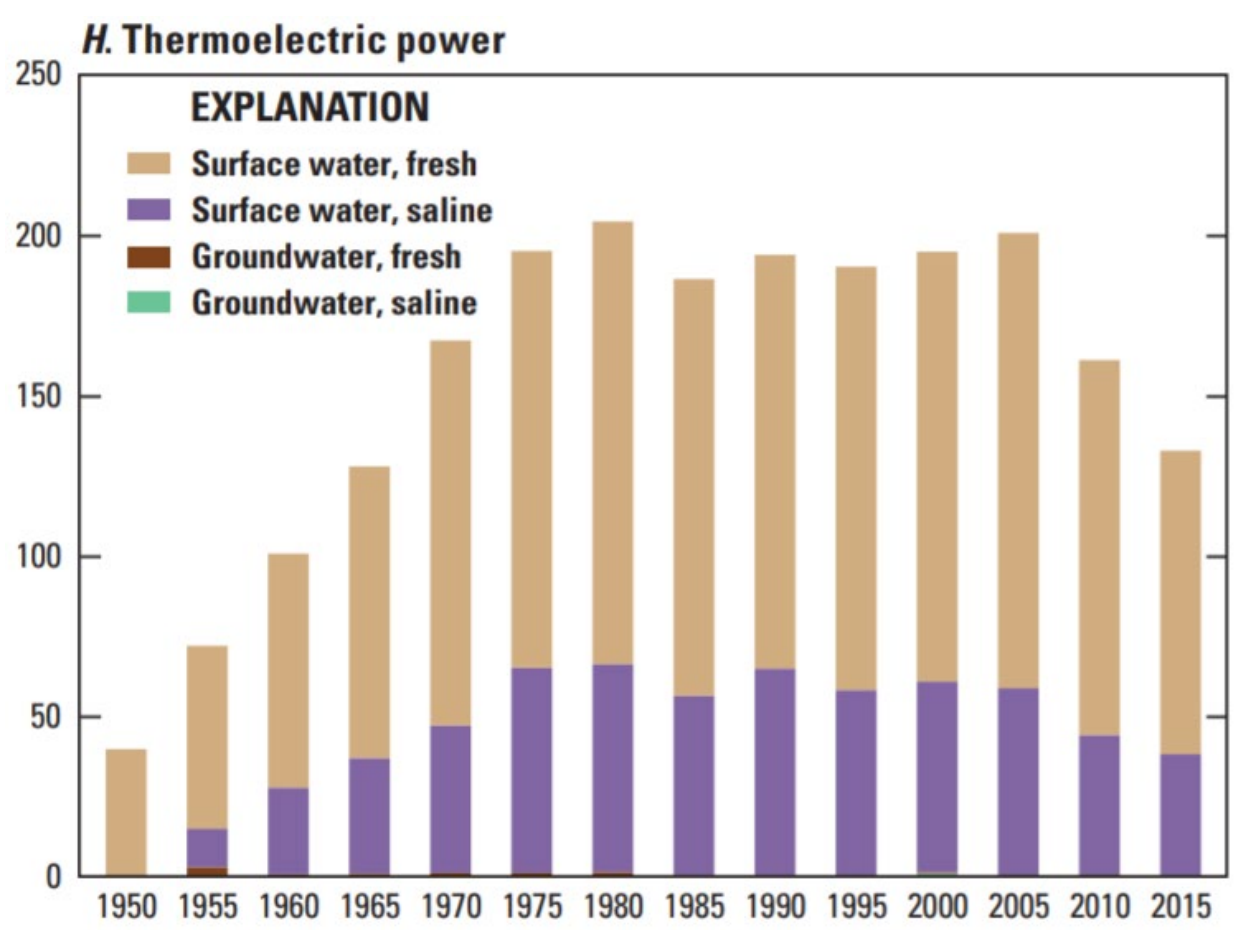

Figure 7. Trends in water use for thermoelectric power generation in the United States (USGS 2018).

Some advanced reactor technologies have already started to address the use of water for cooling. For example, Holtec has claimed their SMR-160 design can operate using an air-cooling system rather than water as its primary cooling source using air-cooled condensers, thereby enabling operation in many arid regions of the world (Holtec 2021). In addition, the NuScale reactor implementation being considered by the Utah Associated Municipal Power Systems has decided to use a dry-cooling approach that will "cut (water use) by more than 90 percent" (Wald 2020).

Another item to consider under water use is the fact that nuclear energy production can produce potable water (e.g., from sea water) using waste heat or the electricity produced. For example, NEI noted:
A single module in a NuScale plant could run a reverse osmosis water plant that made 60 million gallons $(2.3 E+8$ liters) of potable water per day. NuScale calculates that a 12-module plant could provide all the water needed for a city like Cape Town, South Africa, a place that almost ran out of water in 2019. Around the world, more cities will face problems like that as a changing climate changes rainfall patterns, and as increasing urbanization raises water demand (Wald 2020).

It is possible that a NPP could become net-zero in terms of water consumption by offsetting the water consumed via the production of potable water through processes such as reverse osmosis or multi-state flash distillation. The World Nuclear Association noted that multi-stage flash distillation could produce approximately 26 liters of water for each $\mathrm{kWh}$ used for the distillation (World Nuclear Association 2020a). This production value is about 15 times larger than the water consumed per $\mathrm{kWh}$ for a typical NPP.

\section{Key Points}


- Water "use" is not the same as water "consumption." Consumed water is not available for other uses.

- Nuclear power consumes relatively little water compared to some other low-carbon sources.

- Nuclear power can be net-zero with respect to water use since it can be used to produce purified water from sources such as sea water.

\subsubsection{Other material use}

Renewable energy and other emerging technologies are placing a strain on the materials required in their production. These commodities are controllable by countries both using the current mining production capabilities and the minable reserves within the country. Supply risk of rare earths and other minerals and metals has been the subject of concern when it comes to renewable energy development over the coming decades. For example, the European Commission evaluated the supply chain risk of renewable energy and other emerging technologies (EC 2020). As seen in Figure 8, the renewables sector supply chain has, qualitatively, several high or very high supply risks (note that material issues for nuclear are not included in this figure but are addressed later in this section). For example, reliance on rare earth metals affects wind turbine magnet production while solar panel production is less impacted by reliance on metals such as vanadium.

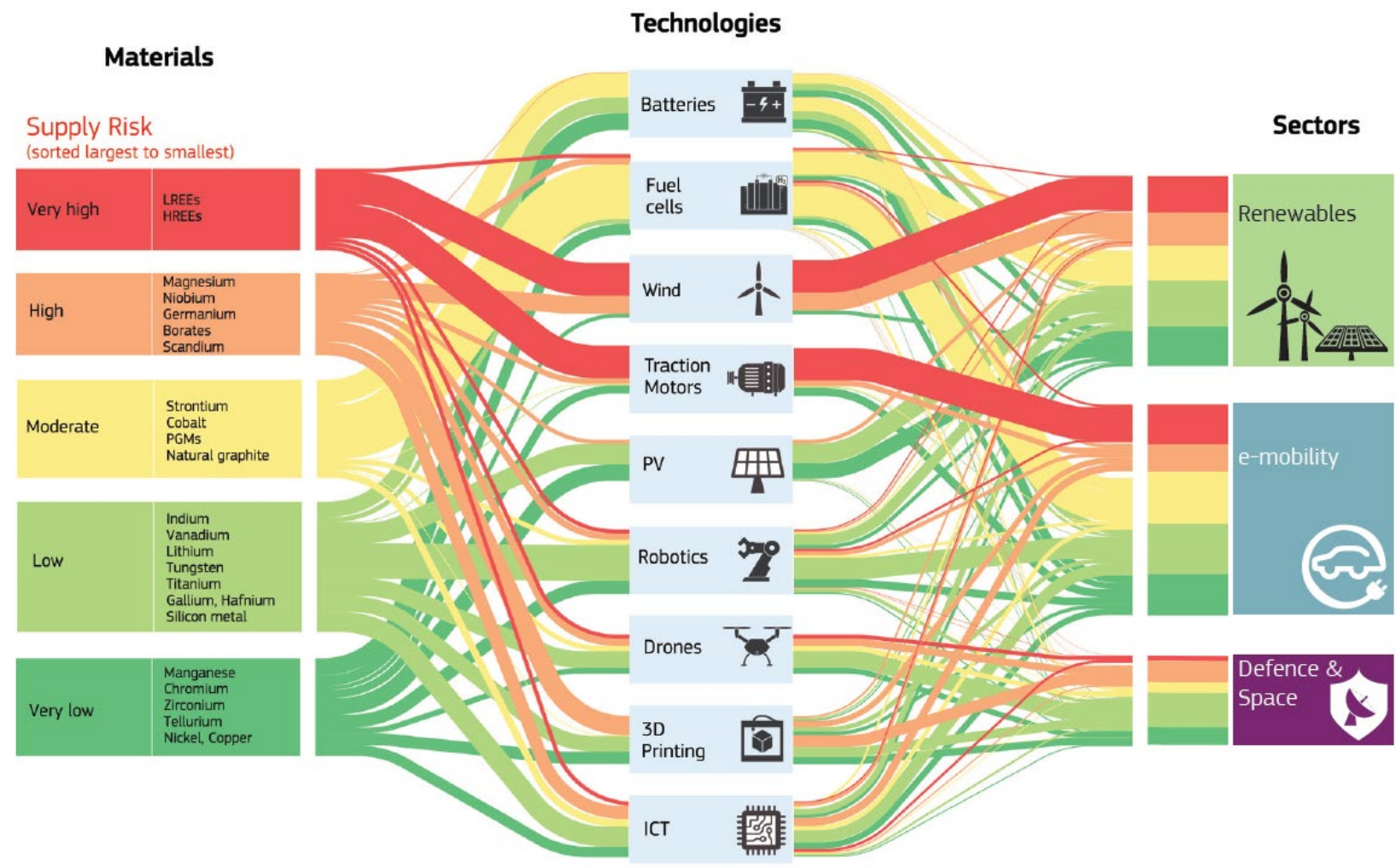

Figure 8. Supply risk of renewable sector and other emerging technologies (EC 2020).

Rare earth metals of the lanthanide series of elements are used extensively in wind turbine magnets. While rare earth metals are not actually "rare," minable concentrations of rare earth metals are in only a few areas of the world. Their impact on both renewables and the production of electric (traction) motors is sizable. The yearly production of rare earth metals and the estimated reserves is shown in Figure 9 and Figure 10, respectively. 


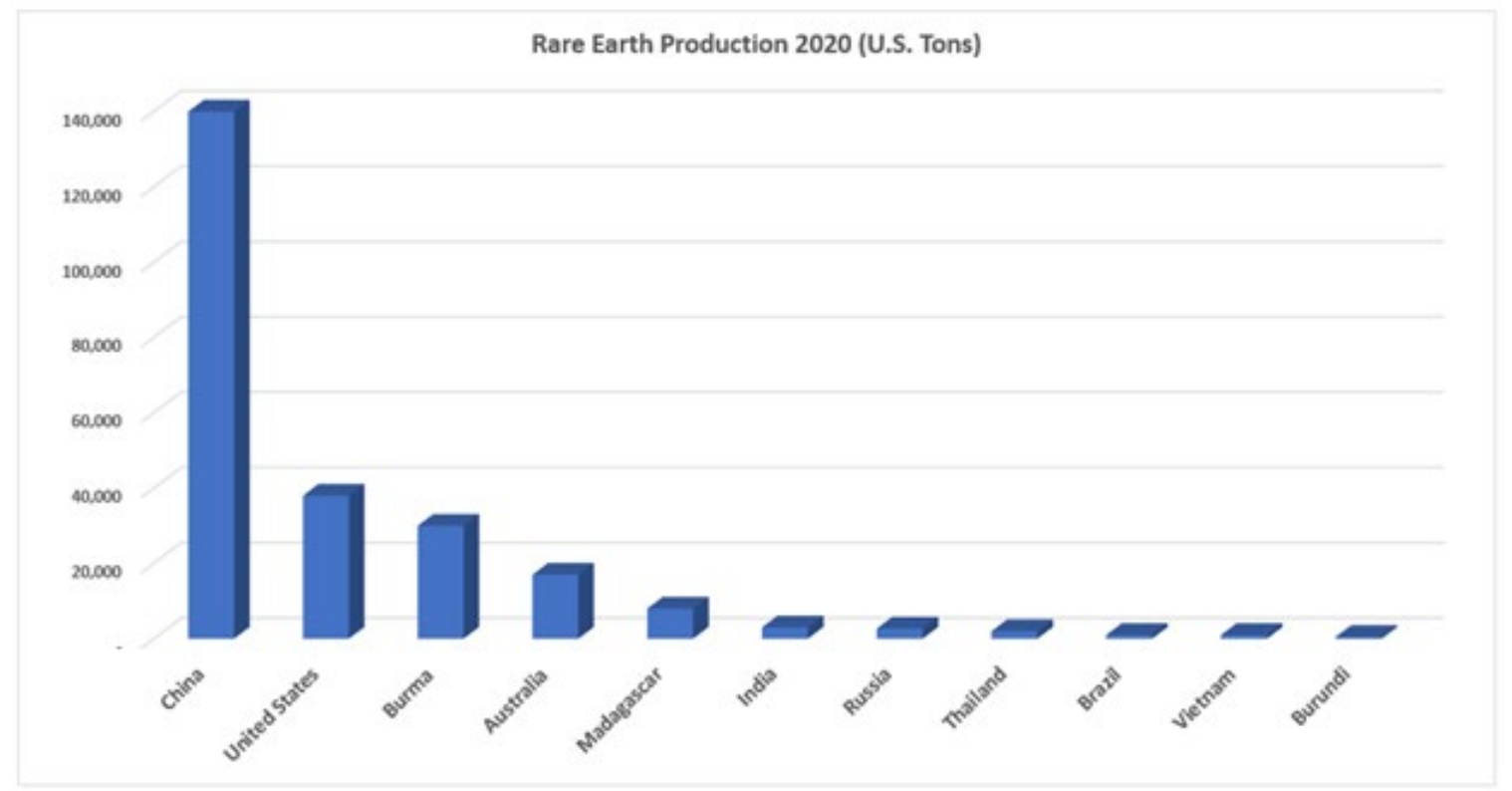

Figure 9. Worldwide rare earth production in 2020 (USGS 2021).

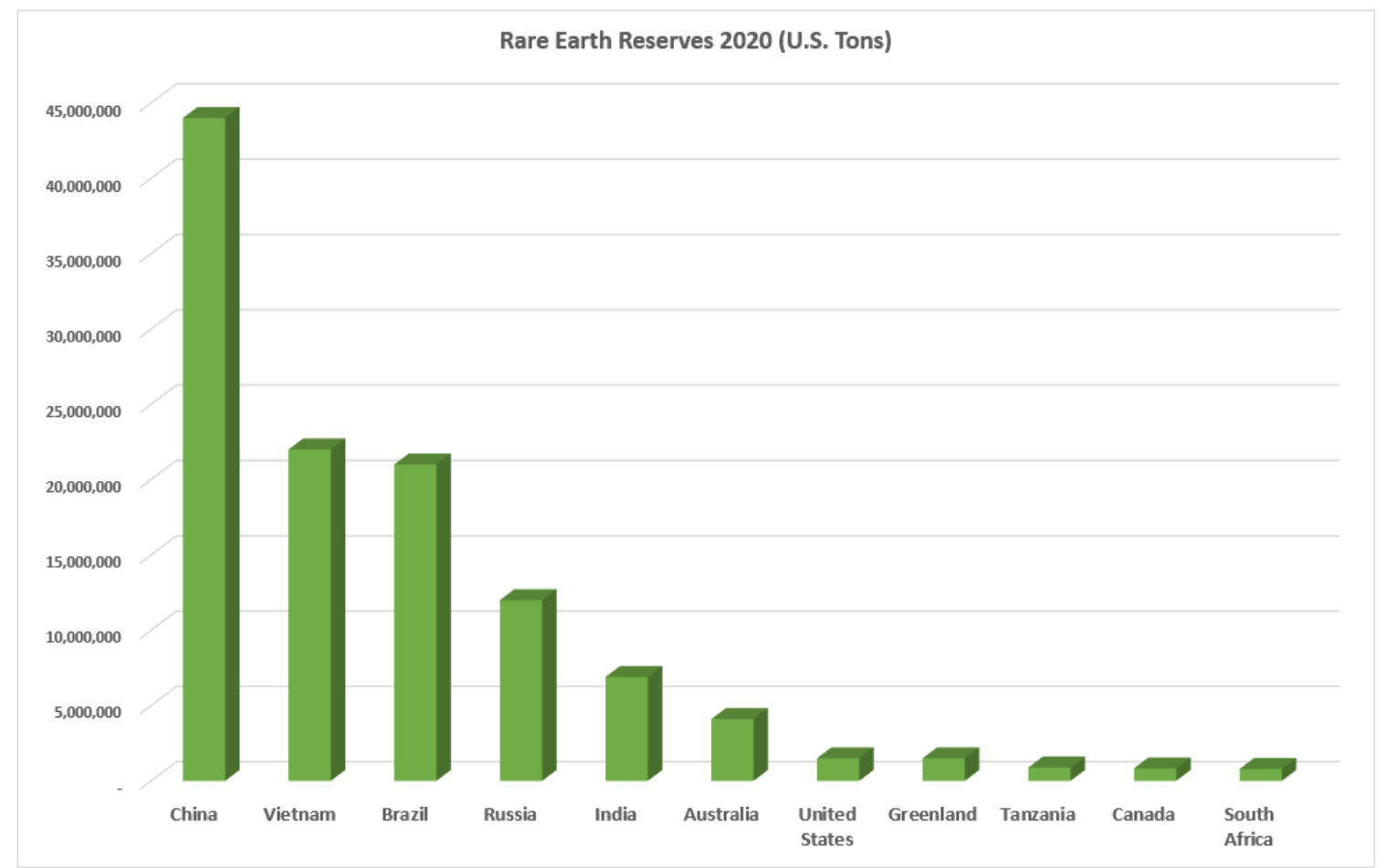

Figure 10. Worldwide rare earth reserves in 2020 (USGS 2021).

The uranium used to fuel the U.S. nuclear fleet is 95\% imported (World Nuclear Association 2021a). The choice to import is a financial decision made based on the world-wide supply of uranium and the 
uranium reserves held by U.S. utilities. As nuclear power is increased over the next decades, the United States will likely increase mining domestic reserves of uranium. The United States Geological Survey (USGS) is reevaluating U.S. uranium resources for the first time since the 1970s. The world-wide supply of uranium, using current levels of resources and without recycling or reprocessing, is expected to more than meet the needs of the world for another 135 years (IAEA 2020). This supply is without taking in account the discovery of new deposits. The supply risk lies in the installed mining capability, which would need to grow with demand, but may not grow fast enough. The projections of the International Atomic Energy Agency (see Figure 11) on uranium resources and demand show that high-end reactor requirements in 2040 could outstrip the current production capabilities.

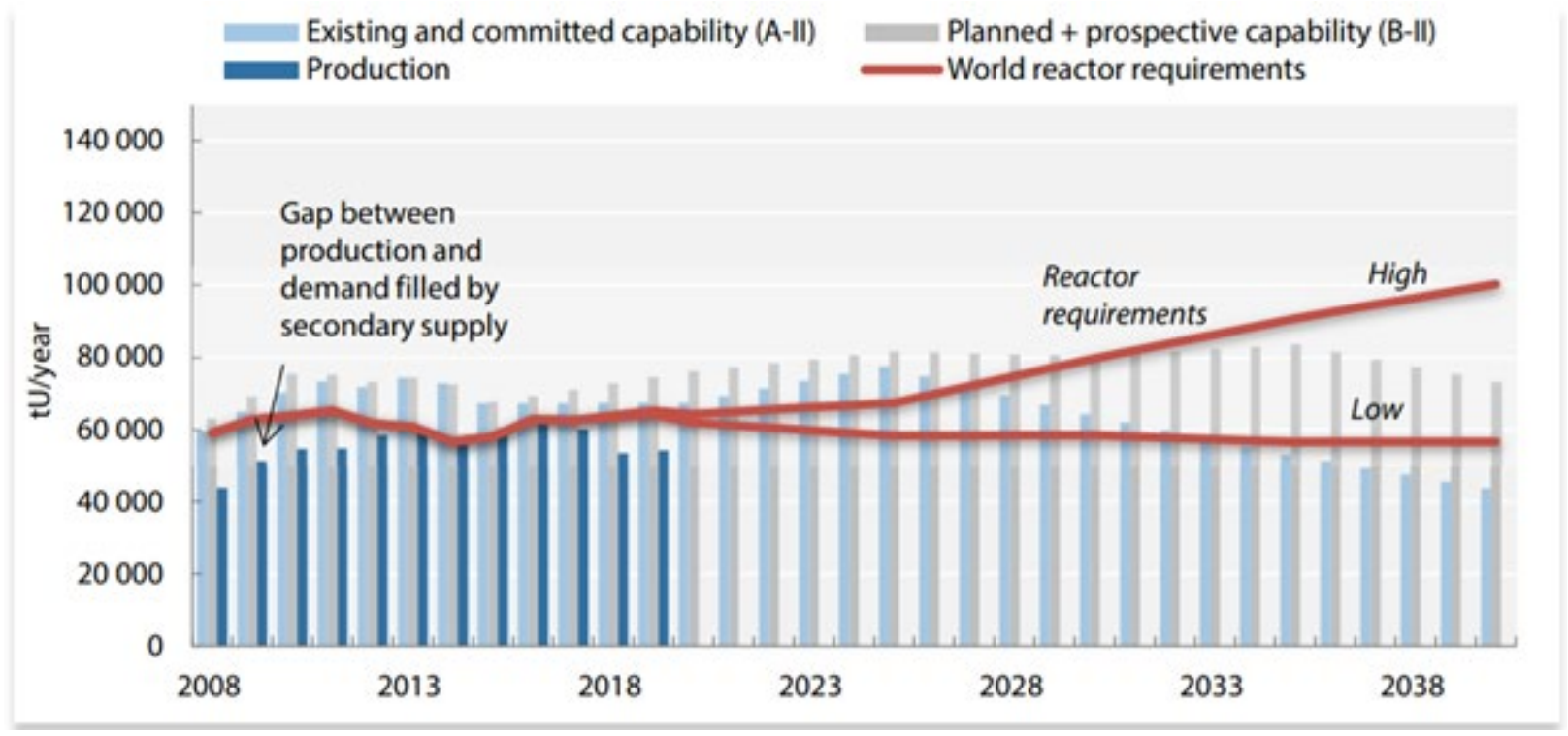

Figure 11. Projected world uranium production capability versus demand through 2040 (IAEA 2020).

While different energy production technologies have different material needs, they also have varying levels of bulk material use per unit energy produced. To achieve an overall net-zero impact, it is necessary to maximize energy production while minimizing material needs. Finding, reaching, extracting, shipping, refining, and then manufacturing vast amounts of materials takes a toll on people, flora, and fauna.

The International Energy Agency (IEA) has also investigated material needs for energy producing systems (IEA 2021). Figure 12 illustrates the material requirements (on a per MW basis) for different energy production technologies. Recall that $1 \mathrm{MW}$ can power approximately 830 homes in the United States. (EIA 2021c). Note though that the overall material needs are only part of the consideration for long-term energy decisions. The other consideration is where these materials are produced and processed into their final forms - this consideration is part of the energy security decision-making.

IEA has also researched the production and processing of key materials needed for energy production technologies. The key countries producing materials is shown in Figure 13 while the processing countries are shown in Figure 14. These figures should be cross-referenced with the mineral needs (Figure 12) for a specific energy production technology to better understand critical energy technology material dependencies. For example, we see that nuclear has a large need for nickel, solar PV a large need for silicon, and onshore wind a large need for zinc. Yet nickel is largely produced in Indonesia, the Philippines, and Russia (USGS 2020a); silicon is largely produced in China, Russia, and Norway (USGS 2020b); and zinc is largely produced in China, Peru, and Australia (USGS 2020c). Lastly, as more and more minerals are mined from the Earth, the quality of the mineral ore tends to continually decline; for 
example, it now takes twice as much raw earth extraction for copper ore to produce the same amount of copper compared to 10 years ago (World Nuclear Association 2021c).

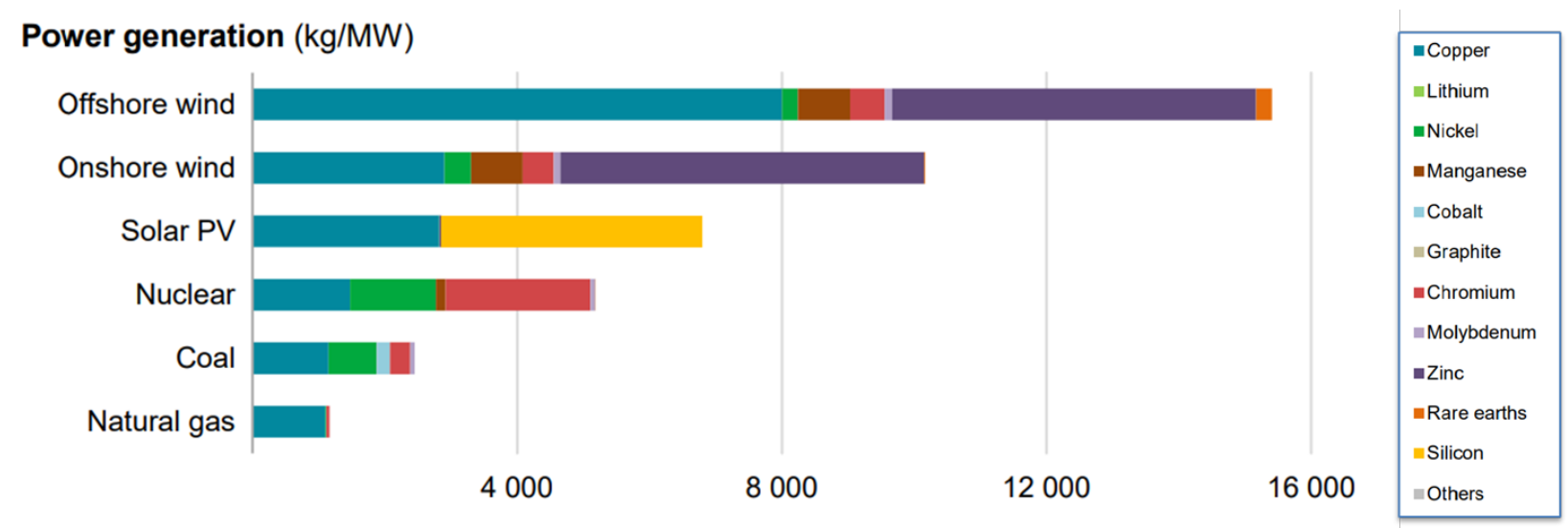

Figure 12. Mineral needs (kg) per MW produced for different energy production technologies (IEA 2021).

Share of top three producing countries in total production for selected minerals and fossil fuels, 2019

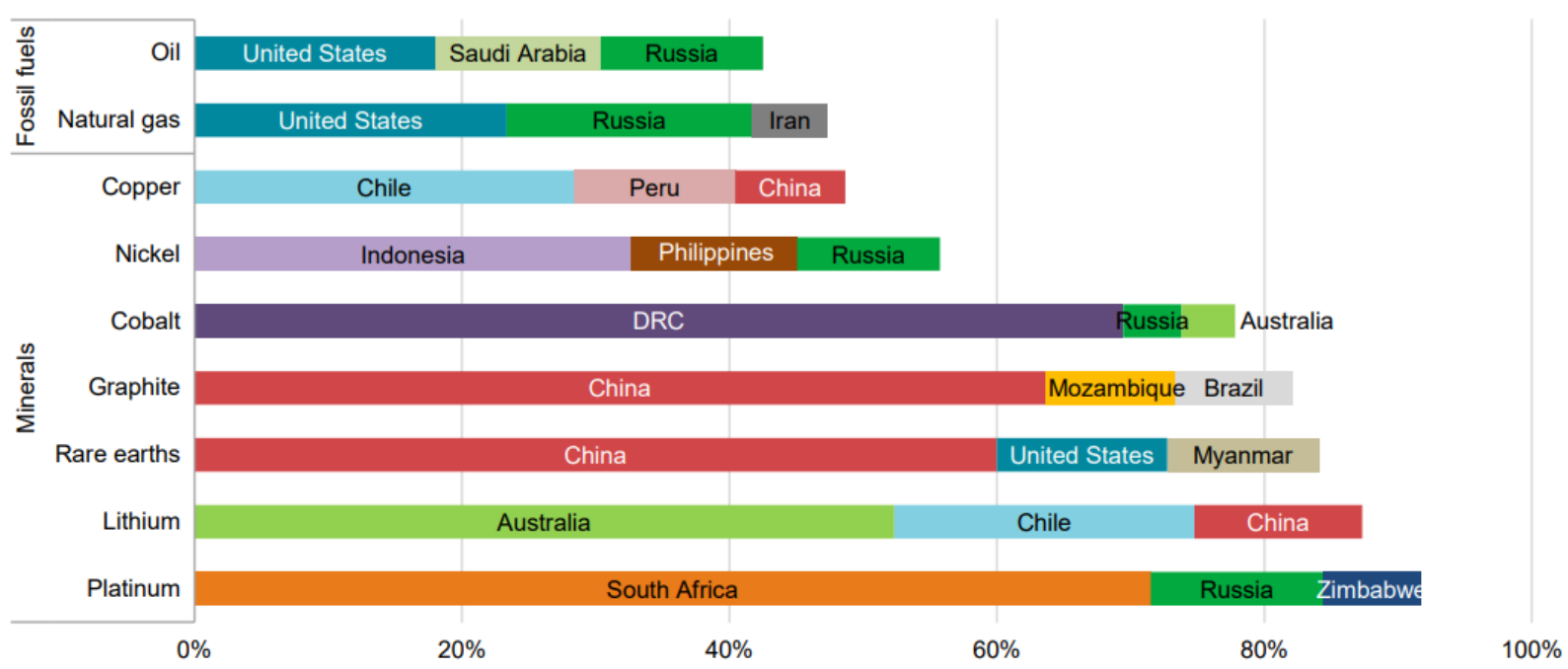

Figure 13. Countries that produce key materials needed for different energy production technologies (IEA 2021). 
Share of processing volume by country for selected minerals, 2019

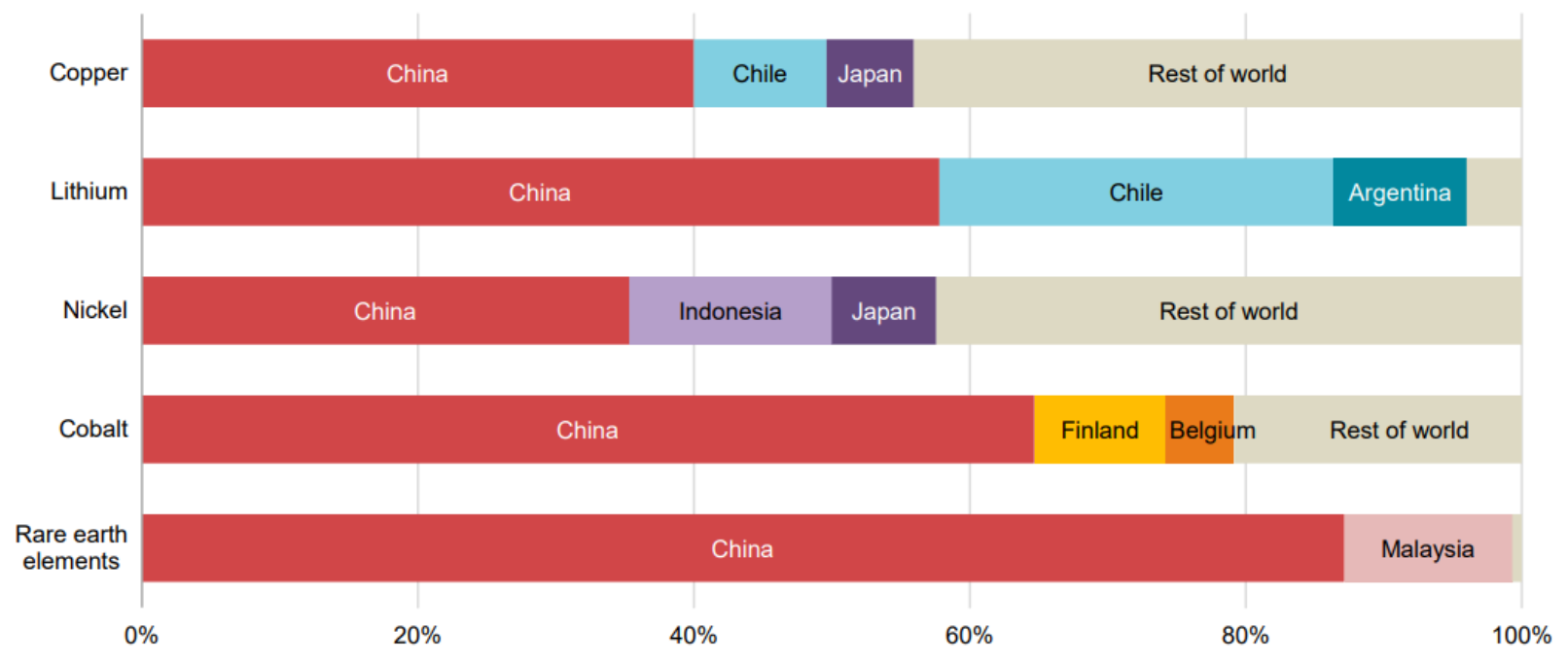

Figure 14. Countries that process key materials needed for different energy production technologies (IEA 2021).

\section{Key Points}

- Minimizing material needs for a unit production of energy is required for net-zero goals.

- As minerals are increasingly mined from the Earth, the quality of the mineral ore tends to decline over time requiring increasing amounts of mining per unit of material required.

- Nuclear has the lowest material resource intensity, per MW generated, of any low-carbon energy production technology.

- In addition to understanding material needs, understanding where raw material comes from is critical to making decisions related to long-term energy security.

\subsubsection{Construction}

The future of nuclear power in the United States will be impacted by the ability to learn from prior construction delays and successes in the use of design simplicity.

Construction of NPPs in the United States since the 1980s has seen delays and cost over-runs. New and resumed construction of large LWRs started in the 2000s. Watts Bar Unit 2 construction, originally started in 1973, was re-initiated in 2007 and finished in 2016 after delays and cost over-runs attributed to expected increased regulation resulting from regulatory actions following the Fukushima nuclear accident investigation (Reuters 2012). Two new AP1000 reactors are under construction at the Vogtle Electric Generating Plant in Georgia (Figure 15). The cost over-runs and delays resulted in the bankruptcy of Westinghouse and more than one federal loan to assist the construction costs, but both units are expected to be operational by 2023. Accurate and reasonable construction times and costs must be achieved for mid- to large-scale NPPs to move forward on a scale that will positively affect carbon-free baseload electrical generation on a national scale. Four key factors impact the construction timeframe and costs: licensing, construction management, complexity of the design, and unique build-in-place safety systems construction. 


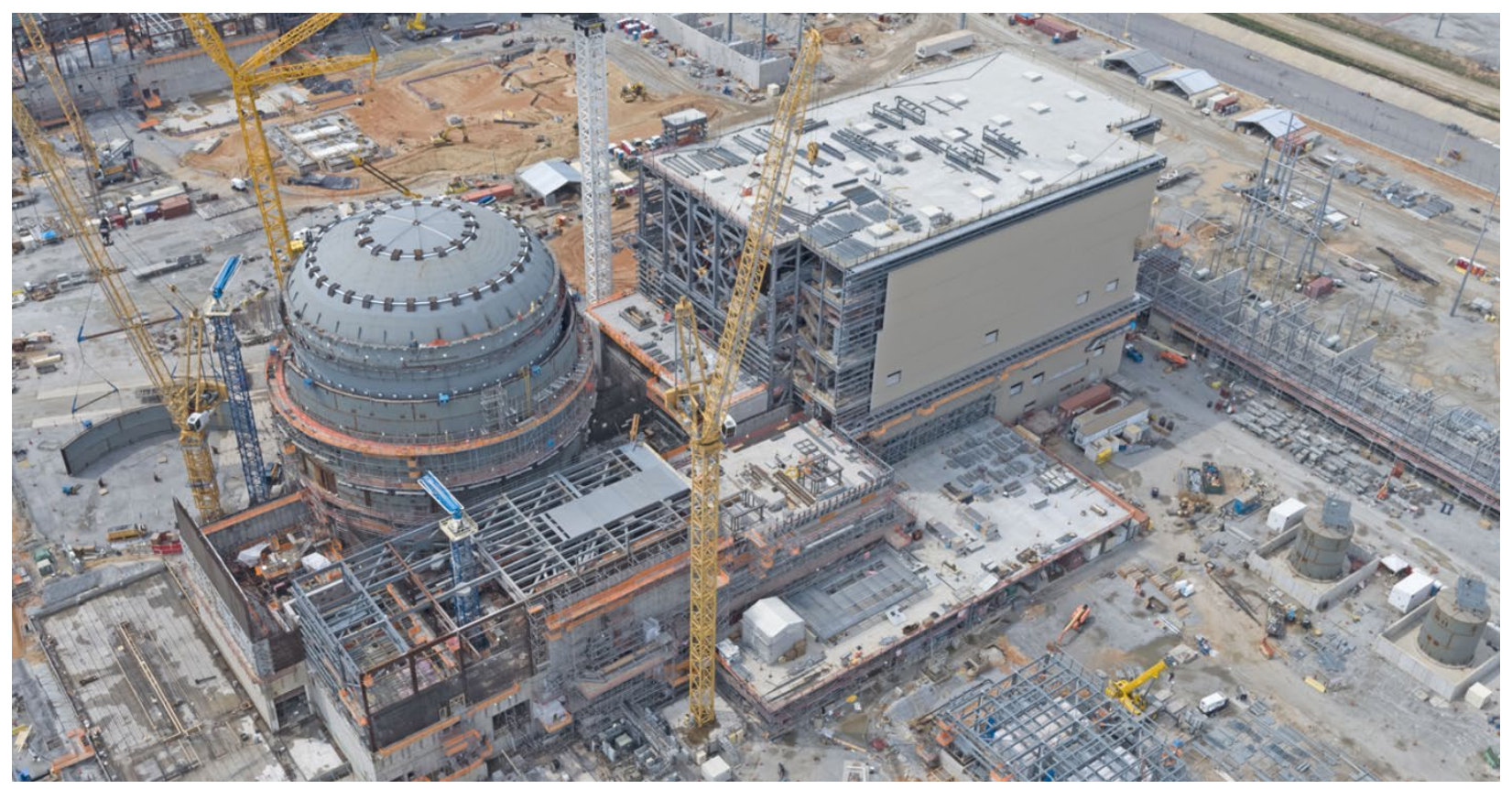

Figure 15. Vogtle Unit 3 construction photo 2019 (Georgia Power Company 2019).

Expensive and long licensing timeframes have delayed many projects. The U.S. Nuclear Regulatory Commission (NRC) has worked in cooperation with industry trade associations to address these issues by encouraging early contact while the reactor design is still underway. Guidance for risk-informed, performance-based, technology-inclusive licensing is actively being produced in cooperation with industry trade associations and national laboratories. This regulatory engagement has helped the overall licensing approach move forward in support of the anticipated increase in advanced reactor licensing. Early interaction positively affected the timeframe of the NuScale SMR reactor licensing and is underway with several advanced reactor developers (NRC 2021b).

The U.S. DOE is leading a project with General Electric Hitachi Nuclear Energy and including other industry and academic partners to demonstrate construction technologies that can reduce construction costs and timeframes (World Nuclear News 2021a).

The high complexity of NPP designs since the 1960s is based on the LWR reactors that need to run at high pressures. High-pressure reactors have high-pressure safety systems which need to be built in place. Building large-scale machinery in place is very expensive and time-consuming. For a modular reactor, the safety system typically is within the module itself, so it can be built at a factory and delivered to the site (Figure 16). The costs of factory-built modules are inherently lower due to in-place manufacturing machining and an economy of scale. The lower complexity advanced reactors have fewer active parts to their systems, which in turn mean less initial capital cost and less maintenance costs going forward.

Regardless of the advantages of small modularity and simplicity of design, any mid- to large-scale NPP remains a large construction project. The recent construction start of China's AP100 SMR demonstration project illustrates that there is still considerable concrete and infrastructure work performed to accommodate the modules (World Nuclear News 2021b). 


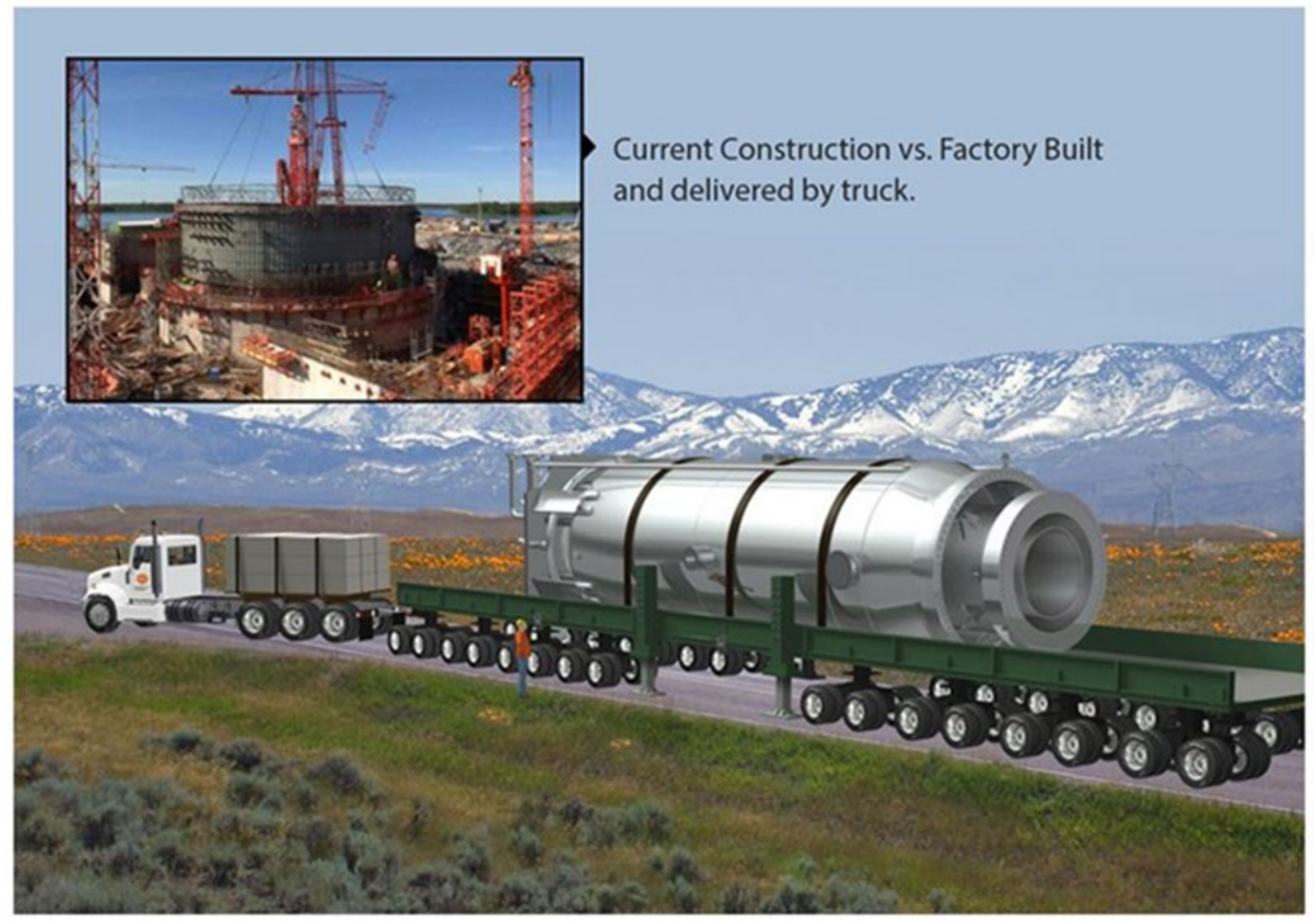

Figure 16. Factory-built SMR modules delivered to site versus on-site construction (Power Tech 2017).

\section{Key Points}

- The construction efficiency of NPPs must be improved to lower costs.

- The U.S. nuclear industry is actively addressing the length and complexity of new reactor licensing through early reactor developer interaction and guidance documentation for riskinformed, performance-based, technology-inclusive licensing.

- The U.S. nuclear industry is addressing construction timeframe and cost through lessons learned and new techniques. 


\subsection{Efficacy}

Efficacy, or the ability to perform an activity satisfactorily, represents several technical characteristics where a positive outcome during energy production is preferred. For example, one of the metrics we describe is "longevity of facilities." It is optimal to have our energy production facilities to have a very long life for numerous reasons, including minimization of material needs, reduced costs, minimization of community impacts during construction, strengthening of energy security, etc. Other energy production characteristics we evaluate in this section include: the ability to produce electricity, the ability to produce heat, the ability to produce fuel used by the energy production technology, the reliability of the energy production process, the continuity of energy production during disruptive events, the costs, the revenue, and how ancillary technologies might be enhanced.

\subsubsection{Electricity production}

Once common facet among all energy production technologies is that they can produce electricity. Some technologies produce electricity directly (e.g., solar) while most produce electricity indirectly by turning a generator. Note that direct energy conversion into electricity, such as solar, is typically not as efficient as indirect approaches; for example, solar efficiency is around 15-20\% while NPPs are around $30-33 \%$ and combined cycle natural gas can exceed $50 \%$ efficiency.

One metric for technology comparison is energy return on investment (EROI) which represents how much electricity a system might produce versus a unit input of energy into that system. To be meaningful, the metric would need to be measured over the lifecycle of the technology. A technology that requires more energy than it produces would not be viable (no current commercial energy system falls into that category). To evaluate EROI for an energy technology, one would need to follow the process found in Figure 18 (Brockway et al. 2019). Several EROI studies were collected and tabulated in (World Nuclear Association 2020b); the averaged results for six different energy production technologies are shown in Figure 17. As can be seen in this figure, nuclear power is second only to hydropower generation. Note that this analysis (i.e., an EROI of 59 for nuclear) considers many factors such as manufacturing, construction (including mining, milling, and enrichment of fuel), and disposition. Energy density and low material use are factors that drive large EROI values. 


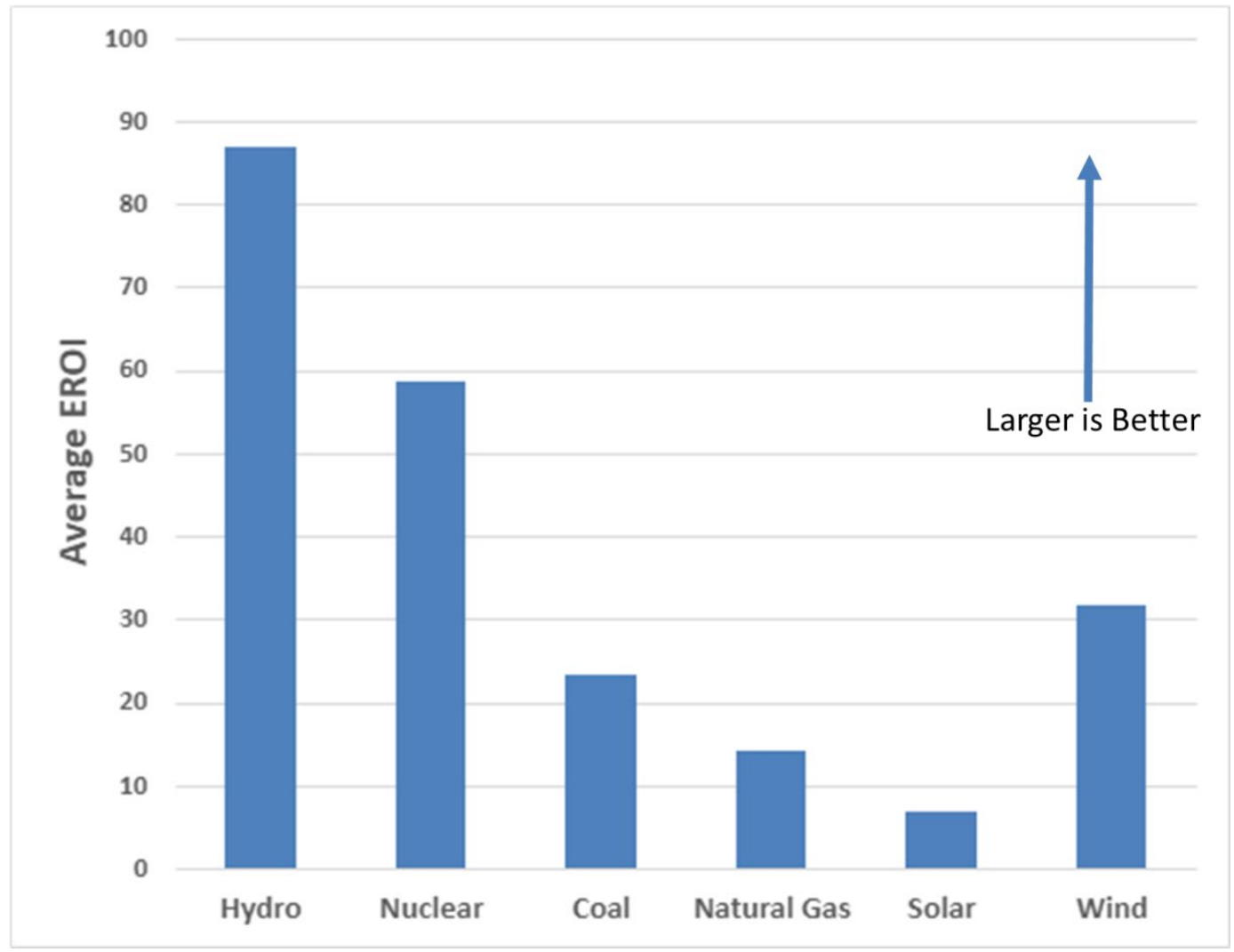

Figure 17. Average EROI for different energy technologies (World Nuclear Association 2020b).

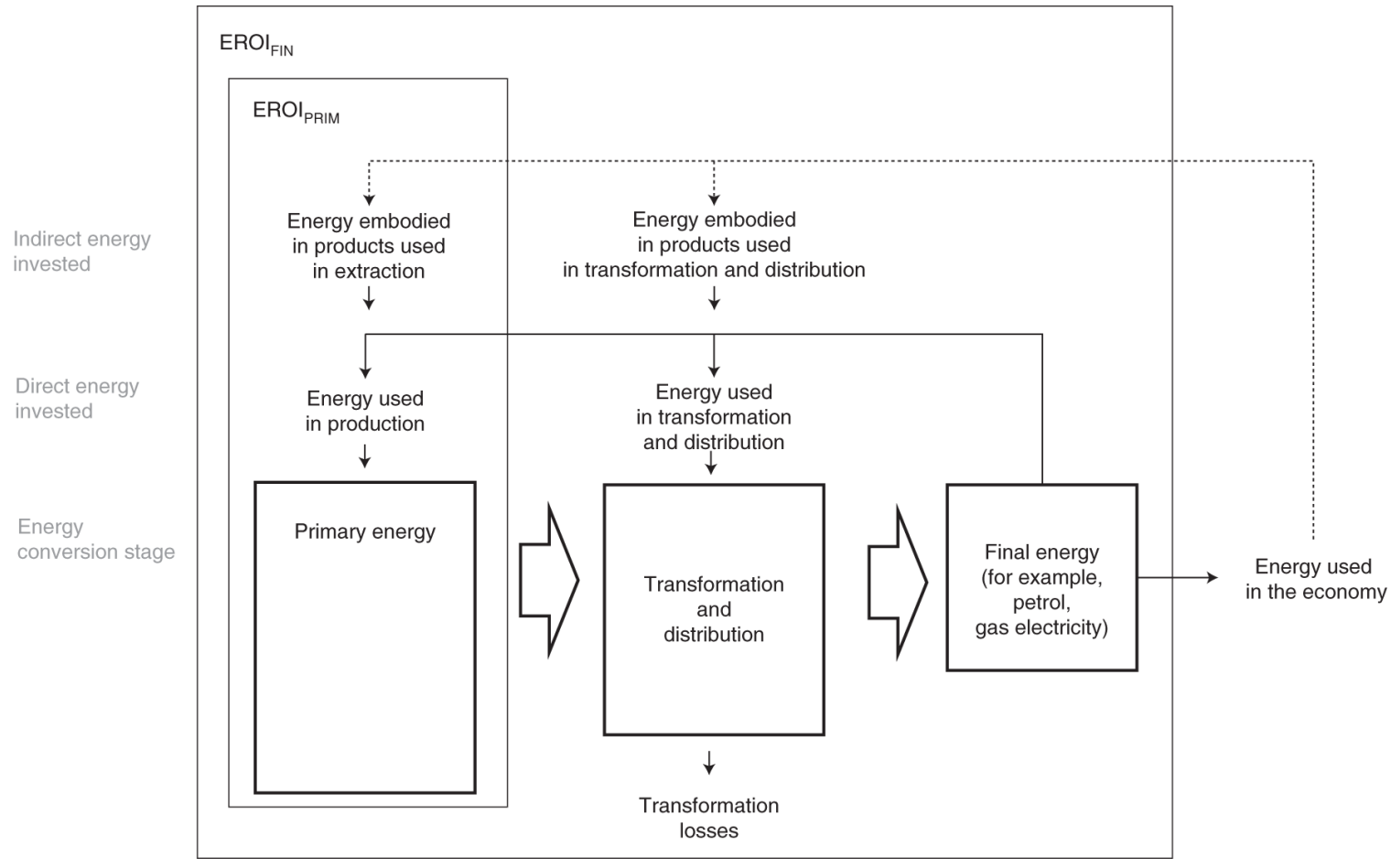

Figure 18. Conceptual framework used to determine EROI (Brockway et al. 2019). 


\section{Key Points}

- All energy production technologies can produce electricity, either directly or indirectly.

- The efficiency of different electricity production technologies varies, typically in the range of $15 \%$ to $50 \%$.

- Measuring the amount of energy produced per unit energy input into a system, or its energy return, shows that nuclear is one of the most efficient energy technologies available.

\subsubsection{Heat production}

Today's large LWRs utilize thermal-mechanical energy conversion to produce electricity for the grid. These reactors typically operate with a thermal efficiency of around 33-37\% (Afework et al. 2021). A typical reactor may have a thermal rating of almost 3,000 MWth, but the output electricity production is around $1 / 3$ of that value or $1,000 \mathrm{MWe}$. This means that nearly $2 / 3$ of the heat produced is currently discarded as waste heat.

While advanced reactors offer the capability to increase the efficiency up to $45 \%$, there are other options to utilize the heat production capabilities found in NPPs. By reusing discarded heat, a process called cogeneration, a NPP could increase its overall thermal efficiency by so much as $30 \%$ (Krikorian 2018). Cogeneration combines the usable waste-heat and electricity production into a single process. Some benefits include increased efficiency, increased reliability of power and cogeneration processes, reductions in environmental impact, and economic benefits to the local area. For cogeneration processes, NPPs are typically divided into two categories:

- Low-temperature reactors: LWRs, SMRs, and heavy water reactors. These reactors provide heat in working temperatures between $280-325^{\circ} \mathrm{C}$.

- High-temperature reactors: high-temperature gas reactors, fast reactors, and molten-salt reactors. These reactors provide heat in working temperatures between $750-1000^{\circ} \mathrm{C}$ (IAEA 2021a).

One such example of low-temperature reactor cogeneration is the Kundankulam NPP in India. This plant not only provides electricity to power homes and businesses but also functions as a desalination plant that supplies potable water to the local town (Krikorian 2018). In the United States, almost 2,000 desalination facilities exist (WWD 2002), however they are powered by the local electricity grid which will contain some level of high-GHG emission energy contribution. Typical desalination plants have significant operating costs, which raises clean-water prices higher. Using nuclear waste heat in a reverse osmosis process can provide water for less than $\$ 1.00 / 1000$ gallons, significantly lower than almost any other option (Schmidt and Gude 2021). In other cases, the waste heat could be used to provide heat to homes and businesses in cold regions or as process heat industrial facilities.

There are many other options available for more efficient use of thermal energy produced in a NPP (see Figure 19). For example, cogeneration in high-temperature reactors offer benefits to many industrial applications. High-temperature reactors can be used to provide high-temperature heat for industrial processing, hydrogen production, liquid fuel production, and thermal energy storage (Royal Society 2020). 


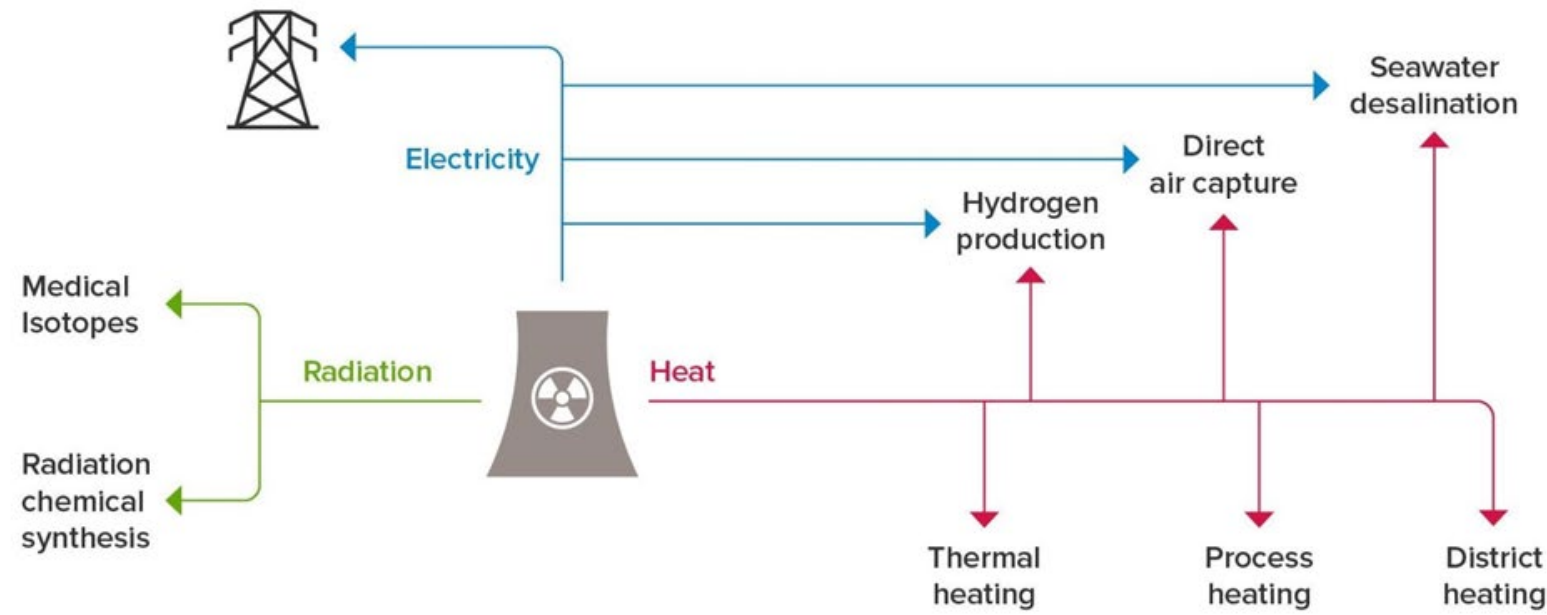

Figure 19. Nuclear cogeneration opportunities (Royal Society 2020).

It is even possible to provide cooling through waste-heat cogeneration. Absorption chillers are very similar and work on the same principles as traditional, mechanical chillers. The difference comes in the compressor style. Absorption chillers utilize heat in place of the mechanical compressor to create pressure and drive the chilling process. Because these chillers utilize waste heat, they can be used to generate nearly free cooling in many cases. This avoids high demand energy pricing during hot summer months (HeatCalc n.d.).

Nuclear cogeneration provides significant opportunities for the use of heat and extra heat from both existing reactors and new advanced reactors. Other renewable energy sources, such as wind, solar, and hydro, all generate electricity to support the energy grid but lack the heat production capabilities of nuclear power plants.

\section{- Key Points}

- NPPs produce extra heat in large quantities (up to $2 / 3$ of their total power) that can be repurposed for useful applications.

- Heat can support efficient industrial processes such as producing liquid and gaseous fuels and to purify water.

- Heat can also be used to provide cooling through absorption chiller systems.

\subsubsection{Fuel production}

Nuclear fission reactors are the only power generation technology that can produce fuel as it is consuming fuel. Depending on the design of the reactor, different types of nuclear fuel can be produced. For example, a nuclear reactor can be designed to produce different isotopes of uranium or plutonium fuel using thorium or uranium as the stock that will be modified via the nuclear reaction in the core. While these types of reactors that produce fuel (i.e., breeder reactors) are not currently used in the United States, some of the advanced reactors under consideration could be designed with this feature. Some efficiencies in the use of fuel material can be realized when using breeder reactors, for example a uranium-238-based breeder reactor can use approximately $70 \%$ of this fuel while a non-breeder reactor would use $1 \%$ (Energy Education 2017).

\section{Key Points}

- Nuclear power is the only technology that can produce fuel as it is being consumed. 
- Nuclear power reactors that produce fuel for future use are not currently used in the United States.

\subsubsection{Production Capability}

The production capability of energy sources represents the ability that a particular source can provided electricity and heat at any time during the year. The trustworthiness of energy sources to be available when needed is important to ensure continuity of heat and electricity for society. Nuclear electricity production is, by far, the most capable form of electricity used in the United States. In 2020, the United States saw (DOE 2021a):

- Nuclear facilities operated (at full capacity) for approximately $92 \%$ of the time

- Natural gas facilities operated approximately $57 \%$ of the time

- Coal facilities operated approximately $40 \%$ of the time

- Wind facilities operated approximately $35 \%$ of the time

- Solar facilities operated approximately $25 \%$ of the time.

This level of electricity production use is captured in Figure 20. Note that the reasons why a particular energy technology is not available during a year vary, for example nuclear facilities are occasionally shutdown to refuel; solar facilities only operate when sunlight is present and the solar array is not obstructed by dust or snow; natural gas facilities may only be started during peak electrical demand; and wind turbines only operate when the wind is blowing. If we translate the electrical production capability into how many days during a year this electricity source is present, we see the results shown in Figure 20 is informative since it directly conveys how much either overbuilding through redundancy or supplemental technology (e.g., energy storages) would be needed to supply power 365 days a year.

Let us think about a hypothetical case, returning to a community of 50,000 homes that requires approximately $532 \mathrm{GWh}$ of electricity over the course of a typical year (EIA 2021c):

- In the case of a community that relied $100 \%$ on nuclear power, the community would only need to "find" additional electrical supplies 29 days a year. The total production that would need to be found is approximately $43 \mathrm{GWh}$.

- For a community that relied $100 \%$ on solar power, the community would need to find additional electrical supplies 274 days a year or approximately $75 \%$ of the time. The total production that would need to be found is approximately $402 \mathrm{GWh}$.

Note that this discussion of our hypothetical community does not include consideration of variations in electrical demand, for example how to handle a maximum (or peak) load versus the average electricity consumed. Instead, power generation sources that are very reliable and available most of the time are efficient from the standpoint that backup supplies need not be extensive, and energy storage may be minimal. Conversely, power generation sources that do not have high availability require large degrees of additional backup generation or energy storage. These additional systems increase overall costs, increase management complexity, and may decrease overall system reliability due to the requirement to ensure either dormant systems become available when needed, or energy storage can function reliably. 


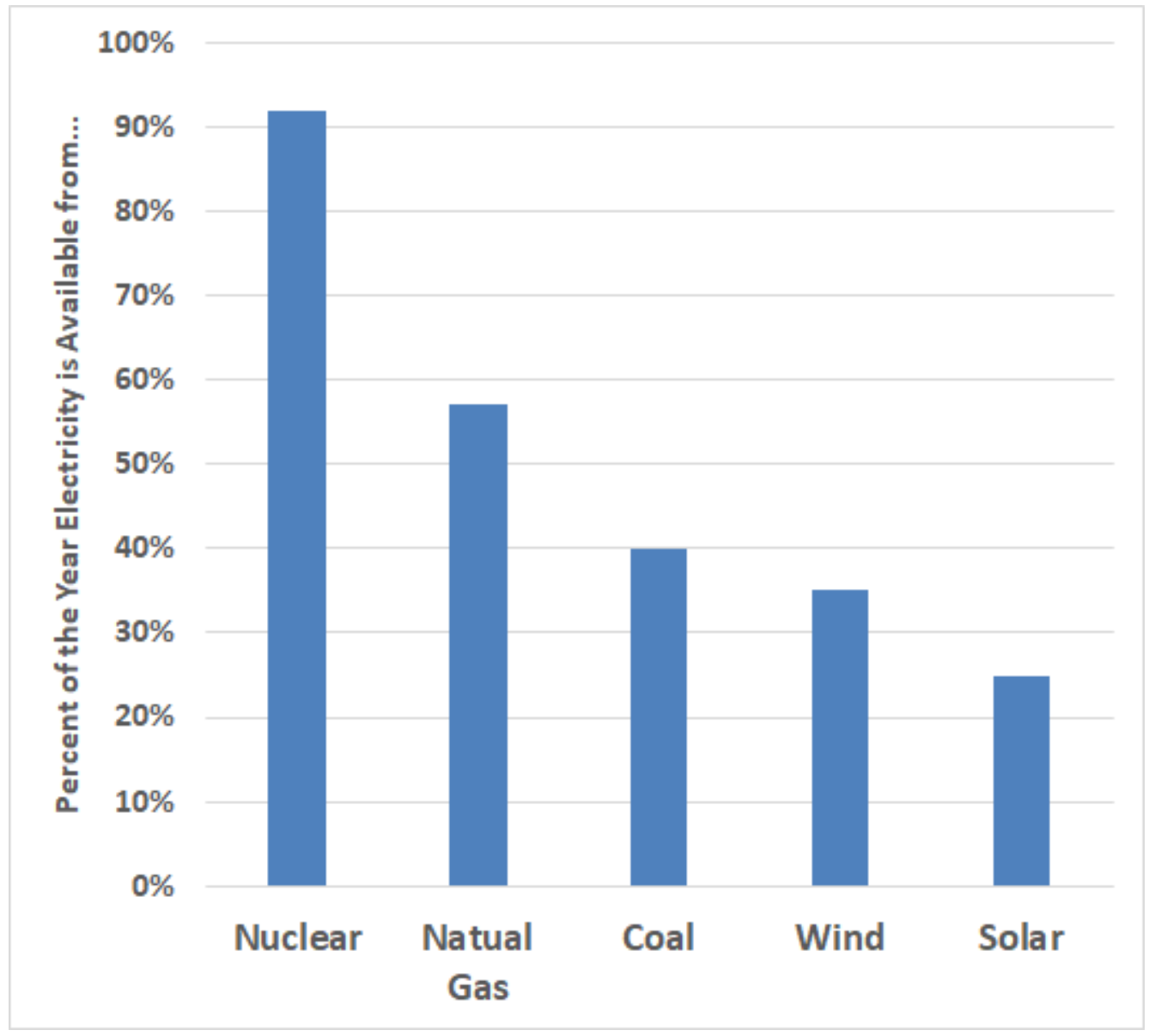

Figure 20. Production of electricity from different energy technologies in the United States in 2020 (DOE 2021a). 


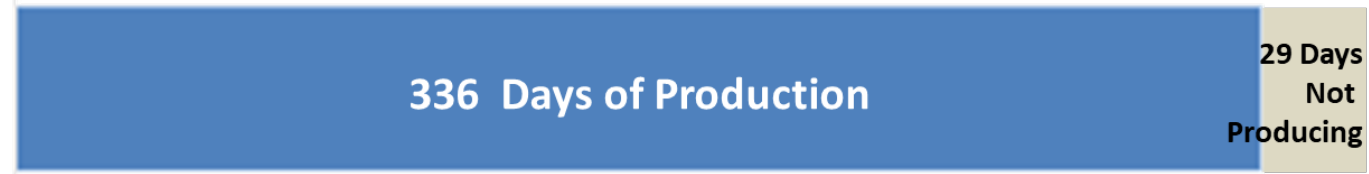

Natual Gas

208 Days of Production

157 Days

Not Producing

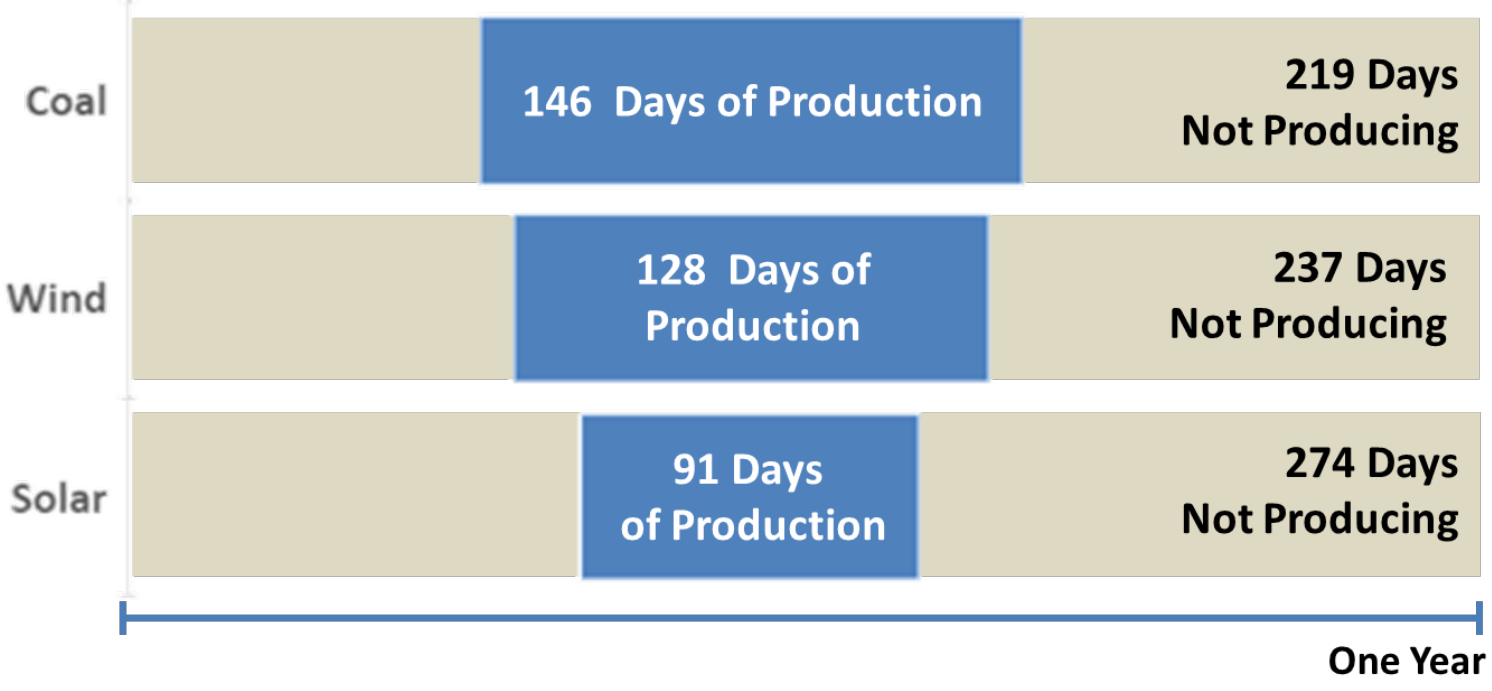

Figure 21. Production, measured in days per year that a specific energy technology is used (or not) to produce electricity, on average, for different technologies in the United States in 2020.

\section{Key Points}

- High reliability of energy sources is critical for society to function efficiently.

- Nuclear power has, by far, the highest demonstrated production level of any type of technology.

- To ensure continuous system efficacy, energy production technologies with low reliability require either backup facilities or large amounts of energy storage.

\subsubsection{Continuity of production}

NPP reliability and availability as affected by internal equipment and management issues have improved steadily and significantly over plant lifetimes to date. Internally initiated plant shutdowns are much less common than they were decades ago (see, for example, Figure 22 which illustrates the decrease in plant transients for pressurized-water reactors). The U.S. nuclear industry has learned a great deal about how to run largely without interruption except for refueling outages. 


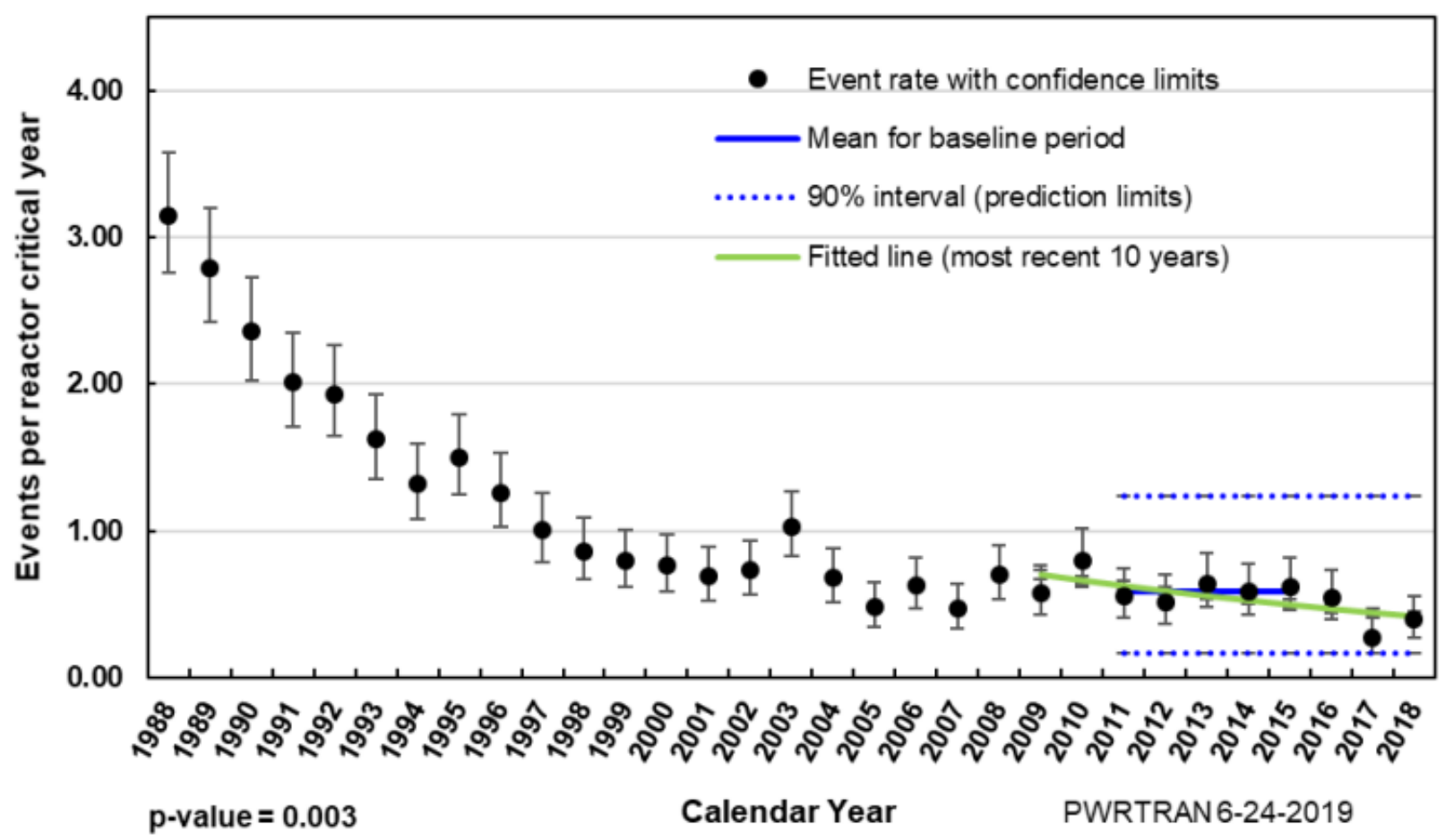

Figure 22. Trend of the general transient frequency for pressurized-water reactors in the United States (Johnson and Ma 2019).

Continuity is also affected by challenges to operation that originate from outside the plant. An important question is to what degree can we count on different types of power generating technology to operate in adverse external conditions now and in the future?

Currently, most U.S. NPPs are not separable from the grid; the plants and the grid are interdependent. In most of the currently operating U.S. fleet, some electrical loads in the plant require external power (from the grid) to maintain generation, and to continue operating at full power, the plant needs to be connected to a load that can take the power that the plant is generating (again, the grid). If some external challenge affects either the offsite supply to certain plant loads or the delivery of power to the grid's customers from the station generator, then the plant may need to shut down for reasons that are not, so to speak, the plant's "fault." Plants are of course designed to tolerate loss of this offsite power, so this is not automatically a safety issue, but if a hurricane is approaching, a plant may shut down partly in anticipation of potential problems with the grid. This shutdown approach may also be adopted by other power generation technologies.

The current situation is changing in key respects: the relationship between the grid and its various plants is evolving. An approach called "flexible plant operations" allows for plants to switch over from supplying the grid to supplying other applications of their energy output, including hydrogen generation or thermal storage (NREL 2020). Plants will have more options regarding what to do with their output and potentially more options regarding how they furnish power to the grid; for example, they could deliver electricity derived from thermal storage to the grid. Sophisticated engineering of the capability for flexible operations could lead to a very significant change in the continuity of integrated plant/hydrogen/storage system operations. These changes do not solve all possible grid-related problems but can improve the integrated plants' ability to serve the grid's customers.

For safety reasons, the structures, systems, and components associated with a NPP are extremely robust. But ultimately, plant systems need to interface with the plant's environs, including but not limited 
to the grid. Structures, systems, and components that are not immediately critical to safety may not have been required to be as robust as the safety systems and may be more vulnerable to things like extreme weather events. In February 2021, one of the two nuclear units in South Texas shut down because of problems related to extreme cold affecting a non-safety plant system (McAuliffe 2021). This was one of multiple things that went wrong in Texas because of extreme temperatures, which had not been planned for in the design of the infrastructure. Alternatively, during an extreme weather event in 2019, several NPPs in Illinois continued to operate, although one New Jersey NPP shut down because of frazil ice affecting water intake pumps (World Nuclear News 2019). During this extreme temperature event, other power sources were impacted as coal piles froze, and natural gas supplies were re-routed for home heating.

In summary, continuity issues for energy production technologies centers around three items:

- Failures and disruptions internal to the facility that cause production to cease or be reduced.

- Events external to the facility (e.g., extreme weather) that cause production to cease or be reduced.

- Disruptions in the fuel supply required by the energy production approach. For example, the current U.S. water drought is projected to impact hydropower by reducing electricity production by $14 \%$ in 2021 (EIA 2021a). In 2018, the United Kingdom wind electricity production in the summer dropped $19 \%$ due to a "wind drought" even though installed capacity increased more than $10 \%$ (Vaughan 2018).

\section{Key Points}

- When considering the continuity of the electricity supply, it is important to think of the grid together with the plants.

- Examples can be identified in which NPPs were adversely affected by temperature extremes or other conditions, but for much of the time, NPP continue to operate through unusual conditions.

- Continuity of power generation can be interrupted by severe weather; continuity of operation is a function of decisions made in the design of the plant's interfaces with its environs.

- As "flexible plant operations" continue to be developed, the relationship between plants and the grid will change to promote enhanced continuity of operations.

\subsubsection{Longevity of facilities}

As of September 1, 2021, there are 93 NPPs in 28 U.S. states, and there are two new nuclear reactors actively under construction: Vogtle Units 3 and 4 in Georgia (EIA 2021d). Figure 23 shows: (1) the oldest operating NPP started operation in 1969, while the newest plant received its operating license in 2016; (2) the first group of NPPs were brought online between 1969 and 1979, and the second group between 1980 and 1996; and (3) many operating NPPs have been issued, are applying for, or plan to apply for a 20-year license extension. This license extension will result in a licensed operating period of up to 60 years. Note, however, that receiving a license extension does not necessarily mean that the plant will continue to operate. Business decisions on extended operation ultimately rely on economic factors; however, economics can often be improved through technical advancements. 


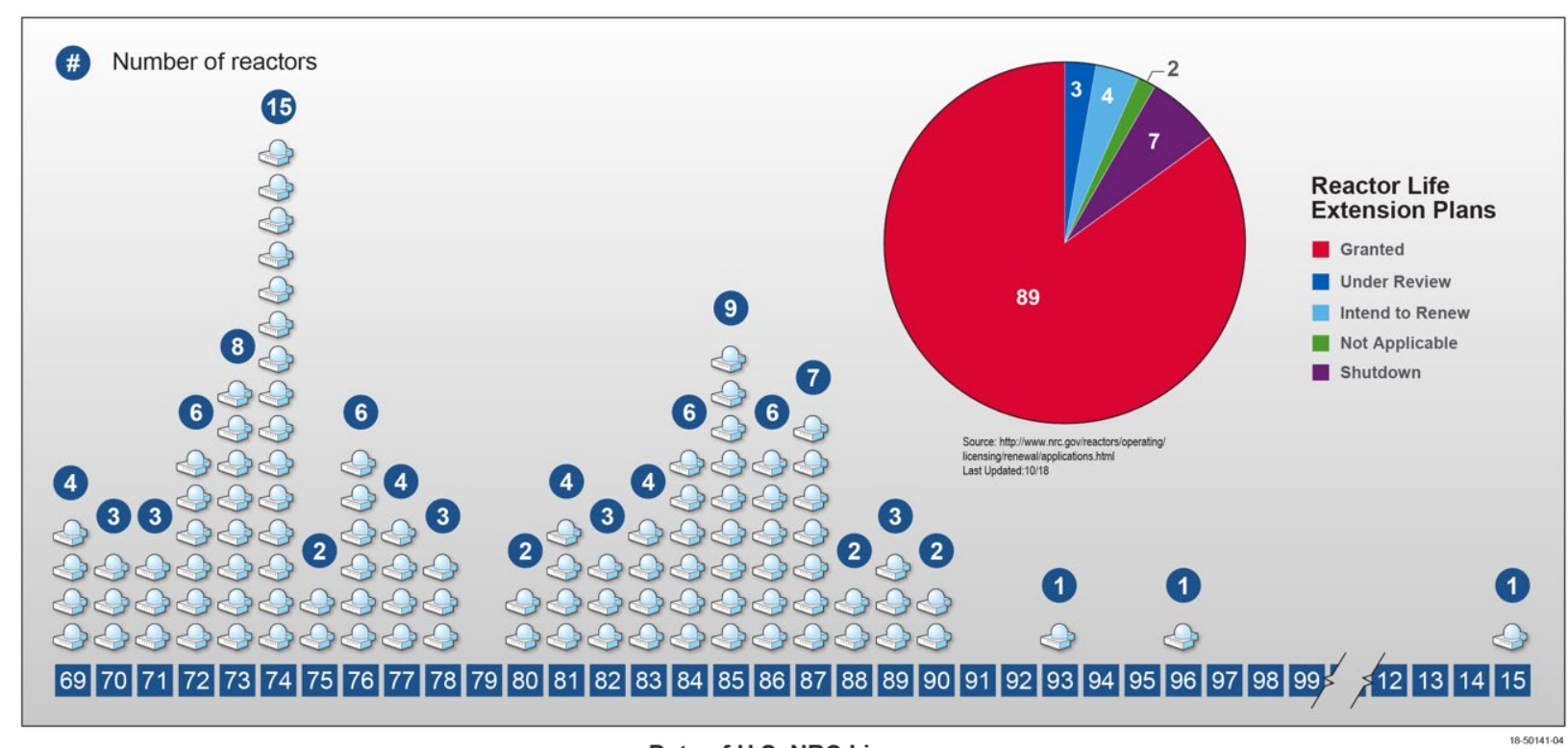

NRC Intormation Digest (NUREG-1350, Volume 27), Appendix A: U.S. Commercial Nuclear
Power Reactors - Operating Reactors - UPDATED 9/25/18

Date of U.S. NRC License

Figure 23. NPP initial license date and license extension plans as of September 2018 (NRC 2018).

Near the year 2030, unless second license renewals are granted, decommissioning of the current fleet of NPPs will begin. Over the three decades beyond 2030, decommissioning of the existing fleet would result in a loss of nearly 100-GWe of emission-free electrical generating capacity, leaving a shortfall of emission-free generating capacity. Early (prior to 60 years of operation) shutdowns due to economic factors will increase this shortfall.

To receive a 20-year license extension, an NPP operator must ensure the plant will operate safely for the duration of the license extension. The 40-year initial operating license period established in the Atomic Energy Act of 1954 was based on antitrust and capital depreciation considerations, not technical limitations. The 20-year license extension periods are presently authorized under the governing regulation of 10 CFR Part 54, "Requirements for Renewal of Operating Licenses for Nuclear Power Plants" (NRC 2020). This rule places no limit on the number of times a plant can be granted a 20 -year license renewal if the licensing basis is maintained during the renewal term in the same manner and to the same extent as during the original licensing term (e.g., the licensee can demonstrate continued safe and secure operation during the extended period). As of 2021, the NRC has approved or is reviewing subsequent license renewal applications from 13 nuclear units to extend their operating licenses from 60 to 80 years of operation. Note that currently, the average age of the U.S. nuclear fleet is almost 40 years old (DOE 2021c), implying the fleet still has many years of potentially useful life remaining. Utilities have announced their intention to submit subsequent license renewal applications for 12 more operating units to $\mathrm{NRC}$ for review.

In addition to the length of how long an energy producing facility will last, longevity should also consider power increases or degradations in the facility. For example, in the United States, power uprates (increasing the power output of the facility, often with minor changes to the facility) have occurred in the nuclear power industry starting in 1977 with the Calvert Cliff plants (each boosting their power output by 5.5\%) (NEI 2021a). Conversely, some types of energy production experience a reduction over time in the energy output due to physical degradation. Examples include the following:

- In the United States, 97 NPPs have seen power increases in the last 30 years (1991 to 2021) (NEI 2021a). The average increase in power output during this time for these facilities was about $8.1 \%$. 
- For solar PV technology, it is estimated that the power output from a panel decreases approximately $0.5 \%$ per year (Mow 2018).

- Since wind turbines are rotating machinery, it would be expected that they would produce less power over time. Studies have shown a degradation rate between $0.2 \%-1.23 \% /$ year (Hamilton et al. 2020) and as high as 1.6\%/year (Staffell and Green 2014). Assuming an average of 0.9\%/year, we would see a total decrease in power output of $27 \%$ over 30 years; this is reflected in Figure 24. (Grubert 2020 ) found that the degradation rate for natural gas and coal facilities over time is essentially zero (this study looked at a 19-year time period, from 2001 to 2018, and is shown in Figure 24).

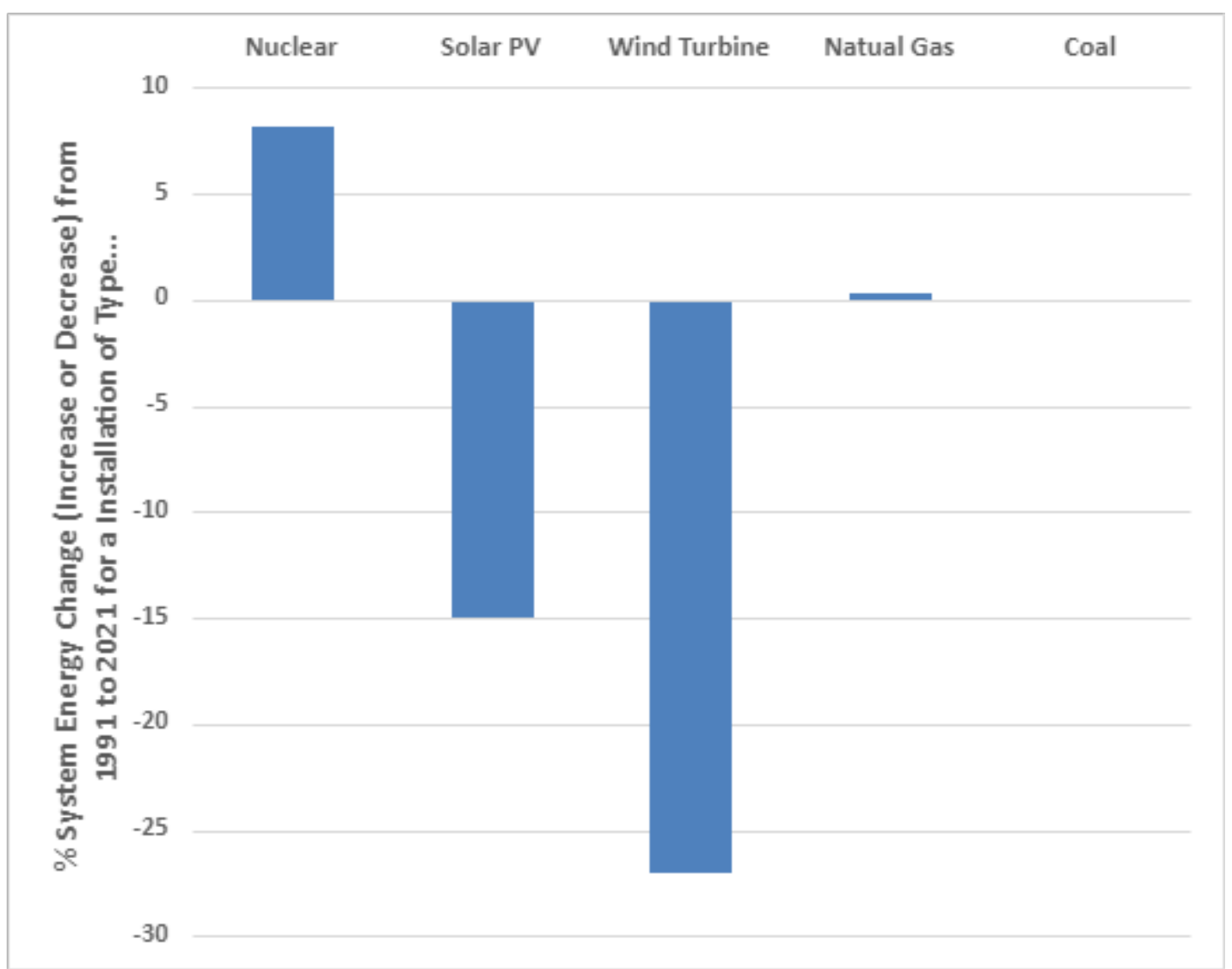

Figure 24. Change in energy production from increases or decreases in performance over a typical 30year period for different energy production technologies.

\section{Key Points}

- NPPs have extremely long lives, exceeding those of many other energy sources.

- The current U.S. nuclear fleet has operated an average of 40 years.

- The current longest authorized U.S. NPPs operating license is 80 years.

- The remaining average lifetime of the U.S. nuclear fleet is very long, probably longer than 40 years.

- Long-lived facilities may see increases or decreases in energy production capability over time. For U.S. nuclear facilities, recent experience has seen an increase in production of over $8 \%$. 


\subsubsection{Operating Costs}

Every form of energy production has a goal of minimizing production costs to enhance economic competitiveness. Nuclear is no exception, and it is why the U.S. nuclear industry has been actively working to reduce capital, fuel, and operating costs. Recent operating cost trends exhibited almost a 5\% reduction in cost in 2020 alone and a total cost reduction at NPPs of 35\% since 2012 (NEI 2021b). These operating cost reduction achievements (of approximately $\$ 1 / \mathrm{MWh}$ per year) are reflected in Figure 25 . If this trend continues for the next 5 years, the U.S. NPP generation costs will be approximately $\$ 25 / \mathrm{MWh}$.

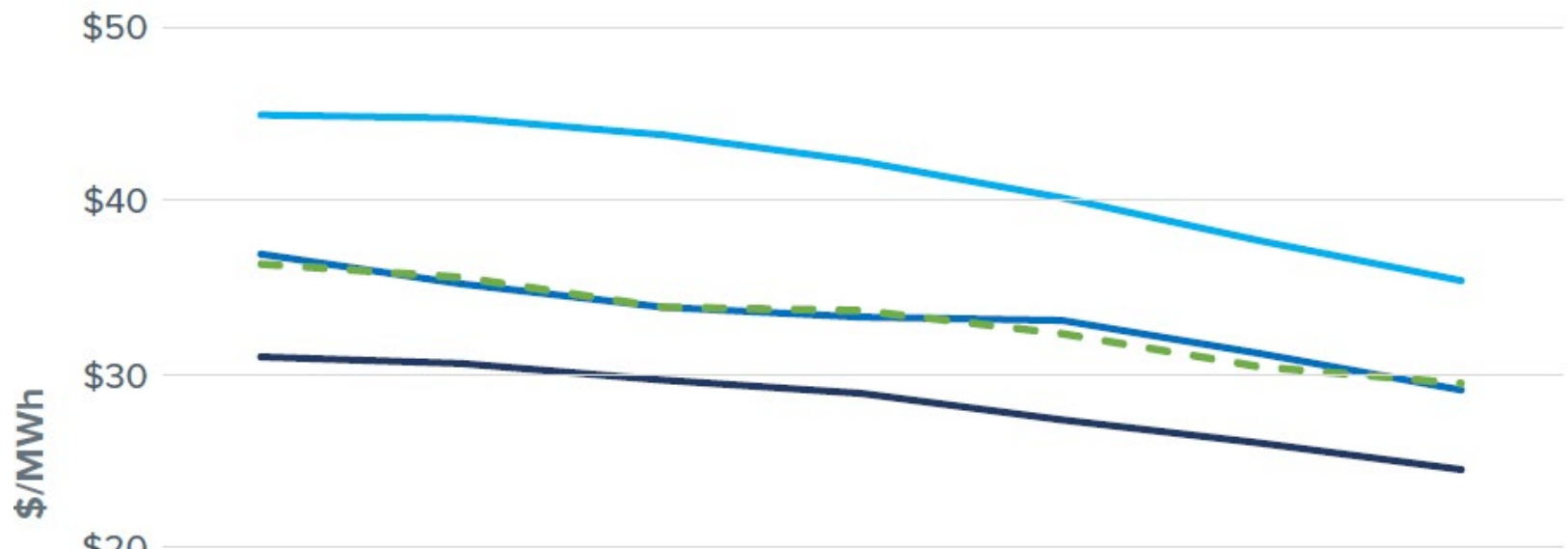

$\$ 20$

$\$ 10$

$\$-$

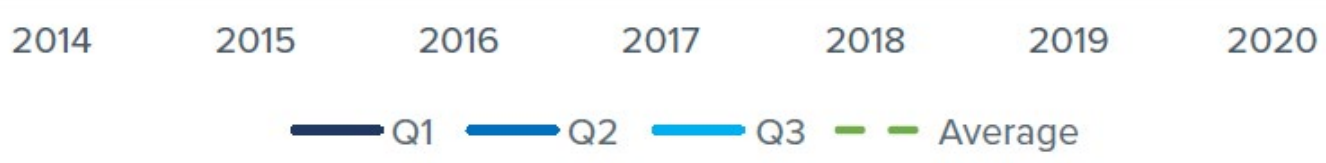

Figure 25. U.S. NPP generating cost reductions (in 2020 dollars) since 2014 (NEI 2021b). Note: Q1 represents $25 \%$ of the plants with lowest costs, Q2 represents the next 25\%, and Q3 represents the next quartile of plants.

The United States government, through the Energy Information Administration, also collects cost data for different energy producing technologies. In 2020, the average production (operations, maintenance, and fuel $)^{1}$ costs ranged from $\$ 0.013 / \mathrm{kWh}$ to $\$ 0.035$ for these technologies as seen in . Nuclear power has the second lowest production costs of the energy production technologies groups shown in Figure 26 with hydroelectric facilities having the lowest production cost in the United States. Note that the "gas turbine, internal combustion, photovoltaic, and wind plant" group includes average expenses from all those types of facilities weighted by net generation.

\footnotetext{
${ }^{1}$ Other costs not considered in these estimates include transmission, distribution, administrative, depreciation, and taxes.
} 


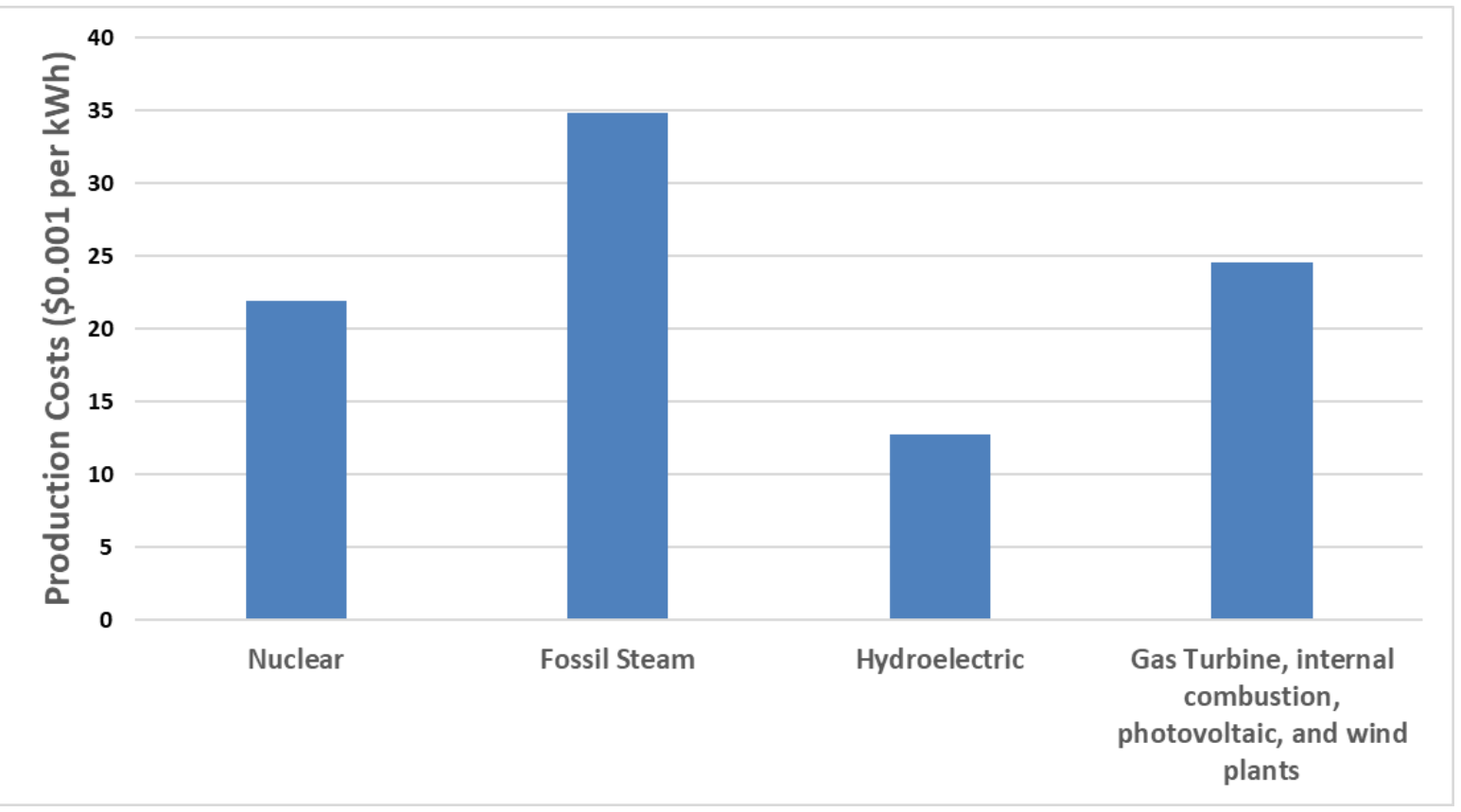

Figure 26. Production costs (including operations, maintenance, and fuel) for different energy technologies (EIA 2021b, Table 8.4).

\section{Key Points}

- NPPs have one of the lowest production costs of any energy source in the United States.

- The operating cost trend in the United States over the last decade has seen steadily decreasing costs.

\subsubsection{Revenue}

Revenue, or the income produced as an outcome of an activity, can be collected in two ways for energy production technology. First, by producing electricity, this product can be sold, thereby creating a revenue stream. This is what is commonly thought of when discussing energy revenue. However, some forms of energy production can also produce revenue by producing other non-electricity products. For example, a NPP could use its excess heat to produce a variety of products, including (Barnert, Krett, and Kupitz 1991):

- Hydrogen

- Refinement of coal and lignite

- Reforming of natural gas to produce synthetic gas and methanol

- Plastic production

- Oil shale processing

- Steel production

- Process steam

- District heating 
- Sea water desalination.

The U.S. nuclear industry is currently moving forward with projects to produce hydrogen at NPPs. It has been estimated that a 1,000 megawatt nuclear reactor could produce more than 150,000 tonnes of hydrogen each year (DOE 2020). Production of nuclear-sourced hydrogen would remove the need for producing hydrogen via natural gas.

A typical NPP receives around \$26-27/MWh (in 2020 dollars) for revenue within the PJM ${ }^{2}$ electric market (Potomac Economics 2021). The total market size for nuclear power in the United States is estimated to be $\$ 34$ billion (IBIS World 2021).

\section{Key Points}

- Diversification of revenue beyond electricity production is possible with nuclear power technology.

- The types of products that can be produced using excess heat from NPPs are very diverse, ranging from desalinated water to steel and hydrogen production.

\subsubsection{Advancing technology}

While the goal of energy production technologies is to produce energy, some technology sectors also have a side benefit of facilitating ancillary technologies. Nuclear power generation has seen innovations in many applications and methods unrelated to energy production, for example:

- Risk, reliability, and safety analysis. Science-based approaches to risk and reliability analysis were developed in the 1970s and have been matured since. These methods, and associated tools and data approaches are widely used outside of the nuclear community to better understand complex systems.

- Computational methods for thermal hydraulics of high-pressure and high-temperature systems. Following the extensive testing of nuclear systems in the 1950-1970s, foundational computer science approaches were developed to be able to mimic the conditions found in pressurized- and boilingwater reactor cooling systems. These algorithms are the precursors to today's digital capabilities for nuclear systems.

- Stochastic simulation approaches. Nuclear reactor calculations can use random number-based calculations to mimic the atomic behavior in the core. These stochastic-based simulation approaches are now widely used to predict system behavior for retail distribution logistics, roadway design, social sciences, and more.

- Human factors and human reliability. Formal methods were developed out of the nuclear power industry that focused on how humans behave when interacting with technology. Understanding human behavior and creating approaches to minimize human error in complex systems are now a pervasive approach to improving how society uses technology such as computers, airplanes, manufacturing facilities, and cars.

- Medical applications of nuclear byproducts. Nuclear technology has motivated the production of medical isotopes that facilitate diagnostic and treatment for a variety of medical conditions. Over 10,000 hospitals around the world use these nuclear byproducts for tens of millions of procedures every year (World Nuclear Association 2021d).

- Radioisotopes for heat and power. Many different types of radioactive material, or radioisotopes, are used for many different purposes ranging from environmental tracers to powering scientific rovers on Mars. The most common purpose of these radioactive materials is possibly the smoke detectors

\footnotetext{
${ }^{2}$ PJM was originally an abbreviation of Pennsylvania, New Jersey, and Maryland, but today, this energy market also includes all or parts of, Delaware, Ohio, Virginia, Kentucky, North Carolina, West Virginia, Indiana, Michigan, and Illinois.
} 
that are in many households around the world. In the scientific community, many applications exist including carbon dating, imaging, and instrumentation.

- Food irradiation. Unlike the title might imply, food irradiation does not make food radioactive. Instead, irradiation makes food safer and have a longer storage life. Today, irradiation of food is used globally, and in Europe, irradiation has been used for decades (USDA 2016).

No other energy production technology has produced as many ancillary technology benefits as nuclear power.

\section{Key Points}

- Nuclear power technology has produced more ancillary technology benefits than any other form of energy production.

- The additional technology benefits from nuclear power include: risk, safety, and reliability approaches; advanced computational methods and algorithms; simulation methods; human factors and human reliability; medical applications; multiple radioisotopes uses; and food irradiation.

\subsection{Society}

Energy production affects society in many ways which are mostly positive by increasing the quality of life through the availability of electricity. However, there are possible negative impacts from energy production, hence the need to understand characteristics such as safety goals and decarbonization.

\subsubsection{Safety goals}

One of five net-zero pillars focuses on safety-safety impacts to the public or the environment. Encompassed in this characteristic is actual and possible energy technology impacts to the public, flora, and fauna over the lifecycle of that technology.

Focusing first on human safety, we can represent this in different ways. One predominant metric simply measures the mortality (the number of deaths directly attributable) for a particular energy production activity, normalized by the amount of power produced. An example of this metric is shown in Figure 27 for different technologies. Some energy production technologies have a large mortality rate, predominantly those that have high emissions impacting public health or require a large mining aspect integral to the energy production (mining of materials to support energy production is a hazardous profession). Other energy sources (solar, wind, hydro, and nuclear) have a relatively low mortality rate. 


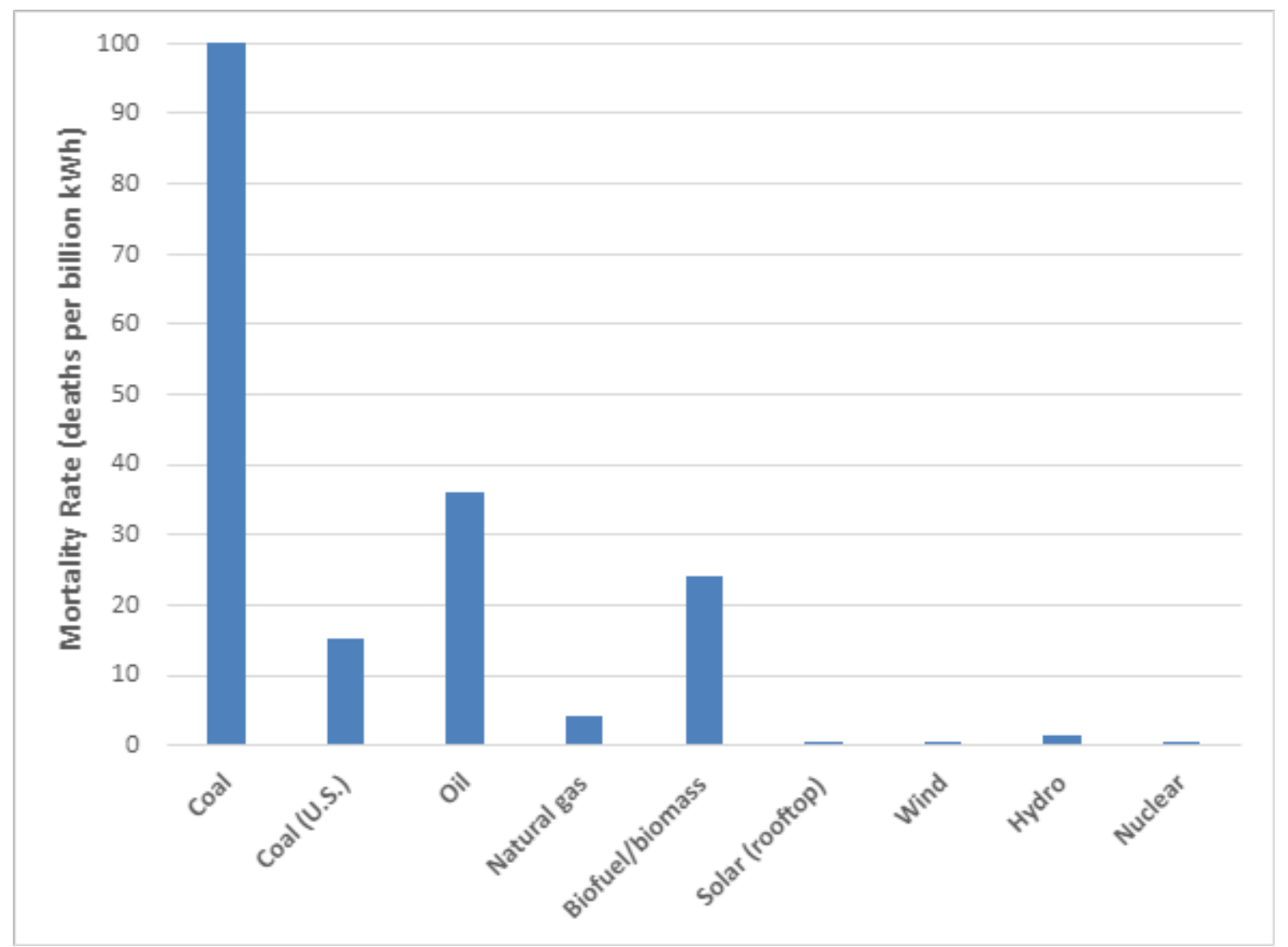

Figure 27. Human mortality rates (global averages) for different energy producing technologies (Brook et al. 2014).

A second way to consider energy production technology risks to the public is to review actuarial statistics related to the number of deaths in a population. A world-wide source for this type of information can be found from the Institute for Health Metrics and Evaluation via its Global Burden of Disease study (see Figure 28) (Ritchie and Roser 2019). One of the major risk factors that has a coupling to energy production is for the category of air pollution (the fourth highest factor in 2017). Any energy production technology that produces air pollution will increase the potential for fatalities on a global scale. Low air pollution energy sources such as solar, wind, hydro, and nuclear will have a relatively low death risk factor since they do not contribute to the factors shown in Figure 28. 


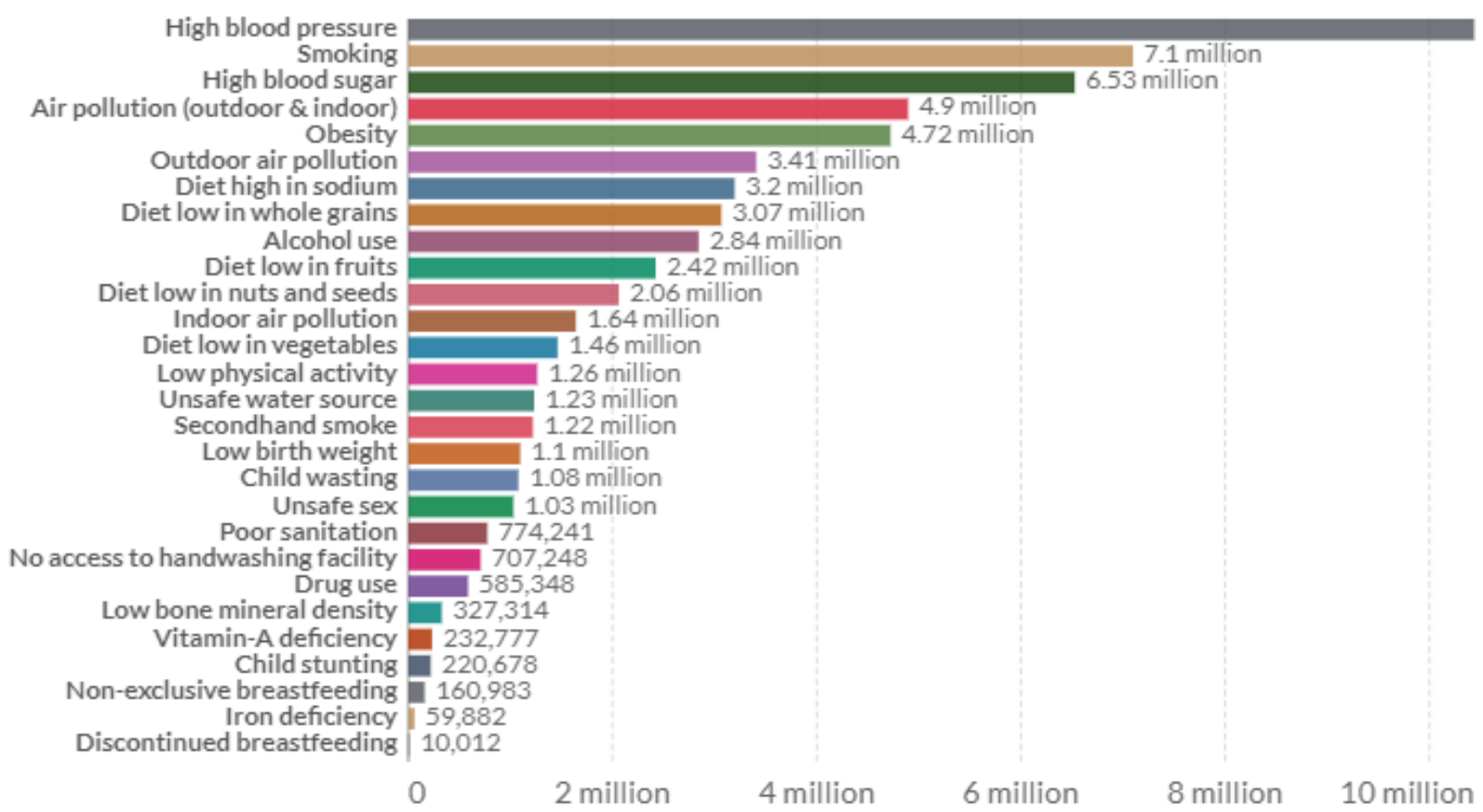

Figure 28. Number of deaths by risk factor in the world for 2017 (Ritchie and Roser 2019).

Lastly, another way to consider energy production technology risks to the public and environment is to make predictive assessments of what events that might occur in the future and could impact the public or workers. For example, we could consider a variety of possible energy production risks including:

- In the United States, the worker death rate for refuse and recycling collectors was over 35 deaths for every 100,000 workers in 2019 (BLS 2020), making it the occupation with the sixth highest death rate. For an energy production technology that sees a large volume of waste or recycling on an annual basis, we could postulate future human fatalities since material from the energy production process will need to be buried or recycled. The impact to the environment may also be measurable depending on the volume and type of material that must be disposed of during disposal.

- In the United States, the worker death rate for roofers was 54 deaths for every 100,000 workers in 2019 (BLS 2020), making it the occupation with the fourth highest death rate. For an energy production technology that requires many roofing hours on an annual basis, we could postulate future human fatalities since the energy production technology will need to be installed on roofs.

- In the United States, one event has occurred at a commercial NPP that resulted in damage to the reactor core and subsequent decommissioning. This event at the Three Mile Island reactor did not result in any fatalities to the public, and the impact to the environment was minimal since the radiation release was substantially less than normal radiation found in nature (NRC 2018). The primary reason that human and environmental risks were low is that multiple layers of defense are present in U.S. NPPs. Further, it is anticipated that advanced nuclear reactors will provide enhanced levels of safety, thereby lowering the overall potential impact to the public as these technologies are deployed and replace other forms of energy production.

- In the United States, radioactive wastes from NPPs are strongly controlled and proactively managed. For example, used nuclear fuel is contained in its original packaging format, which is a robust engineered package, then this package is placed in a steel cylinder that is sealed. This sealed container is then again stored in another surrounding cask, providing multiple barriers (NRC 2021a). Since the total volume of the used fuel produced by NPPs in the United States is small (see Figure 29), the 
potential environmental impact is projected to be small compared to other energy forms that contribute much larger volumes of waste to the environment.

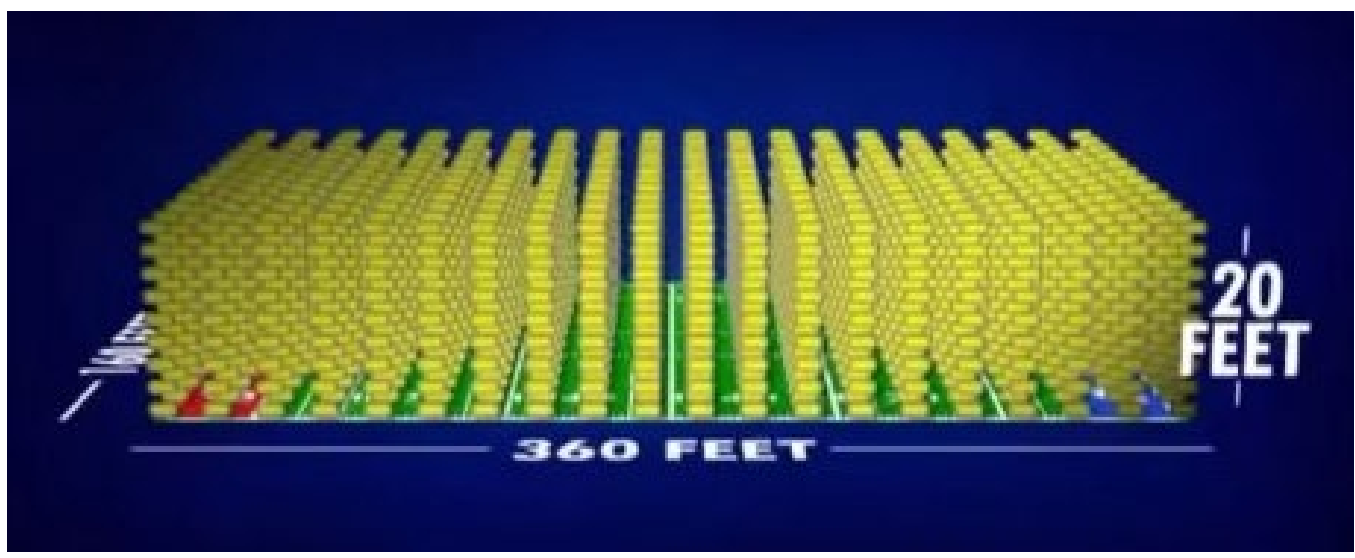

Figure 29. Volume of all the NPP nuclear high-level waste produced in the United States since the 1950s (NEI 2019).

\section{Key Points}

- U.S. NPPs have demonstrated minimal safety impacts to the public or the environment.

- Energy production technologies that require use of workers in high-hazard occupations such as roofers and waste/recycling may unduly impact worker safety.

- Potential future safety impacts from nuclear energy production are small due to inherent safety characteristics and low volume of used fuel produced that must be stored. Advanced reactor technology is likely to result in an increase in safety over current reactor technology.

\subsubsection{Low-carbon emissions}

Nuclear power, like some other sources of production, produces no direct $\mathrm{CO}_{2}$ emissions during electricity generation (Ramseur 2019). However, the direct production (or not) of GHG such as $\mathrm{CO}_{2}$ represents only part of the consideration for low-carbon and net-zero goals. Additional considerations should incorporate GHG emissions during construction, long-term operation, and disposition. One detailed study that considered this "lifecycle approach" to GHG emissions for different energy production systems was by Pehl et al. (2017). This study evaluated the GHG emissions footprint for nine electricity production technologies:

- Coal

- Gas

- Coal with carbon capture and sequestration (CCS)

- Bioenergy

- Bioenergy with CCS

- Hydropower

- Nuclear

- Wind

- Concentrating solar power (CSP)

- Photovoltaics (PV). 
As noted by (Evans 2017), the impact from nuclear technology is:

The study finds each kilowatt hour of electricity generated over the lifetime of a nuclear plant has an emissions footprint of 4 grammes of $\mathrm{CO}_{2}$ equivalent $(\mathrm{gCO} 2 \mathrm{e} / \mathrm{kWh})$. The footprint of solar comes in at $6 \mathrm{gCO} \mathrm{O}_{2} \mathrm{e} / \mathrm{kWh}$ and wind is also $4 \mathrm{gCO} \mathrm{O}_{2} \mathrm{e} / \mathrm{kWh}$. In contrast, coal CCS (109g), gas CCS (78g), hydro (97g) and bioenergy (98g) have relatively high emissions, compared to a global average target for a $2 \mathrm{C}$ world of $15 \mathrm{gCO}$ e/kWh in 2050.

A complicated, yet informative, figure from the study illustrates the above finding (see Figure 30 ). Focusing in on the magnified portion of the figure (and removing the comparison bars from the Synthesis Report of the IPCC Fifth Assessment Report [labeled "AR5"]), we see the relative GHG contributions for four lowest GHG emitters (Figure 31). It is interesting to note that the small GHG footprint from nuclear is driven primarily from operations over the lifetime of the facility, while the other three (wind, CSP, and PV) are larger contributors mostly due to construction.

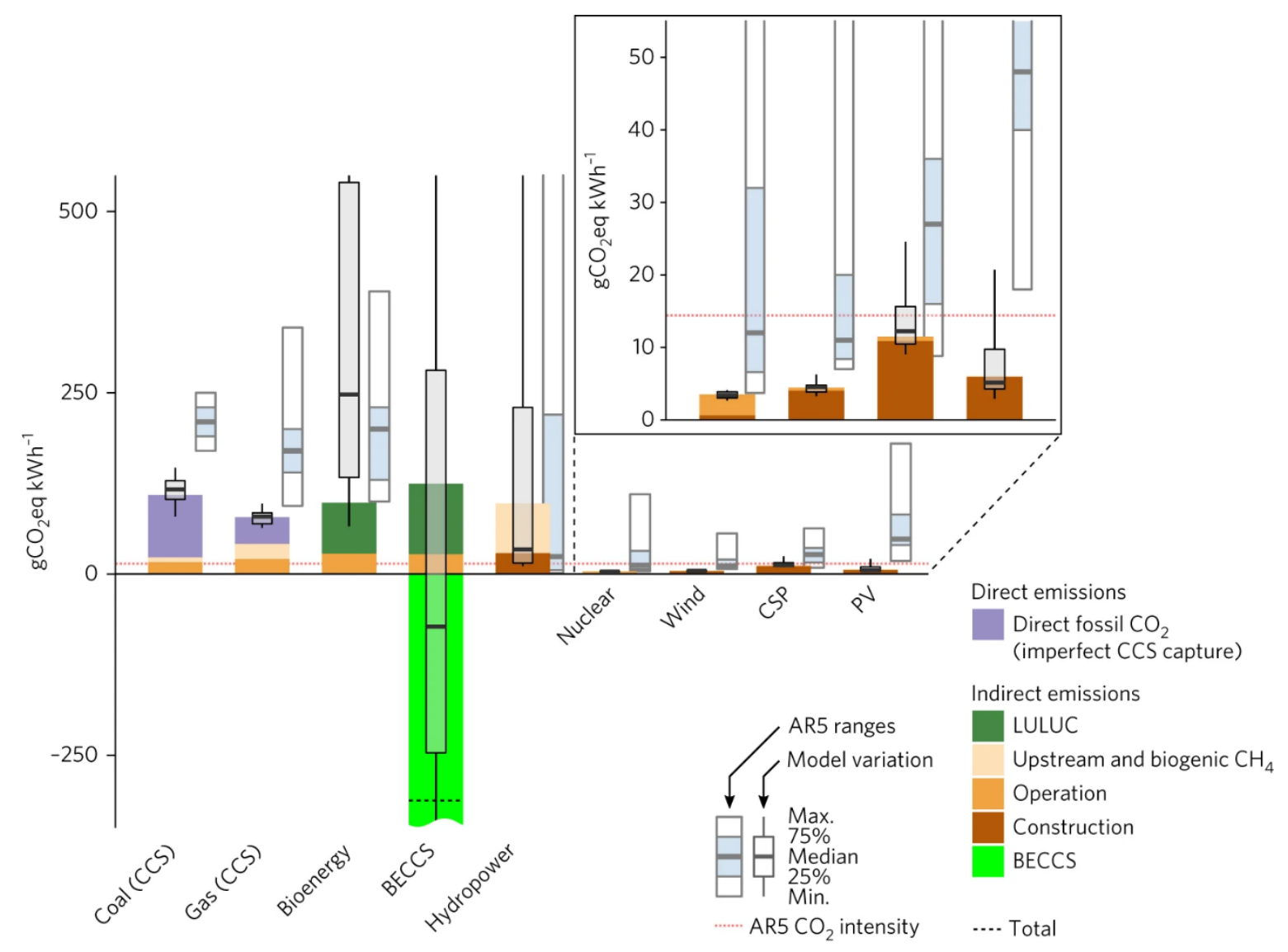

Figure 30. Specific direct and indirect GHG emissions for different energy production technologies (Pehl et al. 2017). 


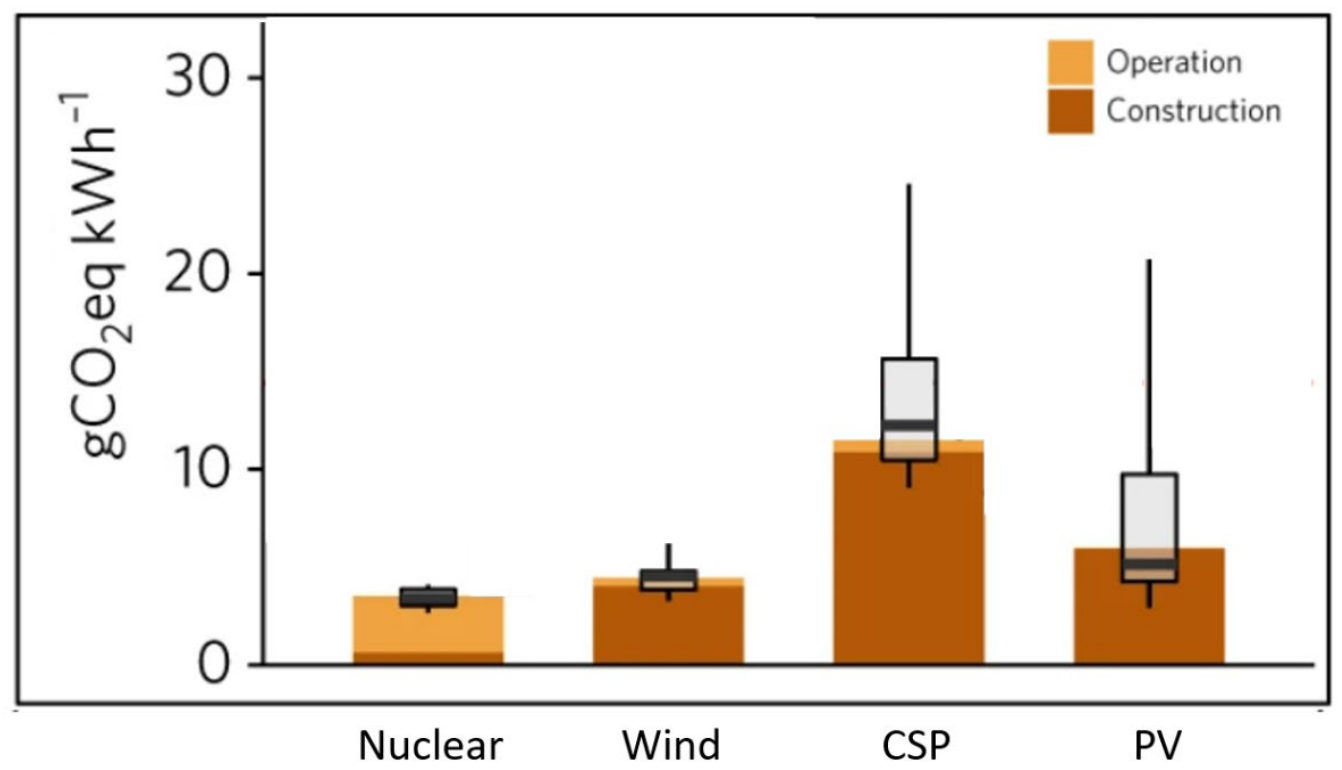

Figure 31. Magnified portion of the specific direct and indirect GHG emissions for different energy production technologies (Pehl et al. 2017).

\section{Key Points}

- NPPs do not release any GHGs when producing electricity.

- NPPs offer the lowest GHG footprint of any current energy production technology when considering the lifetime emissions.

\subsubsection{Decarbonization}

Decarbonization is the process of removing GHGs, especially $\mathrm{CO}_{2}$, from societal emissions by using low-carbon energy technologies or removing the need for $\mathrm{CO}_{2}$ producing activity. Decarbonization extends beyond energy production and includes removing GHG emissions from many aspects of society, including:

- Material manufacturing

- Construction

- Transportation

- Energy production

- Food production.

Radically transforming these sectors to remove GHG production at a large scale is called deep decarbonization. This type of decarbonization is needed if society is to meet its climate goals. Further, nuclear power is needed to realize decarbonization. As noted by NEI (2021):

No other source, renewable or otherwise, contributes as much to meeting U.S. energy demand without emissions as nuclear. Every year, nuclear-generated electricity saves our atmosphere from more than 470 million metric tons of carbon dioxide emissions that would otherwise come from fossil fuels. That's the same as taking nearly 100 million passenger vehicles off the road.

The overall goal for decarbonization is to achieve a net-zero impact for GHG emissions. 


\section{Key Points}

- The overall goal for decarbonization is to achieve a net-zero impact for GHG emissions.

- U.S. NPPs already provide decarbonized electricity production.

- To meet societal climate goals, other industrial sectors (manufacturing, transportation, and food production) in addition to energy production must be decarbonized. Nuclear energy technology can greatly assist these other sectors in decarbonization.

\subsubsection{Localization of resources}

To meet net-zero goals, an energy system should rely on local resources to the extent possible to avoid hidden costs or having to move materials great distances, thereby increasing GHG emissions. However, the GHG emission footprint for the entire lifecycle should be considered, and resources should be sourced (or outsourced) as appropriate; it may be that some materials have a lower GHG impact if not produced locally. The production of energy should also promote inclusion and equity. Displacing or disadvantaging people through mining and manufacturing to produce net-zero energy systems that function away from the impacted group is not truly a net-zero energy system.

The United States produces the most nuclear power in the world, providing about $30 \%$ of the worldwide total (World Nuclear Association 2021e). For these NPPs, most of the materials, design work, and workforce are sourced domestically. While most of the nuclear fuel is currently imported from outside the United States, this is an economic decision, not a resource issue. Uranium is a relatively common element (about a common as tin or zinc) that is found in the Earth and in seawater (World Nuclear Associate 2021). A recent U.S. uranium reserve estimate was over 138 million kg (OECD 2016).

As systems are constructed and operated within a local region, these activities also have positive benefits. For example, construction provides communities with jobs and NPP utilities pay taxes in support of those communities. In the United States, NPPs provide for almost 500,000 jobs and provide $\$ 12$ billion a year in tax revenue (NEI 2019).

\section{Key Points}

- An energy system should rely on local resources to the extent possible to meet net-zero goals.

- For U.S. NPPs, most of the resources required to build and operate the facility are found within the United States.

\subsubsection{Environmental impacts}

Disposition of the energy producing assets is the last step in the lifecycle when considering impacts. A goal for any energy technology is that its impacts be successfully "reversed" such that the site used for the energy production returns to a natural state as soon as possible. This approach is called a greenfield and is the end goal for industrial land use. Generally, the one complication that prevents a site from returning to a natural state is toxic contamination. While each energy production technology brings unique remediation and decontamination challenges, most types of production sites can be restored to a natural state in a relatively short amount of time (e.g., time compared to the lifetime of the facility during operation). For example, in the United States, many locations have been successfully decommissioned including commercial power plants, research reactors, and uranium mining sites, with 10 NPPs decommissioned for unrestricted use (Camper 2021). The appearance of such a site after decommissioning is shown in Figure 32 for the Yankee Rowe NPP location. 


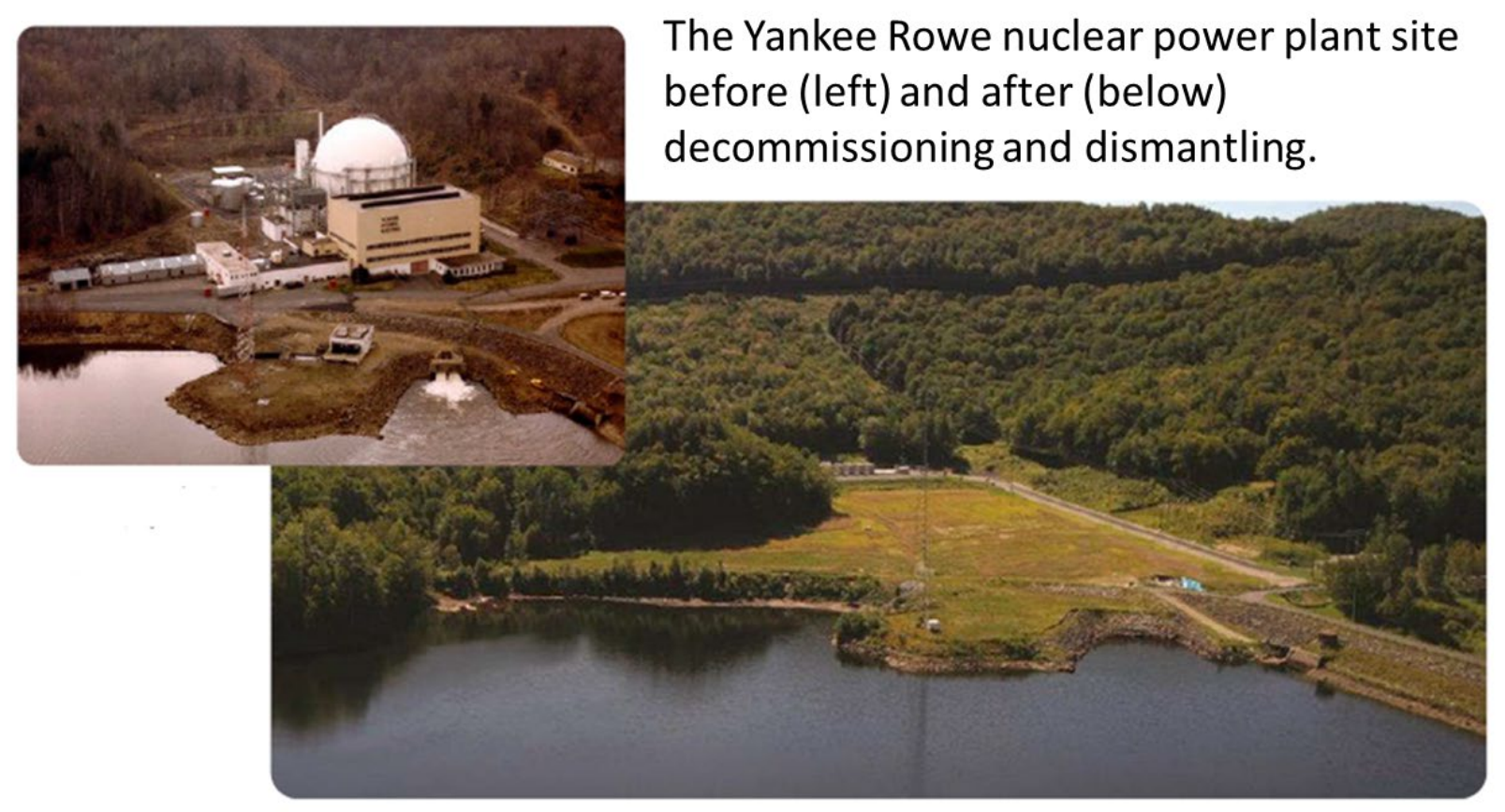

Figure 32. Example of the greenfield remaining after decommissioning a NPP in the United States (Camper 2021).

One potential environmental impact that is common among all energy production technologies is the localized impacts such as mining of fuel and material required to produce and operate a facility. As discussed in Section 2.1.4, minimizing material during energy production is required for net-zero goals. Nuclear power has the lowest resource intensity, per MWh generated, of any low-carbon energy production technology. Consequently, the operational aspect of nuclear is expected to have the lowest overall impact to the environment due to the low material needs. The chance of other environmental impacts during operation of NPPs is low as demonstrated by the lack of impacts from past events and the increasing levels of safety of these facilities over time. The waste generated by NPPs is mostly of lowradioactivity and has had little to no impact on the environment in the United States.

A second type of localized impact from energy production is local environmental changes such as heat, visual aesthetics, and noise. For example, nuclear power uses water to produce electricity (see Section 2.1.3); this water may be heated with respect to the local water resources. This excess heat is typically not used for productive purposes and is instead transferred to the local environment. Other forms of energy production have their own unique local impacts such as wind turbines affecting local bird populations and visual aesthetic challenges.

\section{Key Points}

- Nuclear power has a low environmental impact compared to other power generation options due to its low material needs and managed waste streams.

- NPP locations can be returned to a natural state following the completion of the energy production lifetime for the facility. 


\subsection{Disposition}

The management and disposition of all radioactive wastes are predicated on principles of safety for the protection of people and the environment. This begins with the generation of radioactive waste and includes the periods of storage, transportation, and ultimate disposal, though the means of implementing the protective measures will often differ depending on the period and the type of waste.

\subsubsection{Waste}

Radioactive waste is often broadly classified as low-level, intermediate-level, and high-level waste and spent nuclear fuel, reflecting physical quantity and form, the types of radioactivity contained in the waste, and its disposal pathway (IAEA 2009). Waste volumes and radioactivity are generally inversely proportional. Examples include:

- Low-level waste volumes from nuclear power generation are usually small and comprised of items consumed in operations (gloves, tools, swipes, etc.). Because of the radioactive contamination, this waste stream is typically packaged (often with volume reduction through compaction or incineration) and disposed of in a specially licensed shallow landfill site where the underlying assumption is the waste will decay to background levels before institutional controls are lost ( $\sim 300-500$ years).

- Intermediate-level waste inventories comprise a variety of forms (resins, sludges, and reactor components from reactor decommissioning) and may be divided into volumes amenable to shallow land burial (with sufficient treatment, conditioning, and/or encapsulation) and into volumes that require greater isolation in a geologic repository (often along with high-level waste and spent nuclear fuel).

- High-level waste is generated from chemical reprocessing of spent nuclear fuel to recover fissionable material $(\mathrm{Pu}, \mathrm{U})$ or other isotopes. Liquid high-level waste is solidified through vitrification (mixing into glass) before disposal. Both spent nuclear fuel and high-level waste are sometimes also referred to generically as high-level waste. The ultimate end point for high-level waste and spent nuclear fuel declared as waste (direct disposal) requires emplacement in a specially designed and licensed deep geologic disposal facility to ensure its isolation from the accessible environment for very long times (regulatory performance periods range from 10,000 to one million years).

All NPPs will produce some form and volume of low-level waste, intermediate-level waste, and spent nuclear fuel/high-level waste during operations and from decommissioning. The science and technology of near surface disposal of low and intermediate-level waste is well developed and has been put in use for decades in many places in the world; in the United States, an example of successful storage can be found at the Waste Control Specialists facility in Texas (WCS n.d.).

Deep geologic disposal has been the recommended option for permanent management of spent nuclear fuel and high-level waste for 65 years. The National Academy of Sciences reported that deep geologic disposal was the most promising method to explore for disposing of high-level waste in 1957 and reaffirmed that position in 1966 and 1970. More recently in 2001, the National Academy of Sciences concluded that after 40 years of study "geologic disposal remains the only scientifically and technically credible long-term solution available to meet safety needs without reliance on active management," and there is overwhelming international consensus on geologic disposal as the preferred option (NAS 2001).

The technical requirements for deep geologic disposal of spent nuclear fuel and/or high-level waste are well established, and several countries have made substantial progress towards implementation. While the development of deep geologic disposal for spent nuclear fuel/high-level waste is a sociopolitical challenge in many countries, some have made progress such that disposal operations are expected to commence in the near future (World Nuclear Association 2021b). Finland, which produces one-third of their electricity from nuclear power, recently started construction on the Onkalo deep geological disposal 
facility (IAEA 2019). This repository should be tested in 2023 and initial disposal activities will start in 2025 (WNN 2021c).

The transport and interim storage of spent fuel in dry cask storage systems (after spending time in reactor pool storage) pending final disposition through reprocessing or direct disposal is also well established and safe, with numerous vendors of cask storage systems befitting a variety of spent fuel types and applications (NAC International 2021; NRC 2021c).

For all other energy production technologies, the waste from electricity production either goes directly into the environment (e.g., GHG emissions) or into landfills for the materials that are not recycled.

\section{Key Points}

- All forms of energy production produce waste that must be managed.

- The management of wastes can raise technical and sociopolitical issues.

- Different types of waste from nuclear power generation are managed using corresponding approved technologies.

- The nuclear power industry takes responsibility for its wastes and addresses these costs during electricity production.

\subsubsection{Recycling and reprocessing}

Each energy production technology has their own waste and recycling challenges:

- Nuclear fuel recycling. Spent nuclear fuel may, depending on national policy, proceed to direct disposal in a geologic disposal facility or be reprocessed to recover the fissile material $(\mathrm{Pu}, \mathrm{U})$ that can be reused (recycled) into fresh reactor fuel. Reprocessing and recycling can provide a measure of national energy security by maximizing the availability and use of fissile material. At an international level, addressing the concerns of assuring a uranium supply is the intention of the International Atomic Energy Agency Low Enriched Uranium Bank (IAEA 2021b). Beyond near-term energy security, reprocessing of spent nuclear fuel can help secure the feedstock for advanced reactors and advanced fuel cycles. Considering the scale of investment and time needed to implement recycling, each nation can incorporate a strategy for recycling. National policy decisions on whether to reprocess and recycle spent nuclear fuel hinge on considerations of cost and financing, assuring nonproliferation and security, environmental effects, and energy security strategies (OECD 2013). The United States currently supports research and development on fuel recycling options to improve economics and non-proliferation concerns, but at present, does not recycle commercial spent nuclear fuel. Whether deciding to reprocess or proceed with direct disposal, many nations are a contracting party to several relevant International Atomic Energy Agency nuclear safety conventions including the Joint Convention on the Safety of Spent Fuel Management and on the Safety of Radioactive Waste Management (IAEA 2021c). The Joint Convention helps ensure that national arrangements for spent fuel and radioactive waste management conform to international standards. The Joint Convention notes that all radioactive waste (including spent nuclear fuel and high-level waste) should be disposed of in the nation where it was generated, so far as it is compatible with the safety of the waste, while recognizing that in certain circumstances, shared arrangements might be made. The introduction of reprocessing/recycling of spent nuclear fuel into high-level waste will alter the form and character of the nuclear waste but does not negate the need for assuring its eventual deep geologic disposal.

- Nuclear plant recycling. Apart from nuclear fuel, the other materials to be considered as part of recycling for a NPP are mostly concrete and metals. These types of materials would typically be recycled for use in future construction or industrial applications such as fill or reused metals. The 
choice to recycle material during a NPP decommissioning stage would be primarily determined by costs, but as noted by NEA the "recycling of materials arising from the decommissioning of nuclear facilities is seen to be increasing for both metals and concrete...(NEA 2017)."

- Solar panel recycling. At the end of life, the solar PV panels need to be recycled or disposed of as waste. However, these panels are complicated which makes them complicated to recycle. An individual panel consists of several different materials including glass and long-lived toxic substances. Further, the panel is typically manufactured with glues, electronics, sealants, and multiple layers which makes the disassembly process difficult. To disassemble these, complex processes are required. The majority of current panels in the United States are considered hazardous waste under the Federal Resources Conservation and Recovery Act (Paben 2021). In addition, current recycling approaches are not cost effective, as noted by Paben, "We Recycle Solar spends up to \$25 per panel in processing costs to yield between $\$ 2$ and $\$ 4$ in value from aluminum, copper, lead, glass, silver and silicon" (Paben 2021).

- Wind turbine recycling. It has been estimated that approximately 8,000 turbine blades will need to be disposed of during the 2020-2023 period in the United States (Martin 2020), see Figure 33.

Looking long term, it has been projected for the United States that "the cumulative blade waste in 2050 is approximately 2.2 million tons. This value represents approximately $1 \%$ of remaining landfill capacity by volume." For a wind turbine facility, the concrete foundation and turbine blades are the largest amount of material typically not recycled (Cooperman, Eberle, and Lantz 2021). It is assumed for this discussion that much of steel tower and nacelle (the generator) will be recycled. Typical current-design wind turbines weigh more than 1,000 metric tons, most of that weight is reflected in the blades, base, tower, and nacelle (National Wind Watch). Larger turbines are approaching 3,000 metric tons (Smil 2019).

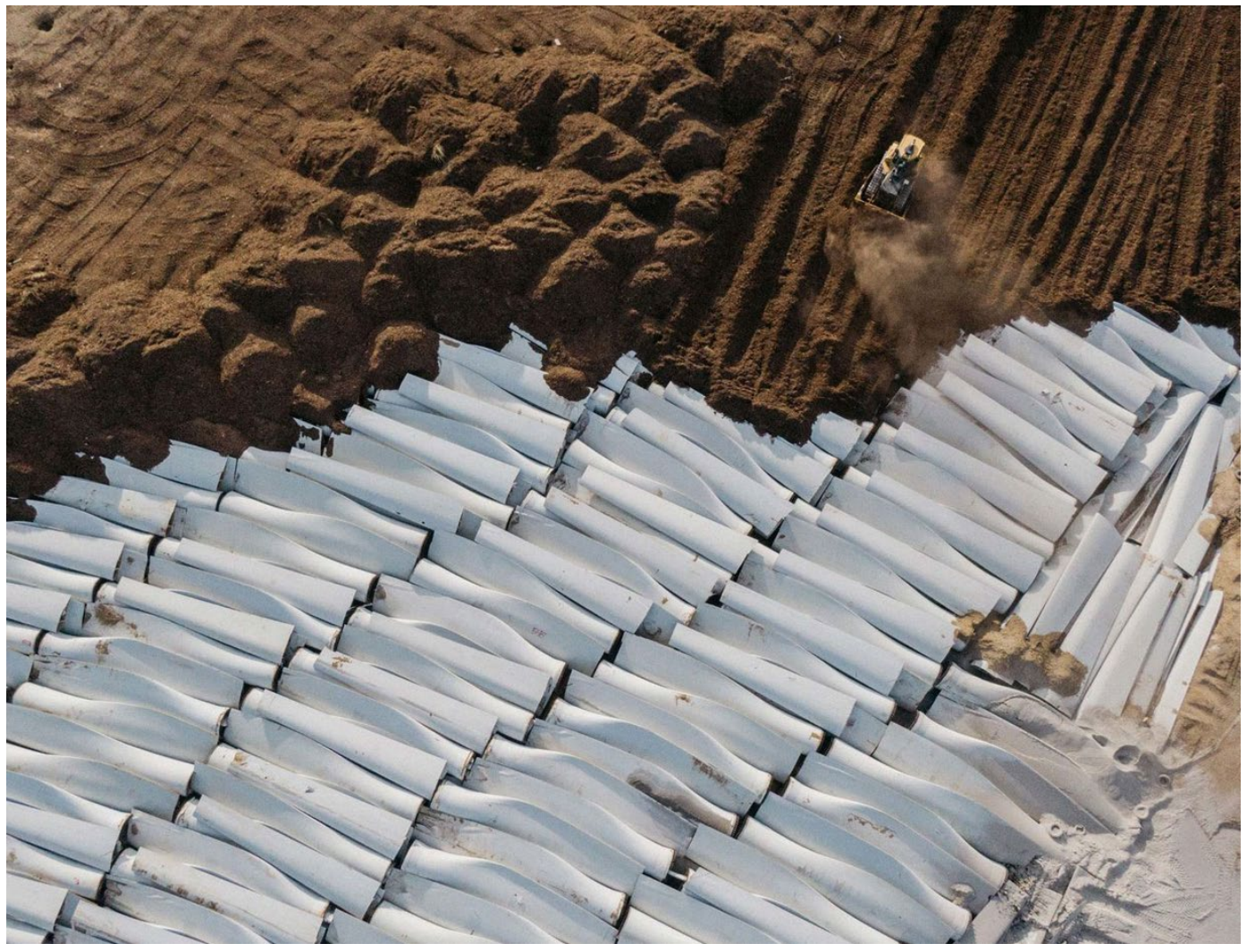

Figure 33. Wind turbine blades being buried in a landfill in Wyoming (Martin 2020; Rasmussen 2020). 


\section{Key Points}

- Many energy production technologies have challenges recycling much of the waste that is produced following electricity generation.

- Nuclear power has the option of recycling spent nuclear fuel into fuel that can be used for future electricity generation, or alternatively, directly disposing of the spent nuclear fuel. 


\section{SUMMARY AND CONCLUSIONS}

Decision-making on future energy technology must consider a variety of impacts, including GHG emissions, water and construction material consumption, disposition of wastes, and the safety of the

public and environment. Additional metrics including economics and secondary benefits also enter this discussion. For all of these energy technology characteristics, an understanding the technical basis for netzero impacts and how those underpin U.S. energy security is critical to building credibility and trust in the selection of future energy sources.

This report provided a summary of five critical areas key to obtaining a net-zero energy impact including:

1. GHG emissions, including carbon dioxide $\left(\mathrm{CO}_{2}\right)$, methane, nitrous oxide, and fluorinated gases (e.g., ozone-depleting gases)

2. Water consumption

3. Material resource consumption

4. Disposition of wastes

5. Impacts to the health and safety of the public and the environment.

Using these net-zero pillars as guides, we addressed a variety of characteristics demonstrating nuclear power leads all other energy production technologies by providing a holistic approach which can lower GHGs in the atmosphere; provide potable water to communities; minimize the global resources needed to provide cooling, heat, and electricity; dramatically reduce the amount of waste going to landfills; and ensure public and environmental safety is commensurate with the energy provided. 


\section{REFERENCES}

Afework, B., J. Hanania, K. Stenhouse, L. V. Suarez, J. Donev. 2021. “Nuclear power plant.” Energy Education. Last modified October 18, 2021. https://energyeducation.ca/encyclopedia/Nuclear power plant.

American Nuclear Society (ANS). 2021. "Wyoming site chosen for Natrium reactor." Last modified November 17, 2021. https://www.ans.org/news/article-3443/wyoming-site-chosen-for-natrium-reactor/.

Argonne National Laboratory (ANL). 2011. "Nuclear Fuel." https://www.ne.anl.gov/pdfs/nuclear/nuclear fuel yacout.pdf.

Barnert, H., V. Krett, and J. Kupitz. 1991. "Nuclear energy for heat applications, International Atomic Energy Agency." 1/1991, IAEA Bulletin. https://www.iaea.org/sites/default/files/publications/magazines/bulletin/bull33-1/33104782124.pdf.

Brockway, P. E., A. Owen, L. I. Brand-Correa, and L. Hardt. 2019. "Estimation of global final-stage energyreturn-on-investment for fossil fuels with comparison to renewable energy sources." Nature 4: 612-621. https://doi.org/10.1038/s41560-019-0425-Z.

Brook, B., A. Alonso, D. A. Meneley, J. Misak, T. Blees, J. B. van Erp. 2014. "Why nuclear energy is sustainable and has to be part of the energy mix." Sustainable Materials and Technologies 1-2: 8-16.

https://doi.org/10.1016/j.susmat.2014.11.001.

Bureau of Labor Statistics (BLS). 2020. "National Census of Fatal Occupational Injuries in 2019." USDL-202265, Department of Labor. https://www.bls.gov/news.release/pdf/cfoi.pdf.

Camper, L. W. 2021. "Maximizing decommissioning lessons learned." American Nuclear Society Nuclear News, November 2021: 12-16.

Colvin, Julian. 2021. "How nuclear technology is less wasteful than solar and why Kentucky should use it." Courier Journal, November 5, 2021. https:/www.courier-journal.com/story/opinion/2021/11/05/nucleartechnology-less-wasteful-kentucky-than-solar-opinion/6248222001/.

Cooperman, Aubryn, Annika Eberle, and Eric Lantz. 2021. "Wind turbine blade material in the United States: Quantities, costs, and end-of-life options.” Resources, Conservation and Recycling 168: 105439. https://doi.org/10.1016/j.resconrec.2021.105439.

Department of Energy (DOE). 2010. "Cooling Water Issues and Opportunities at U.S. Nuclear Power Plants." INL/EXT-10-20208, Department of Energy. https://www.energy.gov/ne/downloads/cooling-water-issuesand-opportunities-us-nuclear-power-plants.

Department of Energy (DOE). 2020. "Could Hydrogen Help Save Nuclear?" ENERGY.GOV. Last modified June 24, 2020. https://www.energy.gov/ne/articles/could-hydrogen-help-save-nuclear.

Department of Energy (DOE). 2021a. "5 Fast Facts About Nuclear Energy." ENERGY.GOV. Last modified March 23, 2021 https://www.energy.gov/ne/articles/5-fast-facts-about-nuclear-energy.

Department of Energy (DOE). 2021b. "3 Reasons Why Nuclear is Clean and Sustainable." ENERGY.GOV. Last modified March 31, 2021. https://www.energy.gov/ne/articles/3-reasons-why-nuclear-clean-andsustainable.

Department of Energy (DOE). 2021c. "What's the Lifespan for a Nuclear Reactor? Much Longer Than You Might Think.” ENERGY.GOV. Last modified March 5, 2021, https:/www.energy.gov/ne/articles/whatslifespan-nuclear-reactor-much-longer-you-might-think..

Dieter, Cheryl A., Molly A. Maupin, Rodney R. Caldwell, Melissa A. Harris, Tamara I. Ivahnenko, John K. Lovelace, Nancy L. Barber, and Kristin S. Linsey, Estimated use of water in the United States in 2015, Circular 1441, USGS. https://doi.org/10.3133/cir1441.

Energy Education. 2017. "Breeder Reactor.” Last accessed January 7, 2022. https://energyeducation.ca/encyclopedia/Breeder_reactor.

Energy Information Administration (EIA). 2020. "U.S. nuclear capacity outages were $35 \%$ higher in summer 2020 than 2019." Today in Energy. Last modified on September 18, 2020, https://www.eia.gov/todayinenergy/detail.php?id=45176.

Energy Information Administration (EIA). 2021a. "EIA expects U.S. hydropower generation to decline $14 \%$ in 2021 amid drought." Today in Energy. Last modified on September 23, 2021.

https://www.eia.gov/todayinenergy/detail.php?id=49676. 
Energy Information Administration (EIA). 2021b. “Electric Power Annual 2020.” U.S. Energy Information Administration, October 2021. https://www.eia.gov/electricity/annual/pdf/epa.pdf.

Energy Information Administration (EIA). 2021c. "How much electricity does an American home use?" Frequently Asked Questions (FAQS). Last modified on October 7, 2021, https://www.eia.gov/tools/faqs/faq.php?id=97\&t=3.

Energy Information Administration (EIA). 2021d. "How many nuclear power plants are in the United States, and where are they located?" Frequently Asked Questions (FAQS). Last modified on November 2, 2021, https://www.eia.gov/tools/faqs/faq.php?id=207\&t=3.

European Commission (EC). 2020. "Critical Raw Materials for Strategic Technologies and Sectors in the EU." Last modified March 9, 2020. https://ec.europa.eu/docsroom/documents/42881.

Evans, Simon. 2017. "Solar, wind and nuclear have 'amazingly low' carbon footprints, study finds." Carbon Brief Ltd., August 12, 2017. https://www.carbonbrief.org/solar-wind-nuclear-amazingly-low-carbon-footprints.

Frisvold, George B. and Tatiana Marquez. 2014. "Water Requirements for Large-Scale Solar Energy Projects in the West." Journal of Contemporary Water Research \& Education 151(1): 106-116. https://doi.org/10.1111/j.1936-704X.2013.03156.x.

Georgia Power Company. 2019. "Vogtle Unit 3.” http://vogtlegallery.georgiapower.com/vogtlephotos/2019 04/vogtle-unit-3-east-side2.jpg.

Grubert, E. 2020. "Same-plant trends in capacity factor and heat rate for US power plants, 2001-2018." IOP SciNotes 1(2). https://iopscience.iop.org/article/10.1088/2633-1357/abb9f1.

Hamilton, S. D., D. Millstein, M. Bolinger, R. Wiser, and S. Jeong. 2020. "How Does Wind Project Performance Change with Age in the United States?," Joule 4(5): 1004-1020. https://doi.org/10.1016/j.joule.2020.04.005.

HeatCalc. n.d. "Heat Recovery for Cooling." Last accessed on November 23, 2021. https://heatcalc.com/heat-tocooling.

Herald, Matthew. 2016. "Potential Impact of Nuclear Power on Water Resources in the Southeast United States." The Journal of Undergraduate Research at the University of Tennessee 7(1): 13. https://trace.tennessee.edu/cgi/viewcontent.cgi?article=1314\&context=pursuit.

Hickman, Hannah. 2019. "What Happens to Nuclear Waste in the U.S.?” Nuclear Energy Institute, November 19, 2019. https://www.nei.org/news/2019/what-happens-nuclear-waste-us.

Holtec. 2021. "SMR-160: The Next Generation Fission Reactor.” https://holtecinternational.com/wpcontent/uploads/2021/01/SMR-Brochure-Insert 1.27.2021.pdf.

IBIS World. 2021. "Nuclear Power in the US - Market Size 2001-2027." Industry Statistics. Last modified September 29, 2021. https://www.ibisworld.com/industry-statistics/market-size/nuclear-power-unitedstates/.

Idaho National Laboratory (INL). 2021. "Advanced Nuclear Directory." https:/gain.inl.gov/SiteAssets/Funding\%20Opportunities/GAINAdvancedNuclearDirectorySeventh\%20Edition_07.01.2021-R1.pdf.

International Atomic Energy Agency (IAEA). 2009. "Classification of Radioactive Waste, International Atomic Energy Agency.” GSG-1, IAEA. https://www-pub.iaea.org/MTCD/Publications/PDF/Pub1419 web.pdf.

mational Atomic Energy Agency (IAEA). 2019. "Developing the First Ever Facility for the Safe Disposal of Spent Fuel." Last accessed January 10, 2022. https://www.iaea.org/newscenter/news/developing-the-firstever-facility-for-the-safe-disposal-of-spent-fuel.

International Atomic Energy Agency (IAEA). 2020. "Uranium 2020 Resources, Production and Demand.” 7551, Nuclear Energy Agency. https://www.oecd-nea.org/jcms/pl 52718/uranium-2020-resources-productionand-demand.

International Atomic Energy Agency (IAEA). 2021a. "Industrial Applications and Nuclear Cogeneration." Topics. Last accessed November 23, 2021. https://www.iaea.org/topics/non-electricapplications/industrial-applications-and-nuclear-cogeneration.

International Atomic Energy Agency (IAEA). 2021b. "IAEA Low Enriched Uranium (LEU) Bank." Topics. Last accessed November 23, 2021. https://www.iaea.org/topics/iaea-low-enriched-uranium-bank. 
International Atomic Energy Agency (IAEA). 2021c. "Nuclear Safety Conventions." Topics. Last accessed November 23, 2021. https://www.iaea.org/topics/nuclear-safety-conventions.

International Energy Agency (IEA). 2021. "The Role of Critical World Energy Outlook Special Report Minerals in Clean Energy Transitions." https://www.iea.org/reports/the-role-of-critical-minerals-in-clean-energytransitions.

Johnson, N. and Z. Ma. 2019. "Initiating Event Rates at U.S. Nuclear Power Plants 1988-2018." INL/EXT-1954513, Idaho National Laboratory.

Krikorian, S. 2018. "Nuclear Power beyond Electricity: towards Greater Efficiency in Energy Production and Water Management." International Atomic Energy Agency, June 28, 2018. https://www.iaea.org/newscenter/news/nuclear-power-beyond-electricity-towards-greater-efficiency-inenergy-production-and-water-management.

Martin, C. 2020. "Wind Turbine Blades Can't Be Recycled, So They're Piling Up in Landfills.” Bloomberg Green, February 5, 2020. https://www.bloomberg.com/news/features/2020-02-05/wind-turbine-bladescan-t-be-recycled-so-they-re-piling-up-in-landfills.

McAuliffe, M. 2021. "Texas nuclear unit returns to service after outage related to cold weather." S\&P Global, February 18, 2021. https:/www.spglobal.com/platts/en/market-insights/latest-news/electricpower/021821-texas-nuclear-unit-returns-to-service-after-outage-related-to-cold-weather.

Mow, B. 2018. "STAT FAQs Part 2: Lifetime of PV Panels.” NREL Blog, April 23, 2018. https://www.nrel.gov/state-local-tribal/blog/posts/stat-faqs-part2-lifetime-of-pv-panels.html.

NAC International. 2021. "Storage Assured.” Solutions. Last accessed November 23, 2021. https://www.nacintl.com/solutions/storage-technologies.

National Renewable Energy Laboratory (NREL). 2020. "Flexible Nuclear Energy for Clean Energy Systems." NREL/TP-6A50-77088. https://www.nrel.gov/docs/fy20osti/77088.pdf

NAS. 2001. "Disposition of High-Level Waste and Spent Nuclear Fuel: The Continuing Societal and Technical Challenges." National Academy of Sciences-National Research Council. Washington, DC: National Academy Press.

National Wind Watch. n.d. "How big is a wind turbine?" Last accessed November 23, 2021. https://www.windwatch.org/publication/nwwpub-size.pdf.

Nuclear Energy Agency (NEA). 2017. "Recycling and Reuse of Materials Arising from the Decommissioning of Nuclear Facilities." https://www.oecd-nea.org/jcms/pl_15012.

Nuclear Energy Institute (NEI). 2019. "5 Benefits of Nuclear Energy Beyond Electricity." Fact Sheet. Last modified February 21, 2019. https://www.nei.org/news/2019/5-benefits-of-nuclear-energy-beyondelectricity.

Nuclear Energy Institute (NEI). 2020. "Nuclear Energy Fast Facts.” Fact Sheet. Last modified December 2020. https://www.nei.org/resources/fact-sheets/nuclear-fast-facts.

Nuclear Energy Institute (NEI). 2021a. "U.S. Nuclear Plant Actual and Expected Uprates by Plant." Statistics. Last modified May 2021. https://www.nei.org/resources/statistics/us-nuclear-plant-actual-and-expecteduprates.

Nuclear Energy Institute (NEI). 2021b. "Nuclear Costs in Context." Report Briefs. Last modified November 2021, https://www.nei.org/resources/reports-briefs/nuclear-costs-in-context.

Nuclear Power. 2021. "Fuel Consumption of Conventional Reactor." Nuclear Fuel. Accessed October 2021, https://www.nuclear-power.com/nuclear-power-plant/nuclear-fuel/fuel-consumption-of-conventionalreactor/.

Nuclear Regulatory Commission (NRC). 2018. "Backgrounder on the Three Mile Island Accident." Fact Sheets. Last modified June 21, 2018. https://www.nrc.gov/reading-rm/doc-collections/fact-sheets/3mile-isle.html.

Nuclear Regulatory Commission (NRC). 2020. "Requirements for Renewal of Operating Licenses for Nuclear Power Plants." Title 10 CFR, Part 54. https://www.nrc.gov/reading-rm/doc-collections/cfr/part054/fulltext.html.Nuclear Regulatory Commission (NRC). 2021a. "Dry Cask Storage.” Spent Fuel Storage. Last modified May 3, 2021. https://www.nrc.gov/waste/spent-fuel-storage/dry-cask-storage.html. 
Nuclear Regulatory Commission (NRC). 2021b. "Pre-application Activities." Advanced Reactors. Last modified September 7, 2021. https://www.nrc.gov/reactors/new-reactors/advanced/ongoing-licensing-activities/preapplication-activities.html.

Nuclear Regulatory Commission (NRC). 2021c. "Dry Spent Fuel Storage Designs: NRC Approved for General Use.” Advanced Reactors. Last modified September 17, 2021. https:/www.nrc.gov/waste/spent-fuelstorage/designs.html.

OECD. 2013. "The Economics of the Back End of the Nuclear Fuel Cycle." 7061, Nuclear Energy Agency. https://www.oecd-nea.org/jcms/pl 14764/the-economics-of-the-back-end-of-the-nuclear-fuel-cycle.

OECD. 2016. "Uranium 2016: Resources, Production and Demand." 7301, Nuclear Energy Agency. https://www.oecd-nea.org/jcms/pl_15004.

Paben, J. 2021. "How the recycling industry is preparing to tackle solar panels." Resource Recycling. Last modified June 18, 2021. https://resource-recycling.com/recycling/2021/06/15/how-the-recycling-industryis-preparing-to-tackle-solar-panels/.

Pehl, Michaja, Anders Arvesen, Florian Humpenöder, Alexander Popp, Edgar G. Hertwich, and Gunnar Luderer. 2017. "Understanding future emissions from low-carbon power systems by integration of lifecycle assessment and integrated energy modelling." Nature Energy 2. https://www.nature.com/articles/s41560017-0032-9.

Potomac Economics. 2021. "A Review of Nuclear Costs and Revenues in PJM." https://www.nei.org/CorporateSite/media/filefolder/resources/reports-and-briefs/potomac-nuclear-coststudy-0421.pdf.

Ramseur, Jonathan. 2019. "U.S. Carbon Dioxide Emissions in the Electricity Sector: Factors, Trends, and Projections.” R45453, Congressional Research Service. https://sgp.fas.org/crs/misc/R45453.pdf.

Rasmussen, Benjamin. 2020. "Fragments of wind turbine blades await burial at the Casper Regional Landfill in Wyoming." Bloomberg Green, February 5, 2020. https://www.bloomberg.com/news/features/2020-0205/wind-turbine-blades-can-t-be-recycled-so-they-re-piling-up-in-landfills

Reuters. 2012, "TVA Cuts Contractors at Bellefonte Nuclear Site." Article. Last modified on March 12, 2012. https://www.reuters.com/article/utilities-tva-bellefonte-idUSL2E8EG37920120316.

Ritchie, H. and M. Roser, Air Pollution, https://ourworldindata.org/air-pollution\#air-pollution-is-one-of-theworld-s-leading-risk-factors-for-death.

Ritchie, H. and M. Roser. 2020. "Electricity Mix." Our World in Data. Last accessed November 23, 2021. https://ourworldindata.org/electricity-mix.

Royal Society. 2020. "Nuclear Cogeneration: civil nuclear in a low-carbon future." Topics and Policy. Last modified on October 2, 2020. https://royalsociety.org/topics-policy/projects/low-carbon-energyprogramme/nuclear-cogeneration/.

Schmidt, J. M. and V. G. Gude. 2021. "Nuclear Cogeneration for Cleaner Desalination and Power Generation - A Feasibility Study." Cleaner Engineering and Technology 2: 100044. https://doi.org/10.1016/j.clet.2021.100044.

SEIA. n.d. "Water Use Management." Initiatives. Last accessed on November 23, 2021. https://www.seia.org/initiatives/water-use-management.

Smil, V. 2019. "Wind Turbines Just Keep Getting Bigger, But There's a Limit." IEEE Spectrum, October 22, 2019. https://spectrum.iee. org/wind-turbines-just-keep-getting-bigger-but-theres-a-limit.

Staffell, I. and R. Green. 2014. "How does wind farm performance decline with age?" Renewable Energy 66: 775-786. https://doi.org/10.1016/j.renene.2013.10.041.

Stevens, L., B. Anderson, C. Cowan, K. Colton, and D. Johnson. 2017. "The Footprint of Energy: Land use of U.S. Electricity Production.” Strata, June 2017. https://docs.wind-watch.org/US-footprints-Strata2017.pdf.

Torcellini, P., N. Long, and R. Judkoff. 2003. "Consumptive Water Use for U.S. Power Production.” NREL/TP550-33905, National Renewable Energy Laboratory. https://www.nrel.gov/docs/fy04osti/33905.pdf.

USDA. 2016. "Irradiation and Food Safety FAQ." Food Safety. Last modified December 20, 2016, https://www.fsis.usda.gov/food-safety/safe-food-handling-and-preparation/food-safety-basics/irradiationand-food-safety-faq. 
USGS. 2021. "Mineral Commodity Summaries.” United States Geological Survey. https://doi.org/10.3133/mcs2021.

USGU 2020a. "Nickel.” U.S. Geological Survey, Mineral Commodity Summaries, January 2020. https://pubs.usgs.gov/periodicals/mcs2020/mcs2020-nickel.pdf.

USGU 2020b. “Silicon.” U.S. Geological Survey, Mineral Commodity Summaries, January 2020. https://pubs.usgs.gov/periodicals/mes2020/mcs2020-silicon.pdf.

USGU 2020c. “Zinc.” U.S. Geological Survey, Mineral Commodity Summaries, January 2020. https://pubs.usgs.gov/periodicals/mcs2020/mcs2020-zinc.pdf.

Vaughan, A. 2018. "UK summer 'wind drought' puts green revolution into reverse." The Guardian, August 27, 2018. https://www.theguardian.com/environment/2018/aug/27/uk-summer-wind-drought-puts-greenrevolution-into-reverse.

Water and Wastes Digest (WWD). 2002. "Desalination in America." Last accessed December 10, 2021, https://www.wwdmag.com/desalination/desalination-america.

Wald, Matt. 2020. "A Nuclear Solution for Climate, Energy and Water." Nuclear Energy Institute, August 4, 2020.” https://www.nei.org/news/2020/nuclear-solution-for-climate-energy-water.

WCS. n.d. "About.” Waste Control Specialists. Last accessed November 23, 2021. https://www.wcstexas.com/about/.

World Nuclear Association. 2020a. "Desalination." Industry. Last modified March 2020, https://worldnuclear.org/information-library/non-power-nuclear-applications/industry/nuclear-desalination.aspx

World Nuclear Association. 2020b. "Energy Return on Investment." Energy and the Environment. Last modified March 2020, https://world-nuclear.org/information-library/energy-and-the-environment/energy-return-oninvestment.aspx.

World Nuclear Association. 2021a. "US Nuclear Fuel Cycle.” Country Profiles. Last modified May 2021, https://world-nuclear.org/information-library/country-profiles/countries-t-z/usa-nuclear-fuel-cycle.aspx.

World Nuclear Association. 2021b. "Storage and Disposal of Radioactive Waste." Nuclear Waste. Last modified May 2021. https://world-nuclear.org/information-library/nuclear-fuel-cycle/nuclear-waste/storage-anddisposal-of-radioactive-waste.aspx.

World Nuclear Association. 2021c. "Mineral Requirements for Electricity Generation." Energy and the Environment. Last modified August 2021, https://world-nuclear.org/information-library/energy-and-theenvironment/mineral-requirements-for-electricity-generation.aspx.

World Nuclear Association. 2021d. "Radioisotopes in Medicine." Radioisotopes \& Research. Last modified October 2021, https://world-nuclear.org/information-library/non-power-nuclearapplications/radioisotopes-research/radioisotopes-in-medicine.aspx.

World Nuclear Association. 2021e. "Nuclear Power in the USA." Country Profiles. Last modified November 2021. https://world-nuclear.org/information-library/country-profiles/countries-t-z/usa-nuclearpower.aspx.

World Nuclear News. 2019. "US nuclear plants operate through polar vortex." World Nuclear News, February 4, 2019. https://world-nuclear-news.org/Articles/US-nuclear-plants-operate-through-polar-vortex.

World Nuclear News. 2021a. "US-led initiative aims to lower advanced nuclear construction costs." World Nuclear News, July 8, 2021, https://www.world-nuclear-news.org/Articles/US-led-initiative-aims-tolower-advanced-nuclear-c.

World Nuclear News. 2021b. "China starts construction of demonstration SMR.” World Nuclear News, July 13, 2021. https://world-nuclear-news.org/Articles/China-starts-construction-of-demonstration-SMR.

World Nuclear News. 2021c. "Construction of test disposal tunnel under way at Onkalo." World Nuclear News, March 1, 2021. https://www.world-nuclear-news.org/Articles/Construction-of-test-disposal-tunnel-underway-at. 